Florida International University FIU Digital Commons

$10-3-2008$

\title{
The Effect of a Clinical Practicum on Elementary Education Preservice Teachers' Development of Reading Expertise
}

Helen Jean Robbins

Florida International University, hparla01@fiu.edu

DOI: $10.25148 /$ etd.FI10022545

Follow this and additional works at: https://digitalcommons.fiu.edu/etd

\section{Recommended Citation}

Robbins, Helen Jean, "The Effect of a Clinical Practicum on Elementary Education Preservice Teachers' Development of Reading Expertise" (2008). FIU Electronic Theses and Dissertations. 214.

https://digitalcommons.fiu.edu/etd/214 


\title{
FLORIDA INTERNATIONAL UNIVERSITY
}

Miami, Florida

THE EFFECT OF A CLINICAL PRACTICUM ON ELEMENTARY EDUCATION

PRESERVICE TEACHERS' DEVELOPMENT OF READING EXPERTISE

\author{
A dissertation submitted in partial fulfillment of the \\ requirements for the degree of \\ DOCTOR OF EDUCATION \\ in \\ CURRICULUM AND INSTRUCTION \\ by \\ Helen J. Robbins
}

2008 
To: Interim Dean Kingsley Banya

College of Education

This dissertation, written by Helen J. Robbins, and entitled The Effect of a Clinical Practicum on Elementary Education Preservice Teachers' Development of Reading Expertise, having been approved in respect to style and intellectual content, is referred to you for judgment.

We have read this dissertation and recommend that it be approved.

Lynne D. Miller

Kingsley Banya

Gail Gregg

Joyce C. Fine, Major Professor

Date of Defense: October 3, 2008

The dissertation of Helen J. Robbins is approved.

$\begin{array}{r}\hline \begin{array}{r}\text { Interim Dean Kingsley Banya } \\ \text { College of Education }\end{array} \\ \hline \begin{array}{r}\text { Dean George Walker } \\ \text { University Graduate School }\end{array}\end{array}$

Florida International University, 2008 
(C) Copyright 2008 by Helen J. Robbins

All rights reserved. 


\section{DEDICATION}

I dedicate this dissertation to my patient and loving husband, Joel, who has encouraged and supported me throughout this lengthy process; to my children, Lillian and Herbie, and to my grandchildren, Adrian, Alexander, and Andrew. This dedication is also extended to my Grandparents, Helen and Herbert Loewen, who instilled in me a love of knowledge, the value of an education, and who taught me the art of perseverance and determination. 


\section{ACKNOWLEDGMENTS}

I wish to thank the members of my committee for their input and guidance. Dr. Joyce Fine, who served not only as my major professor, became my mentor and friend. Without your cutting-edge thinking and your development of a fourth reading course, a supervised clinical practicum, I would not have had a sound foundation for my dissertation. Your dedication, guidance, and confidence in my abilities enabled me to complete this degree with excellence. Dr. Lynne Miller, you helped guide my thinking; thank you for your invaluable time, encouragement, support, and your expertise, which gave me clear direction and valuable insight. Dr. Gail Gregg, your feedback and expertise was very much appreciated. Dr. Kingsley Banya, thank you for your support and encouragement.

I also wish to thank Dr. Paulette Johnson for her expertise and patience while working with me on the quantitative analyses; and, Dr. Linda Bliss and Dr. Isadore Newman for their expertise and invaluable feedback. 
ABSTRACT OF THE DISSERTATION

THE EFFECT OF A CLINICAL PRACTICUM ON ELEMENTARY EDUCATION PRESERVICE TEACHERS' DEVELOPMENT OF READING EXPERTISE by

Helen J. Robbins

Florida International University, 2008

Miami, Florida

\section{Professor Joyce C. Fine, Major Professor}

The purpose of the study was to measure gains in the development of elementary education teachers' reading expertise, to determine if there was a differential gain in reading expertise, and last, to examine their perceptions of acquiring reading expertise. This research is needed in the field of teacher education, specifically in the field of reading.

A quasi-experimental design with a comparison group using pretest-posttest mixed-method, repeated measures was utilized. Quantitative data analysis measured the development of reading expertise of elementary preservice teachers compared to early childhood preservice teachers; and, was used to examine the differential gains in reading expertise. A multivariate analysis of variance (MANOVA) was conducted on pre- and posttest responses on a Protocol of Questions. Further analysis was conducted on five variables (miscue analysis, fluency analysis, data analysis, inquiry orientation and intelligent action) using a univariate analysis of variance (ANOVA). A one-way ANOVA was carried out on gain scores of the low and middle groups of elementary education preservice teachers. Qualitative data analysis suggested by Merriam (1989) 
and Miles and Huberman (1994) was used to determine if the elementary education preservice teachers perceived they had acquired the expertise to teach reading.

Elementary education preservice teachers who participated in a supervised clinical practicum made significant gains in their development of reading expertise as compared to early childhood preservice teachers who did not make significant gains. Elementary education preservice teachers who were in the low and middle third levels of expertise at pretest demonstrated significant gains in reading expertise. Last, elementary education preservice teachers perceived they had acquired the expertise to teach reading.

The study concluded that reading expertise can be developed in elementary education preservice teachers through participation in a supervised clinical practicum. The findings support the idea that preservice teachers who will be teaching reading to elementary students would benefit from a supervised clinical practicum. 


\section{TABLE OF CONTENTS}

CHAPTER

PAGE

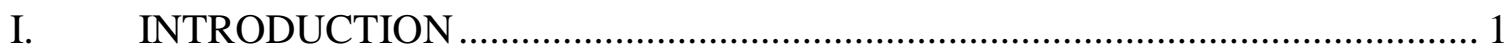

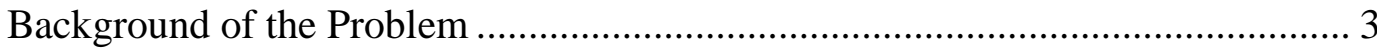

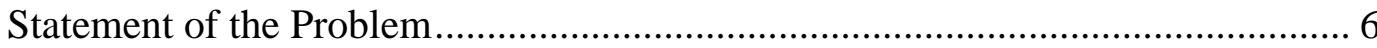

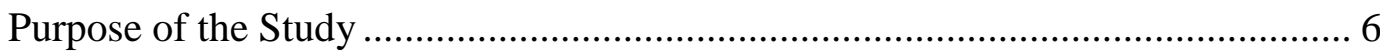

Questions and Related Hypotheses .............................................................. 7

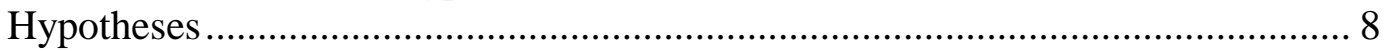

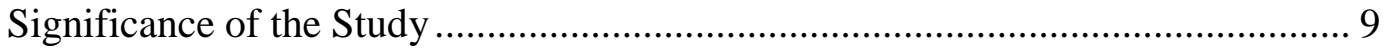

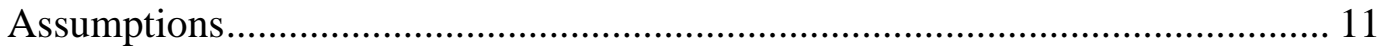

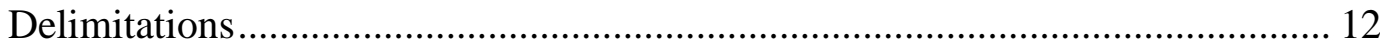

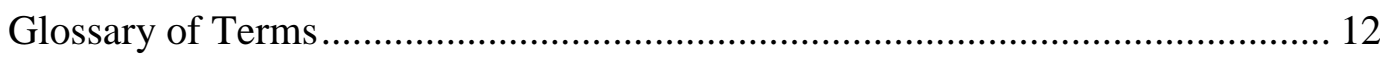

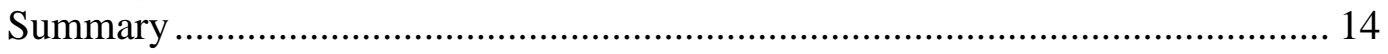

II. REVIEW OF THE LITERATURE ……………..................................... 18

Early Elementary Teacher Preparation for Reading Instruction........................... 18

Addressing the Gaps in Preservice Teacher Preparation for Reading

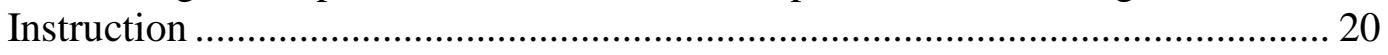

Current elementary Teacher Preparation for Reading Instruction ........................ 22

Why Preservice Teachers May not be Ready to Teach Reading ........................... 33

What is Needed in Preservice Teacher Preparation for Reading Instruction........ 41

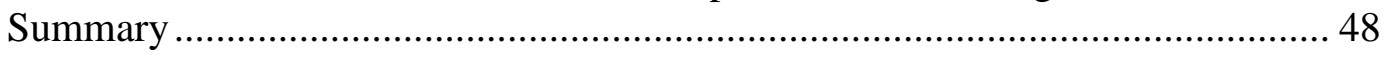

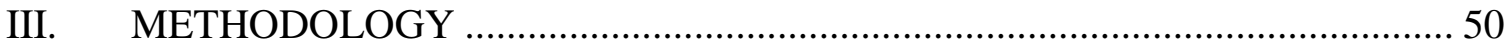

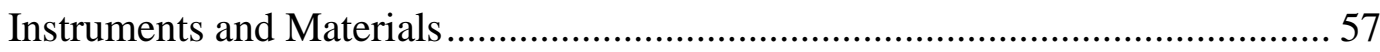

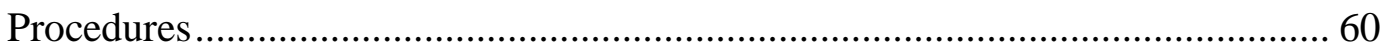

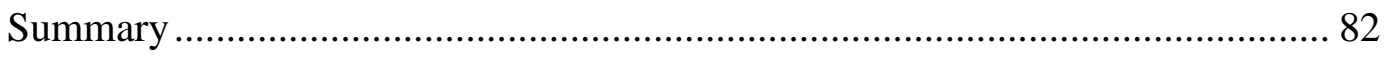

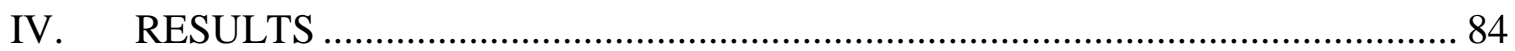

Overall Sample Characteristics ........................................................................... 85

Scoring Procedures for Protocol of Questions.................................................. 86

Discussion of the Results of Testing Research Hypothesis One .......................... 95

Discussion of the Results of Testing Research Hypothesis Two.......................... 99

Discusssion of Research Hypothesis Three ......................................................... 103

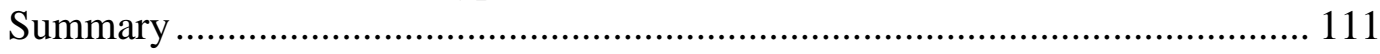

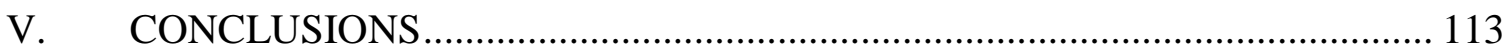

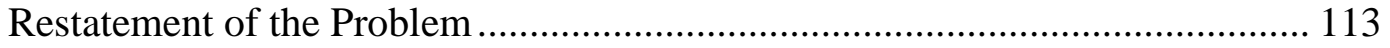

Design and Procedures.................................................................................... 113

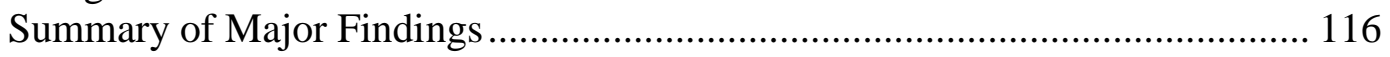

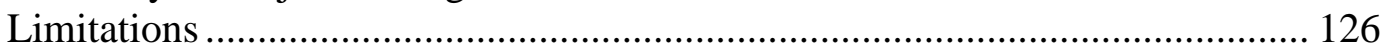

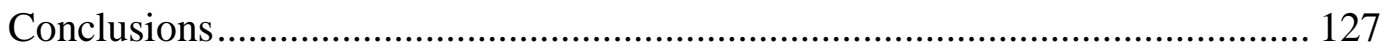

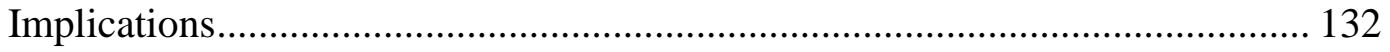




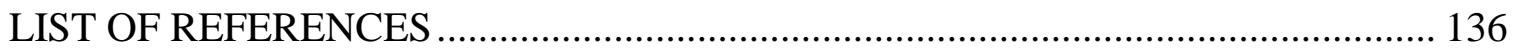

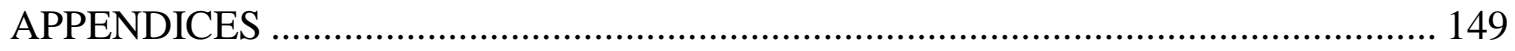

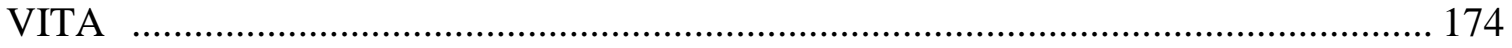




\section{LIST OF TABLES}

TABLE

PAGE

1. Number of Elementary Education Preservice Teachers Taught by Instructor and School (Experimental Group)

2. Interclass Correlation Coefficients for Interrater Reliability of Elementary

Education Preservice Teachers and Early Childhood Preservice Teachers

3. Means and Standard Deviation of Protocol of Questions on Pretest and Posttest by School and Instructor (Experimental Group)

4. Pretest and Posttest Means for Protocol of Questions for Experimental Group and Comparison Group....

5. Elementary Education Preservice Teachers' Gain in Reading Expertise by Pretest Group 


\section{CHAPTER I}

\section{INTRODUCTION}

The No Child Left Behind Act of 2001 (2002), requires schools to help all children develop literacy at increasingly higher levels. Some children from poor, minority, or nonEnglish speaking families and children who have innate dispositions for reading difficulties, need the support of high-quality school environments and excellent reading instruction to be sure of reading success (Snow, Burns, \& Griffin, 1998). These children often lack basic reading, language, and English literacy skills, and reading at higher levels of literacy is a challenge for many of these children. Elementary classroom teachers, not reading specialists, are solely responsible for the reading instruction of all children, and ultimately, for their reading achievement (Valencia \& Buly, 2004). Additionally, a large number of students who should be capable of reading given adequate instruction are not doing so, suggesting that the instruction by their teacher available to them is not appropriate (Snow, Burns, \& Griffin, 1998). In light of this, and the national, state and public focus on reading, there is a need to look at ways in which preservice teachers are prepared to teach reading.

The federal government (Elementary and Secondary Education Act, 1965), and the report of the National Commission on Excellence in Education, A Nation at Risk (1983), raised the public awareness of the importance of reading. However, it wasn't until the No Child Left Behind Act of 2001 (2002), that the focus shifted to the preparation of "high-quality" teachers and it became clear this was what was needed to help reach the goal of all children reading proficiently by 2013-2014. Since the No Child 
Left Behind Act of 2001 (2002), mandates "highly qualified" teachers, this suggests a different approach to meet the reading needs of children. One might expect this approach would be improving elementary teachers' reading instruction by examining how best to develop preservice teachers' reading expertise so teachers become highly qualified. Yet, the emphasis in many school districts is on training teachers to follow reading programs and curriculum materials mandated by the district. Although teacher quality seems to make an important difference in student achievement (Darling-Hammond et al., 2005), there is limited research about the processes that teachers undergo to develop expertise in learning to teach reading (Anders, Hoffman, \& Duffy, 2000).

To address the need for teachers to be highly qualified the current study was conducted to examine the effect of a supervised clinical practicum on preservice teachers' development of reading expertise. Two needs are evident in reading teacher preparation of elementary education preservice teachers: specific ways in which they are prepared to teach reading, and how reading expertise may be developed prior to student teaching. The study sought to define ways in which preservice teachers are prepared to teach reading while acquiring the high level of reading expertise needed to ensure the reading achievement of all students. It examined the effect of a supervised clinical practicum, the specifics needed to teach reading, the development of reading expertise from novice to a more expert-like pedagogical level and the ability to identify the needs of readers on which to base instructional decisions. It also examined preservice teachers' perceptions of acquiring expertise to teach reading. The study sought to contribute to the knowledge base of how preservice teachers are prepared to teach reading. 


\section{Background of the Problem}

\section{Preparation to Teach Reading}

Teachers are being asked to teach more with respect to reading, and a quality reading education matters more now than it has at any time in the history of public schools (Barone \& Morrell, 2007). Teachers face classrooms that are diverse; students come from many different cultural and ethnic backgrounds as well as achievement levels, and many students live in poverty (Lefever-Davis, 2002). In addition, elementary classrooms include students who are second-language learners and students who have a variety of physical, emotional, and learning problems. Elementary teachers who are solely responsible for teaching reading must be knowledgeable about reading and understand how to teach reading in order to meet diverse learning needs.

To compound issues of the pressure on teachers to teach all children to read, there is a great deal of variability in the ways in which preservice teachers are prepared to teach reading. The International Reading Association's National Commission on Excellence in Elementary Teacher Preparation for Reading Instruction (2003) identified variations in the content and experiences provided in teacher preparation programs in the United States. As reported in the executive summary of Prepared to Make a Difference (2003):

Some programs require as little as one, three-semester course in reading methods while others offer as many as 18 semester hours in reading coursework that covers topics ranging from the structure of English to teaching reading comprehension. Some practicum hours have supervised, "hands-on" experiences in reading, and others offer as many as 50-60 hours every semester. (p.2)

In a description of current practices, the International Reading Association's commission's survey of preservice teachers' preparation in reading (Hoffman, Roller, \& National Commission on Excellence in Elementary Teacher Preparation for Reading 
Instruction, 2001) provides data on judgments of program quality offered by teacher educators. Some of the findings included: (a) the average number of courses in reading was two or more (b) there were extensive field experiences in teaching reading prior to student teaching; supervised and connected to course content (c) learning to teach reading to diverse learners was a major focus and (d) most of the teaching faculty had classroom experience in teaching as well as advanced degrees in reading. These data provide information on some of the aspects needed in reading teacher preparation; however, there was no insight into the effectiveness of reading teacher preparation.

The challenge in preparing preservice teachers to teach reading is they must be able to link new knowledge learned through coursework to instructional practices through field experiences. There is little doubt that field experiences working with students for sustained lengths of time and linking these experiences to methods courses is important in developing preservice teachers' knowledge of teaching reading (Danielson, Kuhlman, \& Fluckiger, 1998). Reading teacher preparation that is field based and emphasizes practicum experiences seems to have the most positive effects; specifically, supervised, relevant, field-based or clinical experience in which preservice teachers receive constant support, guidance, and feedback (Hoffman et al., 2001).

Although the local, state and federal levels have finally recognized how much high quality teachers matter, there is limited research with respect to how teachers are best prepared to teach reading to enable them to be high quality teachers (Snow, Burns, \& Griffin, 2005; Hoffman, 2004). If one hopes to achieve the goal of the No Child Left Behind Act of 2001 (2002), then there must be a shift from the idea of "teacher proof" curriculum materials and reading programs to a focus on teaching preservice teachers to 
become highly qualified to teach reading. More practicum experiences provided for preservice teachers help them to apply what they learn in coursework, and most importantly, the support they receive during practicum experiences helps them make sense of what they are learning (Andrew, 1990).

\section{The Development of Reading Expertise}

Expertise to teach reading is the ability to progress from learning basic elements of teaching reading, accumulating knowledge of how to each reading, and making decisions about students' instructional needs. Modern learning theory is clear that expertise is developed within specific domains, learning is situated within a specific context, and within a specific context learning needs to be developed and transferred (Hammerness et al., 2005). Expertise to teach reading matters more than curriculum materials, pedagogical approaches, and reading programs (Allington, 2002) and it can be developed through experiences, careful deliberation and reflection on practice, usually through supervision by experienced mentors (Cochran-Smith, 2000).

Therefore, the purpose of this study was to examine the development of reading expertise in an elementary education preservice teacher preparation program. The study examined the effect of a supervised clinical practicum on elementary education preservice teachers' development of reading expertise. It looked at the specifics needed to teach reading, the development of reading expertise from novice to a more-expert-like pedagogical level, and the ability to identify reading needs of diverse students in order to make knowledgeable instructional decisions. 
Statement of the Problem

The present study:

1. Addresses the need to look at specific ways in which elementary education preservice teachers are prepared to teach reading; and,

2. Addresses the need to examine the effect of clinical practicum experiences in which elementary education preservice teachers apply what they learn about teaching reading in a supervised clinical practicum that includes a one-on-one tutoring experience, as compared to early childhood education preservice teachers who do not participate in a clinical practicum.

\section{Purpose of the Study}

This study sought to:

1. Measure gains in the expertise of elementary education preservice teachers' ability to teach reading. Specifically, how well are they able to assess miscue analysis, fluency analysis, data analysis, inquiry orientation, intelligent action, after participating in a supervised clinical practicum as compared to early childhood education preservice teachers who did not participate in a supervised clinical practicum.

2 Determine if a clinical practicum has a differentiated effect on the elementary education preservice teachers whose entry level of reading expertise is in the low and middle thirds, and to determine if a clinical practicum provides the necessary support for them to attain the highest level of reading expertise possible.

3. Examine elementary education preservice teachers' perceptions after participating in a supervised clinical practicum to determine if they perceive they have acquired the expertise to teach reading. 
Questions and Related Hypotheses

This study had three research questions. The first question focused on measuring the gains in reading expertise of elementary education preservice teachers through the use of video cases, after they participated in a supervised clinical practicum, as compared to early childhood preservice teachers who did not participate in a clinical practicum. The second research question asked if there is a differentiated effect on the development of reading expertise of preservice teachers entering the clinical practicum with different levels of reading expertise. The third question asked if elementary education preservice teachers perceive they have acquired the expertise to teach reading.

\section{Research Question 1}

What is the effect of a supervised clinical practicum on the development of reading expertise of elementary education preservice teachers compared to the development of reading expertise of early childhood preservice teachers who did not participate in a supervised clinical practicum? Specifically, are they able to assess:

- Miscue analysis: Errors from the three cueing systems; semantic (meaning), syntactic (structure) and graphophonic (visual).

- Fluency: A reader's speed, expression, phrasing, and attention to punctuation.

- Data analysis: Data in order to analyze/interpret a reader's performance based on observation and assessment of miscue analysis, fluency and comprehension.

- Inquiry orientation: Appropriate information about a reader through reasonable reading assessment technique(s).

- Intelligent action: And make reasonable instructional decisions geared to reading strategy instruction, not fixing mistakes. 


\section{Research Question 2}

Is there a differentiated effect of the clinical practicum depending on the entry levels of expertise the elementary education preservice teachers have at the beginning of the clinical practicum?

Research Question 3

Do preservice teachers who participate in the clinical practicum perceive they have acquired the expertise to teach reading?

\section{Hypotheses}

$H_{I a}: \quad$ Elementary education preservice teachers who participate in a clinical practicum experience tutoring a low-achieving student in reading under the direct supervision of a reading expert in undergraduate teacher preparation will significantly increase in their development of reading expertise compared to early childhood education preservice teachers who did not participate in a clinical practicum. Specifically, how well are both groups able to assess:

- Miscue analysis: Errors from the three cueing systems; semantic (meaning), syntactic (structure) and graphophonic (visual).

- Fluency: A reader's speed, expression, phrasing, and attention to punctuation.

- Data analysis: Data in order to analyze/interpret a reader's performance based on observation and assessment of miscue analysis, fluency and comprehension.

- Inquiry orientation: Appropriate information about a reader through reasonable reading assessment technique(s).

- Intelligent action: And make reasonable instructional decisions geared to reading strategy instruction, not fixing mistakes. 
$H_{2 a}$ : Elementary education preservice teachers who, at the onset of the clinical practicum are in the low and middle third on the pretest will demonstrate significant gains in their level of development of reading expertise.

$H_{3 a}: \quad$ Elementary education preservice teachers who participate in a clinical practicum tutoring a low-achieving student under the direct supervision of reading expert in their undergraduate preparation will perceive they have acquired the expertise to teach reading.

\section{Significance of the Study}

How should teachers be taught to teach reading? This question has received little attention from the reading research community and relatively few researchers have asked questions about the processes that teachers go through as they learn and continue to learn to teach reading (Anders, Hoffman, \& Duffy, 2000). Although teacher education is the key to instructional improvement (Darling-Hammond, 1997), there is a lack of empirical evidence to guide decisions about programs, curriculum and instruction in addition to knowing how teachers should be taught to teach reading (Anders, Hoffman, \& Duffy, 2000).

Learning how to teach reading requires content and pedagogical knowledge and skill relative to the complex processes of reading, and this develops over time. From this perspective, the purpose of a preservice teacher education program is to provide prospective teachers with the background knowledge about the structure of written language, the nature of the reading process, how to assess students' reading capabilities, and multiple methods of teaching reading. Additionally, its purpose is to provide prospective teachers with specific experiences of teaching reading to enable them to 
match appropriate instruction specific to student needs, and to evaluate the outcomes. These specific kinds of experiences should scaffold preservice teachers in their development of expertise in teaching reading.

Studies designed to examine the kinds of teacher education that support teacher learning suggest that under the right circumstances, with particular kinds of learning experiences, preservice teachers can develop a more expert practice even as beginning practitioners ( Darling-Hammond \& Macdonald, 2000; Koppich, 2000; Miller \& Silvernail; Zeichner, 2000). This suggests that new teachers can demonstrate more accomplished practice than previously thought when they experience a strong, more purposeful preparation (Hammerness et al., 2005).

Smith (2005) conducted an exploratory study based upon the seminal work of Dewey (1933) and Rodgers (2002). He examined the feasibility of (a) a reading methods course promoting habits of inquiry in preservice teachers, and (b) using "video cases" as a means of both promoting habits of inquiry and measuring the extent to which five preservice teachers enrolled in a reading methods course developed the dimensions of inquiry-based teaching. Two means were used to develop habits of inquiry. First, each preservice teacher tutored a struggling reader once a week for 45 minutes for 8 weeks. Second, video cases of readers were viewed and discussed to allow scrutiny and reflection among preservice teachers. The findings of this study showed that the use of video cases helped to move novice teachers to more sophisticated levels of inquiry about teaching reading. One of the implications of this study was video cases also have the potential to help measure gains in teachers' level of reading expertise. 
It is important to extend Smith's work from looking at inquiry using video cases to validate the development of expertise in a supervised clinical practicum. The focus of this study was to examine the effect of a supervised clinical practicum on preservice teachers addressing; (a) specific ways in which preservice teachers are prepared to teach reading; and, (b) the development of reading expertise in preservice teachers prior to student teaching. The study examined and described the nature and extent of an undergraduate supervised clinical practicum which includes one-on-one tutoring of a low-achieving second grade student. The clinical practicum combined coursework and clinical work within the framework of a teacher preparation program. This study sought to explore the effect of a supervised clinical practicum on preservice teachers' development of reading expertise, to measure the gain in their reading expertise over time, and to examine preservice teachers' perceptions of acquiring reading expertise.

\section{Assumptions}

This study is based on the following assumptions:

1. Preservice teachers develop conceptions of teaching reading that may be based on their own experiences as students; therefore, they may be likely to teach in the way they themselves were taught.

2. When preservice teachers observe good teaching it tends to reinforce the view that teaching is effortless because the knowledge and experience supporting it are not visible.

3. Many preservice teachers view good reading instruction as a deployment of lock-step skills for all students, so learning to teach looks like acquiring the skills. 
4. Ideas, concepts and strategies about teaching reading discussed in preparation courses already seem familiar, thus preservice teachers develop simplistic beliefs associated with these concepts.

5. The complex process of reading requires content and pedagogical knowledge.

6. Learning to teach reading develops with experience and over time.

\section{Delimitations}

Miscue analysis, fluency analysis, data analysis, inquiry orientation, and intelligent action were chosen to measure elementary education preservice teachers' development of expertise to teach reading since they were the appropriate elements of teaching reading. Three classes of elementary education preservice teachers were chosen to participate in the study; they attended one university, had completed the same three requisite reading courses, and were enrolled in a fourth reading course that provided the experience of a supervised clinical practicum.

\section{Glossary of Terms}

Clinical practicum: A place, usually a school related to a college or university, where preservice teachers may gain experience learning to teach reading tutoring a lowachieving reader under the direct supervision of a reading expert.

Instructional reading level: The reading ability or grade level of material that is challenging, but not frustrating for the student to read successfully with normal classroom instruction and support. Note: Although suggested criteria vary, better than 95 percent word-identification accuracy and better than 75 percent comprehension are often used as standards in judging whether a student is reading at this level. 
Reading achievement: The level of reading ability at which an individual is estimated to be functioning for instruction.

Reading expertise: The ability to progress from learning the basic elements of teaching reading, accumulating knowledge of how to teach reading, making decisions about what they are going to do, and reflecting on what is working based on their experience. Expertise was measured by gains in the ability to assess miscue analysis, fluency analysis, data analysis, inquiry orientation, and intelligent action, as assessed through responses to a Protocol of Questions (See page 57, Protocol of Questions).

Reading process: (a) an act of reading taken as a whole; what happens when a person processes text to obtain meaning. (b) any of the subprocesses, such as word identification or comprehension that are involved in the act of reading.

Reading specialist: A general term referring to educational personnel with advanced training in reading education

Running record: An informal assessment procedure with high reliability (.90) on error reliabilities) that informs teachers regarding students' decoding development (Clay, 1987).

Scaffold: In learning, the gradual withdrawal from a more-educated (e.g., teacher) support, as through instruction, modeling, questioning, feedback, etc., for a child's performance across successive engagements, thus transferring more and more autonomy to the child (Harris \& Hodges, 1995). 
Video cases: Videos that can pose "real-world events that challenge teachers," a reader makes several significant miscues but is still able to answer comprehension questions in a way that allows them to scrutinize and reflect upon what is observed (Smith, 2005). Each video portrays a low-achieving reader with different reading difficulties, i.e., miscues, fluency, comprehension.

\section{Summary}

The importance of expertise when teaching reading is understood as well as the idea that teacher preparation programs seem to be the logical and most conducive place to teach preservice teachers how to teach reading. However, there is limited research on how and under what circumstances preservice teachers develop the expertise needed to teach reading effectively. Further complicating the process that preservice teachers undergo to learn how to teach reading, there are many variations in the content and experiences used to teach reading provided for elementary education preservice teachers prior to student teaching. Colleges and universities play a significant role in helping to achieve the goal of a "high-quality" teacher in every classroom. Therefore, the content and structure of elementary education preservice reading teacher preparation programs should be examined. The purpose of this study was to examine the effect of a supervised clinical practicum embedded in a preservice reading teachers' preparation on the development of reading expertise of elementary education preservice teachers.

Chapter 2 reviews the research on classroom teacher reading preparation from the last half of the $20^{\text {th }}$ century and the efforts to improve preservice teachers' reading preparation. It also discusses reasons why preservice teachers may not be prepared to teach reading after completing their preservice teacher education and last, the ways in 
which people learn is discussed, how this is not aligned with teacher learning, and how it may be applied to preservice teacher reading preparation.

Chapter 3 describes the quasi-experimental methodology using a mixed method repeated measure pretest-posttest design. Quantitative analysis was used to test $H_{l a}$ and $H_{2 a}$. A multivariate analysis of variance (MANOVA) was conducted on each of the elementary and early childhood teachers' responses to the pretest and posttest Protocol of Questions. The interaction was significant, therefore each of the five variables were tested with a univariate ANOVA. To test $H_{2 a}$ a one-way ANOVA with pregrouping was carried out on the five variables to determine if there was a differentiated effect of the clinical practicum depending on the levels of expertise the elementary education preservice teachers had at the beginning of the practicum. Qualitative methodology using techniques and procedures suggested by Merriam (1988) and Miles and Huberman (1994) were used to determine if the elementary education preservice teachers perceived they acquired the expertise to teach reading.

Chapter 4 presents the results of the statistical tests; tables are provided to describe the statistical results and a narrative to discuss the qualitative findings. For Hypothesis $\mathrm{Hl}$, the results of a multivariate analysis of variance (MANOVA) indicated there was a significant main effect by group $\mathrm{F}(5,68)=5.71$, $\mathrm{p}<.001$ and a significant time effect from the pre to posttest Protocol of Questions for the five areas of reading behaviors, $\mathrm{F}(5,68)=2.52, \mathrm{p}<.038$. There was also a significant interaction of group by time from pre to posttest Protocol of Questions in all five areas, $\mathrm{F}(5,68)=3.82$, $\mathrm{p}=.004$. Since the multivariate interaction was significant, each of the five variables, miscue 
analysis, fluency analysis, data analysis, inquiry orientation and intelligent action were tested for interaction of group by time with a univariate ANOVA.

For Hypothesis $2 \mathrm{H} 2$, a one-way ANOVA with pregrouping was carried out on the five areas of reading behavior. After pretest scores were divided into three groups, with approximated one-third of the preservice teacher in each group, a one-way ANOVA was carried out on the gain scores to see if the lower and middle groups made significantly higher gains from the pre to posttest. The preservice teachers whose entry level of reading expertise was in the low and middle thirds based on their pretest made significant gains on the posttest in all five areas of observable reading behavior, miscue analysis, fluency analysis, data analysis, inquiry orientation and intelligent action. The preservice teachers who entered the clinical practicum with a higher level of reading expertise did not make significant gains in expertise.

For Hypothesis $3 \mathrm{H3}$, the responses of 46 elementary education preservice teachers were analyzed qualitatively. The preservice teachers responses were coded, the codes were used to organize and cluster parts related to elementary education preservice teachers' perceptions of acquiring reading expertise. Three themes emerged; (a) selfefficacy to teach reading; (b) preservice teachers' perceptions of acquiring reading expertise, and (c) preservice teachers gained insight; they realized their knowledge of teaching reading impacted student achievement. Results indicated the elementary education preservice teachers perceived they acquired the expertise to teach reading.

Chapter 5 presents how elementary education preservice teachers' development of reading expertise was measured and compared to early childhood preservice teachers' development of reading expertise. Included is a discussion of the mixed-method 
approach using quantitative and qualitative data analyses which provided insights into elementary education preservice teachers' processes of developing expertise to teach reading.

It was concluded that the elementary education preservice teachers gained reading expertise after participating in a supervised clinical practicum. Implications for a preservice teacher preparation for all preservice teachers who will be teaching reading would be the inclusion of a clinical practicum. 


\section{CHAPTER II}

\section{REVIEW OF THE LITERATURE}

This study examines the effect of a supervised clinical practicum on the development of reading expertise of elementary education preservice teachers. Expertise to teach reading is the ability to progress from learning the basic elements of teaching reading, accumulating knowledge of how to teach reading, making decisions about appropriate reading instruction, and reflecting on what is working based on experience.

This chapter contains a review of the literature of (a) classroom teacher reading preparation from the last half of the $20^{\text {th }}$ century and the efforts to improve preservice teachers' reading preparation; (b) why preservice teachers may not be prepared to teach reading at the conclusion of their preservice program, and last, (c) the way in which people learn and how this may be applied to elementary education preservice teacher reading preparation.

\section{Early Elementary Teacher Preparation for Reading Instruction}

In the 1950s and 60s Mary Austin, along with her student Coleman Morrison collected data on the quantity and quality of reading teacher preparation from programs across the United States (Hoffman \& Roller, 2001). Austin and Morrison, (1962) conducted a study to learn how colleges and universities were preparing teaching of reading and also to suggest ways for improving preparation. The study used a survey and a field study of teacher preparation institutions across the country. Their findings included a lack of specific course offerings for preservice teachers, a lack of field and practicum experiences, and a mismatch of the qualifications of those who were teaching 
the preservice teachers. The findings of the study also showed that nearly all colleges and universities required one course in reading, however, the time given to reading might be as little as 12 clock hours, and much more emphasis was put on primary reading skills than on intermediate reading skills. Austin and Morrison's final report, The Torch Lighters (1962), concluded that there was not enough attention to the teaching of reading in most undergraduate programs and described changes needed on the content covered and the methods of preparation. Austin and Morrison (1962) made twenty-two recommendations including senior faculty playing a more active role instructing future teachers and requiring the equivalent of three semester hours in reading. The most important aspect of this study is that it was influential in raising standards in regards to reading preparation in many universities and colleges (Smith, 2002).

Morrison and Austin (1976) replicated the study to determine if progress had been made regarding their recommendations. The results suggested that 14 of the recommendations were in effect, and two recommendations were somewhat implemented. Two of the important recommendations in effect impacting the follow-up study were more courses were required and more courses were taught in field-based settings. Though Austin and Morrison's studies (1962, 1976) were informative and provided information to those who wanted changes in practice, preservice reading teacher preparation was described superficially. Anders, Hoffman and Duffy, (2000) in a review of preservice teacher education, discuss Austin and Morrison's studies (1962, 1976), and state that more interesting questions such as "What goes on in reading teacher preparation?" "How are they being taught?" and "With what effects"? were not addressed. Additionally, since most of the recommendations from the early studies of 
Austin and Morrison $(1962,1976)$ had been put into effect or were somewhat implemented, from that point the profession stopped thinking seriously about reading teacher education (Hoffman \& Roller, 2001). From 1965 - 1996 there were 19,457 studies conducted in reading, however only 140 have of those studies focused on preservice teacher reading preparation. The 140 studies that were identified varied in methodology, factors investigated, and significance of findings. They also varied in the quality and thoroughness of research and at best offered a general sense of inquiry into preservice teacher preparation (Anders, Hoffman \& Duffy, 2000). This left gaps in the research literature on preservice teacher reading preparation.

Addressing the Gaps in Preservice Teacher Preparation for Reading Instruction In 1999 the International Reading Association (IRA) formed the National Commission on Excellence in Elementary Teacher Preparation for Reading Instruction to address the gaps in the research literature on preservice teacher reading preparation. The goal of the commission was to develop and implement research that would identify qualities of effective teacher preparation programs in reading. The commission planned three studies; the first was a national survey of current practices across the United States, the second study examined the features of excellent reading teacher preparation programs, and the third study examined the effects of preparation on teaching practices during the first years of teaching.

The International Reading Association (IRA) Commission's survey of preservice preparation in reading described current practices concerning reading teacher education (Hoffman \& Roller, 2001). The commission survey collected descriptive data on existing programs and judgments of program quality by teacher educators. Some of the findings 
were: (a) the average number of semester course hours in reading was approximately two courses, (b) there were extensive field experiences prior to student teaching (c) most of the teaching faculty had classroom experience in teaching as well as advanced degrees in reading; and, (d) a major focus was learning to teach diverse learners. The data provided information on the structure and variation of reading teacher education programs but they did not provide insight into the effectiveness of the programs.

The commission's second study examined seven universities and one college, judged as excellent by a panel of prominent reading educators, in preparing elementary teachers to teach reading (Harmon et al., 2001). The panel identified a set of excellent 4year undergraduate programs that met the accepted standards within the profession. Eight critical features of excellent programs were identified: (a) a comprehensive curriculum that helps students acquire a cohesive knowledge base for literacy; (b) course-related field experiences where they have opportunities to interact with excellent models and mentors (c) a vision of literacy, good teaching and quality teacher education; (d) resources to support excellent teacher preparation (intellectual, financial, and professional) (e) preparation of teachers who adapt instruction in response to increasing diversity (f) autonomy of teacher education programs within institutions; (g) a learning community among faculty, students, and mentor teachers: and (h) teacher educators who continually assess students, their program, their graduates, and themselves to guide decision making and program development.

In the third study, the commission followed a group of graduates from these excellent teacher preparation programs through their first years of teaching (Maloch et al., 2003). That study of reading teacher preparation followed a large sample of teachers 
over three years. The researchers examined the interpretive experiences of the teachers, observations of teaching, and student outcomes. The study was the most comprehensive longitudinal research into reading teacher preparation ever conducted. The intent of the study was to examine the effectiveness of the graduates of excellent reading teacher preparation programs in terms of classroom practices and student achievement. The study was guided by two questions: (1) What effects do participation in and completion of an excellent reading teacher education have on the experiences of teachers as they enter schools? and (2) How does teachers' preparation relate to their teaching practices? The evidence gathered suggest that preservice teachers' participation in high-quality reading teacher preparation that focuses on the teaching of reading positively influenced the experience of the beginning teachers (Maloch et al., 2003). The findings provided compelling evidence that an investment in quality reading teacher preparation at the undergraduate level contributed to effective teaching and learning of reading in elementary schools. The evidence suggests that participation in high-quality teacher preparation that focuses on the teaching of reading influenced the experience of the teachers and the quality of student engagement. However, Hoffman et al. (2005) in an article which reported that study, expressed the need for additional examination of teacher preparation since the question in the research community still remained; how should teachers be prepared to teach reading?

Current Elementary Teacher Preparation for Reading Instruction Research on teacher education is sometimes not specific to reading (DarlingHammond, 2000) and is evidenced by a lack of studies that focus on preservice reading teacher preparation. However, more recently there have been studies conducted on 
preservice reading teacher preparation that are more specific to teaching reading, and offer more insight into what is needed to prepare preservice teachers to teach reading. A study that helped preservice teachers gain ideas about teaching reading and developing ideas about themselves as teachers of reading was conducted by Hughes, Packard, and Pearson (2000). They investigated preservice teachers' use of hypermedia and video cases to learn about literacy instruction. They believed what was needed in teacher preparation programs was a vehicle to bring the context of actual classrooms for preservice teachers to view, analyze, and critique theoretical perspectives from a set of videotaped cases. Hughes et al.(1997) used an existing set of videotaped cases demonstrating reading strategies used in successful classrooms from the Center for the Study of Reading's (CSR) video series to develop the Reading Classroom Explorer (RCE). The set of videotaped cases presented a hypermedia learning environment showing teachers' successful reading instruction delivered to elementary-age students across the United States. The videotaped cases were designed to be readily accessible resources showing exemplary teaching approaches to engage elementary students who were from diverse, cultural, linguistic, and intellectual backgrounds. The Reading Classroom Explorer (RCE) was situated in teacher education and provided a mix of theory and practice, connecting pedagogy with the complexities of teaching reading via technology. The participants in the exploratory study were preservice teachers enrolled in a reading methods course. The preservice teachers observed and discussed the videotaped cases pertinent to what they were learning about teaching reading in the methods course. The videotaped cases were used as a source they were able to draw upon when asked to compare the use of whole language and skills orientations to teach reading 
when asked to complete paper assignments. In addition to the use of the videotaped cases the preservice teachers were offered other sources to draw upon, including classroom observations and textbook reading assignments. The purpose was to better understand how preservice teachers make sense of the videos and hypermedia in relation to their experiences in coursework and field-based observations. The data sources for that exploratory study were three paper assignments, preservice teachers' reactions to the media component of the methods course, video-taped sessions of the preservice teachers using the Reading Classroom Explorer (RCE) in conjunction with a paper assignment. Additional data sources were a follow-up interview in the semester following the methods course focusing on how the Reading Classroom Explorer (RCE) might be used in their internship year, and interviews one year later focusing on the impact of the Reading Classroom Explorer (RCE) on their teaching practice. The data was collected over a two year time span, beginning with the semester the preservice teachers took the methods course and ending with their internships. The preservice teachers participated to varying extents; each decided what combination of data the researchers could use or collect and much of the analysis focused on seven preservice teachers due to the differences in the amount and type of data the preservice teachers agreed to share. The data was analyzed qualitatively and the researchers concluded that preservice teachers gained ideas about teaching reading and developed ideas of themselves as teachers through the use of multiple classroom cases. The study was exploratory not experimental, thus their results suggest possible relationships between experiences and learning, rather than definitive conclusions about causes of student knowledge, skills, and 
dispositions, however, the preservice teachers' experiences were limited to media and hypermedia; they did not have the experience of working with students.

The experience of working with students, such as one-on-one tutoring, has been touted as one of the most effective strategies to help struggling readers acquire necessary reading skills (Juel, 1996; Shanahan, 1998), and in a study comparing one-on-one tutoring to small group tutoring, Pennell et al. (1994) reported more powerful effects on the reading achievement of students who received one-on-one instruction. A number of studies have provided preservice teachers with experiences working with students in oneon-one tutoring settings. However, the rationale for one-on-one tutoring experiences, the consistency and intensity in tutoring programs and the components of successful tutoring vary in those studies.

Wanda Hedrick (1999) conducted a study to examine the effects of tutoring by preservice teachers. It was designed to answer the question, "Will accelerated reading progress in third, fourth, and fifth graders be demonstrated after one year of one-on-one tutoring by preservice teachers?" The preservice teachers were in their senior year and were enrolled in a course that required unsupervised one-on-one tutoring at an elementary school. Most of the preservice teachers had had two or more courses on teaching reading. The 11 preservice teachers who participated in the study tutored a student for one and one-half hours two times per week during the 10 week semester. The elementary students who participated in the one-on-one tutoring were identified by the teachers in the elementary school as at-risk for school failure; students who would benefit from one-onone reading instruction. The framework for tutoring the students came from elements of established literacy programs but the preservice teachers were also encouraged to adjust 
reading instruction based on specific reading assessments. They made instructional decisions based on informal reading assessment, observations, and collaboration with other tutors, and/or the professor. Communication with the professor was limited to a minimum of three times during the semester via email to discuss progress or problems. The Basic Reading Inventory (Johns, 1997) provided the beginning and ending reading levels of the tutored students and they were quantitatively analyzed using a paired samples t-test. The students benefited from the one-on-one tutoring delivered by preservice teachers. Although they made significant gains in reading as a result of the one-on-one tutoring, there were no measures of the preservice teachers' gains in their ability to teach reading. That study only focused on the reading achievement of the students as a result of one-on-one tutoring.

In another study, one-on-one tutoring of students who were "at-risk" for reading failure was used to help preservice teachers make connections between theory and practice. Hedrick, McGee, and Mittag (2000) examined preservice teachers' learning from a one-on-one tutoring experience. A qualitative approach was used to allow the researchers to determine the beliefs, attitudes and perceptions of preservice teachers towards elementary students who were at-risk for reading failure. The data sources were three open-ended email surveys that asked the preservice teachers to respond to interview-type questions constructed by the researchers (e.g., describe the student you are tutoring), solicited and unsolicited e-mail correspondence from the preservice teachers (the researchers encouraged further communication about tutoring experience, questions, concerns, problems, comments), video-taped focus group sessions, and the researchers' reporting of events and perceptions. That study documented the practical experiences of 
one-on-one tutoring and their perceptions of teaching "at risk" students, in addition to helping the preservice teachers make connections between theory and practice.

Duffy and Atkinson (2001), through preservice teachers' experience tutoring oneon-one, examined preservice teachers' beliefs, understandings and instruction of struggling readers as they evolved over time in two university reading education courses having a field component. The research followed 22 preservice teachers through one year of their teacher education program. The content of the first course was theory, research and practice of reading instruction. Using the framework of Vacca, Vacca, and Gove (1995), instruction was modeled for the preservice teachers as to how personal, practical and professional knowledge could be used to inform their reading instruction. The second course included a four-week internship in which each preservice teacher tutored an elementary student who was experiencing difficulties in learning how reading. During the first course, data sources included preservice teachers' essays describing their ideas on how reading should be taught, a literacy autobiography, and three learning logs on the topics of reading materials, word identification and fluency, comprehension and vocabulary and an analysis of the reading program in their internship site. During the second course, data sources included a reflection on teaching struggling readers written by the preservice teachers at the beginning of the second course, emailed messages from the preservice teachers to one of the researchers, and a final essay on teaching struggling readers written by preservice teachers at the end of the second course. A qualitative content analysis was used; the researchers analyzed the assignments of the 22 preservice teachers across the one year, after completion of the two courses. The researchers concluded that preservice teachers improved in their abilities to integrate their personal, 
practical and professional knowledge to inform their reading instruction; their misunderstandings of reading instruction decreased; their ability to examine reading instruction critically increased; the estimations of their preparedness to teach struggling readers increased, they valued the use of assessments; and they valued their tutoring experiences. The results of that study suggest most of the preservice teachers were able to see how their tutoring experience would inform their future instruction, especially reading instruction for students who experience reading difficulties.

Fang and Ashley (2004) extended the previous research. The preservice teachers tutored a struggling reader and gained an understanding of why some children have difficulty learning to read, however, their own knowledge, skills and insights about teaching reading were also developed. Fang and Ashley (2004) examined 28 preservice teachers' construction of professional knowledge, skills, and insights in a nine-hour (a week), field-based reading block. The reading block was designed to provide the preservice teachers with the knowledge, skills and insights needed to teach students who experience reading difficulties. The reading block was divided into three parts. Part one, (3 weeks) provided theory in language, learning and teaching; part two, (3 weeks) provided instruction in literacy assessments; and part three (8 weeks) provided strategies to help students' increase their reading potential. Infused in the field-based reading block was a tutoring component. Each preservice teacher tutored an elementary student who was identified by the classroom teacher as "at risk" for reading failure. The students were tutored two times a week for 45 minutes. Prior to this experience the preservice teachers had taken one basic reading methods course. In addition to the instructors' lectures on assigned readings pertaining to theory and practical issues in language, 
learning, and teaching, the instructors helped the preservice teachers plan and implement reading lessons for the children, observed the tutoring sessions and provided feedback to the preservice teachers. Two preservice teachers tutored one child on an alternate basis because Fang and Ashley (2004) believed that students benefit from and become more reflective by observing partners tutoring. Data sources for the study were surveys, journals, interviews, case-study reports, and beliefs-into-practice papers, in addition to instructors' observation notes about preservice teachers' discussions and tutorial sessions. The primary data were self-reported and the preservice teachers' interpretations of the reading block were from their own thoughts and words. In their concluding discussion Fang and Ashley (2004) suggest that the preservice teachers developed substantial knowledge, skills, and insights about reading education, gained more confidence in themselves as reading teachers and they gained an understanding of why some children have difficulty learning to reading.

Another study used one-on-one tutoring as a way for preservice teachers to learn about themselves and to develop beliefs and self-efficacy of reading development. Shaw and Dvorak (2007) conducted a study to identify the literacy knowledge, beliefs and selfefficacy of 52 elementary preservice teachers who were enrolled in a reading methods course. The preservice teachers completed 10 practicum sessions; five of the sessions they worked with a primary reader and then worked with an intermediate reader in the second five weeks. They worked with the student in reading one day a week in the practicum setting in which they conducted informal reading assessments and implemented instructional activities. They also met one day a week in a university classroom. The instructor of the course was present at the elementary school 
coordinating the practicum and supervising the preservice teachers. The preservice teachers responded to three assessments at the beginning and at the end of the semester. The researchers used the Theoretical Orientation to Reading Profile (TORP, DeFord, 1985) to measure information about the preservice teachers' beliefs about phonics, comprehension, fluency, strategies, sight words, text, and reading difficulties. Quantitative analysis was used to compare pre-posttest means for each statement. A second assessment, The Teachers' Sense of Efficacy for Literacy Instruction Scale (TSELS, Johnson \& Tschannen-Moran, 2003) was quantitatively analyzed and pairedsamples t-tests were used based on the pre-post results. The third assessment was an instructor-made open-ended short-answer questionnaire asking preservice teachers to discuss their knowledge about reading (e.g. what causes reading difficulties; describe their personal reading practices). The questionnaire was analyzed qualitatively using case study techniques (Merriam, 1988).

The results of the study were significant and indicated that the preservice teachers were able to articulate their knowledge and beliefs about literacy development and instruction before and after coursework; however, the researchers, Shaw and Dvorak (2007) noted that it would be premature to conclude that these preservice teachers are well-trained and highly informed. The importance of that study is that preservice teachers were able to analyze their beliefs, and consider and apply new information about how reading was taught. Most important was that the experience in their preservice preparation changed their thinking about teaching reading as a result of the knowledge they gained about reading and the experience they had tutoring one-on-one. 
Finally, Smith (2005), in an exploratory study, examined the feasibility of (a) a reading methods course promoting habits of inquiry in preservice teachers and (b) using video cases as a means of promoting habits of inquiry and measuring the extent to which preservice teachers developed the dimensions of inquiry-based teaching. The participants were five preservice teachers enrolled in a second reading methods course. The focus was to apply methods of assessment and instruction with one child. Each preservice teacher tutored a struggling reader for 45 minutes once a week for eight weeks. During the semester the preservice teachers observed and discussed four video cases. Each video case depicted struggling readers, each displaying different reading tendencies. The preservice teachers' discussions of the video cases focused on describing facts about the reader, analyzing the facts based on theories of reading, and developing an instructional plan, if given the opportunity to work with the student.

Data sources for the study were a protocol of interview questions (Smith, 2005). The preservice teachers responded to a protocol of interview questions at the beginning and at the end of the semester. Quantitative and qualitative methodology was used to analyze the data. A paired samples $t$-test was calculated to compare the mean pretest score to the mean of the posttest score on the protocol of interview questions. A descriptive, deductive analysis was used to compare and contrast the preservice teachers' pretest and posttest responses.

The results of Smith's (2005) research indicate that the reading methods course had a profound effect on helping preservice teachers develop habits of inquiry about teaching reading. Specifically, two course features were strongly associated with helping preservice teachers learn how to teach reading: tutoring one student for eight weeks, and 
the use of video cases. The video cases provided examples of students with real-life reading problems and allowed the preservice teacher to analyze and discuss them, which provided them with far more than just reading it in a book. The researcher believed that video cases not only had the potential for helping move novice teachers towards more sophisticated levels of inquiry, but they also had the potential for helping to measure teachers' level of expertise. There is pressure on teacher preparation programs to "scientifically" prove that they do make a difference, therefore, research methods are needed such as used in this study that can begin to measure levels of teacher expertise (Smith, 2005). The current study builds upon the work of Smith, using video cases and a larger population to quantitatively measure the development of reading expertise.

In summary, most of the studies discussed above helped preservice teachers to develop knowledge and beliefs about themselves, helped them connect theory and practice, and helped them to relate to and understand that reading instruction is especially important for "at risk" or struggling readers. The data analysis approaches were relevant in providing information on how preservice teachers were able to learn about and understand the importance of teaching reading to struggling readers, how they gained knowledge about teaching reading in addition to the insights they learned about themselves which connected to some aspects of learning about teaching reading. Those studies did not specifically address how preservice teachers may be taught how to teach reading. One study did, however, report that preservice teachers were able to develop habits of inquiry about reading instruction and the gains in their knowledge were measured quantitatively. One of the implications of that study was the importance of "scientifically" proving teacher education makes a difference in preparing preservice 
teachers to teach reading. It is important to examine and understand the aspects of elementary education preservice teachers reading preparation that may contribute to their development of reading expertise. It is equally important to measure preservice teachers' learning, to determine if the reading teacher preparation they receive in their preservice reading preparation effected and contributed to their expertise in learning how to teach reading.

Why Preservice Teachers May Not Be Ready to Teach Reading Young men and women are certified as teachers after fulfilling course requirements and some prescribed number of hours in field experiences. As soon as these requirements are achieved, they are given a full list of responsibilities associated with being a teacher (Snow, Burns, \& Griffin, 2005). Teacher development is not in line with what we know about adult development, human learning, and the description of the knowledge teachers need to acquire. Other forms of professional preparation require long periods of supervised practice, years of full-time study and internships before being allowed to practice their profession (Snow, Burns, \& Griffin, 2005). Even with the mandate of the No Child Left Behind Act of 2001 (2002) demanding high-quality teachers, and the national and state focus on the reading achievement of students, preservice teacher preparation to teach reading falls short in the amount of supervised practice required before entering a classroom.

Although it is important to acquire background knowledge of teaching and learning to read, preservice teachers need to receive specific and practical information and experience as to how, as new teachers, they can create a classroom environment to teach reading effectively to their students (Ehri \& Williams, 1996). Learning to teach 
reading is a developmental process and this process often begins in preservice teacher preparation. Therefore, it is important to examine the ways in which preservice teachers are prepared to teach reading but it is equally important to determine if the understanding of teaching reading within that preparation in fact takes place (Ehri \& Williams, 1996).

What is missing in discussions and debates about preservice teacher preparation to teach reading is how they learn to teach reading. It is believed that instead of professional learning, teachers' practices and learning change as a result of the curriculum or standards. Teacher learning is sometimes seen as something that happens from experience, or as the product of training in particular methods, however, teacher learning begins years before, in teachers' preservice preparation. Although preservice teacher reading preparation includes coursework and field experiences, what is not included in that preparation are empirically validated theories of teacher learning and how those theories may be used to prepare preservice teachers. The ways in which teachers learn how to teach may be roughly equated to the ways in which cognitive psychology now informs the education of schoolchildren (Ball \& Cohen, 1999).

People have speculated about how people learn for centuries. Teacher learning, understanding how people learn, how children develop, how language is acquired and used are components that are critical for effective teaching. Bransford, DarlingHammond and LePage (2005) used the frameworks introduced in How People Learn: Brain, Mind, Experience and School (National Research Council, 2000), and How People Learn: Bridging Research and Practice (Donovan, Bransford, \& Pelligrino, 1999) to provide a framework for thinking about learning from these perspectives: 
- The learner and his strengths, interests, and preconceptions;

- The knowledge, skills, and attitudes we want people to acquire and how they may be able to do so in order to transfer what they've learned;

- The assessment of learning that both makes students' thinking visible and, through feedback, guides further learning; and

- The community within which learning occurs, both within and outside the classroom. (p. 32)

From these perspectives, teacher learning is divided into four components; (a) learning-centered teachers have knowledge of child development, language, cultural backgrounds, and special needs, and they connect to students' knowledge and experiences helps them to learn (b) knowledge-centered teachers pay attention to what they teach and why; they consider how specific topics and ideas may best be taught (c) assessment-centered teachers connect assessments and the feedback from assessments and use this as another source of learning, not just an evaluation of it. Finally, the process of teacher learning is (d) community-centered, as it is influenced by the norms of the community in which it occurs and it provides supportive and enriched settings in which people can learn from one another. Effective teachers know how to balance the four components of the framework (Bransford, Darling-Hammond, \& LePage, 2005). Preparing learner-centered, knowledge-centered, assessment-centered, and communitycentered reading teachers requires providing supervised experiences that are situated in settings that reflect today's challenges of teaching diverse populations in schools.

Hammerness et al. (2005) identified three major principles of learning from How Students Learn: History, Mathematics, and Science in the Classroom (National Research 
Council, in press), and How People Learn: Brain, Mind, Experience, and School

(National Research Council, 2000); these principles complement the framework for teacher learning indicated above. Hammerness et al. (2005) used these principles to align issues of teacher learning with principles for teacher learning and about how children and adults learn and acquire competence.

1. Prospective teachers come to the classroom with preconceptions about how the world, and teaching, works. These preconceptions, developed in their "apprenticeship of observation," condition what they learn. If their initial understanding is not engaged, they may fail to grasp the new concepts and information, or they may learn them for purposes of a test but revert to their preconceptions outside the classroom.

2. To develop competence in an area of inquiry that allows them to "enact" what they know, teachers must (i) have a deep foundation of factual and theoretical knowledge, (ii) understand facts and ideas in the context of a conceptual framework, and (iii) organize knowledge in ways that facilitate retrieval and action.

3. A "metacognitive" approach to instruction can help teachers learn to take control of their own learning by providing tools for analysis of events and situations that enable them to understand and handle the complexities of life in classrooms. (p. 366)

It is a challenge to construct an approach to teach preservice teachers how to teach reading; however, an even bigger challenge is to understand and redirect a preservice teacher's thinking due to the misconceptions and perceptions about teaching learned years before a student begins initial preparation to become a teacher. The misconceptions and perceptions about teaching may hinder the manner in which preservice teachers learn how to teach reading. Sociologist Dan Lortie (1975) used the term apprenticeship of observation to refer to the processes by which prospective teachers develop conceptions of teaching based on their own experiences as students. Students have a great deal of experience in classrooms, and many learn from outstanding teachers who have taught 
them. These apprenticeships can result in serious misconceptions about teaching. One is the widespread idea that teaching is easy; students observe the superficial aspects of teaching, but not the underlying knowledge, skills, planning and decision making. Munby, Russell, and Martin (2001) state that even when observing good teaching or experiencing it for oneself, one cannot easily get a deep understanding of the complexity of the work: "Good teaching tends to reinforce the view that teaching is effortless because the knowledge and experience supporting it are invisible to those taught. Good teaching looks like the ordering and deployment of skills, so learning to teach looks like acquiring the skills" (p. 887). Drawing on their apprenticeship of observation in order to learn to teach reading most likely will not improve teachers' practice.

Learning to teach requires teachers to come to think about and understand teaching in ways quite different from those they have learned from their own experiences. As indicated above, the "apprenticeship of observation" (Lortie, 1975) has a major effect on misconceptions about teaching and learning. The limited vantage point of the preservice teacher does not result in the acquisition of professional knowledge; instead it produces a tendency to imitate the most easily observed aspects of teaching. Preconceptions can also make learning difficult for preservice teachers. For example many of the concepts and ideas discussed in preparation courses are ideas that already seem familiar to the students, concepts such as group learning, assessment and diversity. Preservice teachers often already have clear beliefs associated with these concepts and therefore tend to assimilate what is being taught to their preexisting schemas. This can make it difficult to develop deeper understandings of the concepts (Hammerness et al., 2005). 
Teachers must not only develop the ability to "think like a teacher" but also to put what they know into action; "the problem of enactment" (Kennedy, 1999). There is a major difference between "knowing that" and "knowing why and how" (Simon, 1980). Another issue in learning to teach is "the problem of complexity," helping prospective teachers to develop metacognitive habits of mind that can guide decisions and reflection on practice in support of continual improvement (Hammerness et al., 2005).

The demographics of the student population in today's schools have changed drastically. Students considered part of a racial or ethnic minority group increased from $22 \%$ in 1972 to $31 \%$ in 1986 to $43 \%$ in 2006. In 2006 Hispanic students represented 20\% of public school enrollment up from 6\% in 1972 and 11\% in 1986 (National Center for Education Statistics, 2008a). Between 1979 and 2006, the number of school-age children (ages 5 - 17) who spoke a language other than English increased from 3.8 million to 10.8 million, or from 9 to $20 \%$ of the population in this age range (National Center for Education Statistics, 2008b). Many students who are of racial and ethnic minorities, live in poverty, and speak a first language other than English (Banks et al., 2005). Children from poor, minority, or non-English speaking families and children, who have innate predispositions for reading difficulties, need the support of excellent reading instruction to ensure reading success (Snow, Burns \& Griffin, 1998). Many preservice teachers lack experience teaching diverse populations of students and students who are struggling to learn to read. Most teachers are European Americans from middle-class backgrounds who speak only English. Even if preservice teachers share some overlap of cultural background, other differences such as socio-economic levels may make it difficult to appreciate students' backgrounds. Thus, most teachers do not have the same 
cultural frames of reference; they bring little cross-cultural background knowledge and experience, or the same points of view as the students they will be teaching ( $\mathrm{Au}, 1980$; Heath, 1983; Lee, 1993; Su, 1997).

In the past, many teacher education programs have been criticized for being overly theoretical, having little connection to practice, offering fragmented and incoherent courses, and lacking in a clear, shared conception of teaching. Conceptual and structural fragmentation was consistent in studies of teacher education conducted throughout the 1980s (Feiman-Nemser, 1990; Floden, McDiarmid \& Werners, 1989; Goodlad, Soder, \& Sirotnik, 1990; Howey \& Zimpher, 1989; Zeichner \& Gore, 1990). Programs that are largely a collection of unrelated courses without a common conception of teaching and learning are not agents for affecting practice among new teachers. (Zeichner \& Gore, 1990).

Additionally, in the typical preservice course of study, very little time is allocated to preparation of teaching reading (Snow, Burns \& Griffin, 1998). All states require that K-3 teacher candidates do some course work in the teaching of reading (National Association of State Directors of Teacher Education, 1996). In some cases, reading is embedded in a course for teaching language arts, and the focus is not specifically on reading.

As indicated above, there are inconsistencies in the ways in which preservice teachers are prepared to teach reading. The International Reading Association's National Commission on Excellence in Elementary Teacher Preparation for Reading Instruction (2003) concluded that there is tremendous variation in the content and experiences 
provided across the 1,150 teacher preparation programs in the United States, as reported in the commission's executive summary of Prepared to Make a Difference (2003)

Some programs require as little as one, three-semester course in reading methods, while others offer as many as 18 semester hours in reading coursework that covers topics ranging from the structure of English to teaching reading comprehension. Some offer practicum hours with supervised, "hands on" experiences in reading, and others offer as many as 50-60 hours every semester. (p. 2)

An important role for preservice teacher education is to change initial frames of reference (Kennedy, 1998). Preservice teacher education is ideally situated to foster such a shift in thinking. It is located between teachers' past experiences as students in classrooms and their future experiences as teachers in classrooms. From their experiences, teachers develop the ideas that will guide their future practices. If these ideas are not altered during preservice teacher education, teachers' own continuing experiences will reinforce them, supporting even more strongly their understandings of teaching, and reducing the likelihood that these ideas might ever change.

Learning how to teach reading is a process that develops over time. The ability to teach changes in predictable ways as the novice teacher gains experience. Tochon and Munby (1993) draw a distinction between teaching which operates with a diachronic, i. e. linear, time epistemology and teaching where there is a synchronic approach to time which allows connections to be made between the learner and curriculum. Tochon and Munby's (1993) analysis suggest that a reliance on diachronic teaching is more evident among less experienced practitioners and evidence of synchronic action among the more experienced. Synchronic teaching importantly presupposes that teachers are interpreting agents with the professional freedom to respond knowledgeably in a deliberative way to 
learners' pedagogic needs. This analysis raises questions about how novice teachers can be helped to become the kinds of teachers needed to help learners to develop dispositions to engage with and learn from the opportunities available to them.

What is Needed in Preservice Teacher Preparation for Reading Instruction This past decade has seen many proposals to reform education (Ball \& Cohen, 1999). Reformers advocate changes in assessment and standards, decision making and curriculum; however, what comprises a better education is complex. Teachers are expected to teach diverse learners to become competent and skilled, have an understanding of what they are doing, and communicate effectively. On a daily basis teachers confront complex decisions that rely on many different kinds of knowledge and judgment and that can involve high-stakes outcomes for students' futures (Bransford, Darling-Hammond \& LePage, 2005).

The importance of teacher development is evident, and rather than "covering the curriculum," teachers are expected to find ways to support the needs of all students (Darling-Hammond, 1990). Teachers are expected to prepare all students for thinking work: framing problems; finding, integrating, and synthesizing information; creating new solutions; learning on their own; and working cooperatively (Darling-Hammond \& Cobb, 1996). The kind of teaching required to meet these demands for more thoughtful learning cannot be produced through teacher-proof materials or regulated curriculum (Darling-Hammond \& Cobb, 1996).

What preservice teachers need to understand about reading processes is complex, and it is important to note that learning how to teach reading as a process that develops over time. Having knowledge about reading processes and their acquisition enables 
teachers to understand what they are doing, why, and where they are headed with their instruction (Ehri \& Williams, 1996).

A key element for successful learning is the opportunity to apply what is being learned and refine it (National Research Council, 2000). Carefully constructed field experiences can enable preservice teachers to reinforce, apply, and synthesize concepts they are learning in their coursework (Baumgartner, Keener \& Rust, 2002; Denton 1982; Henry, 1983). Studies of learning to teach suggest that immersing teachers in the materials of practice and working on particular concepts using these materials has the potential to be particularly powerful for preservice teachers' learning (Ball \& Cohen, 1999; Lampert \& Ball, 1998). Ball and Cohen (1999) have termed this kind of learning "learning in and from practice." This idea emphasizes the importance of teachers spending substantial time learning in real classrooms.

Brown, Collins, and Duguid (1989) define apprenticeship in a way that is different from the "apprenticeship of observation" (Lortie, 1975). "Apprenticeship helps to emphasize the centrality of activity in learning and knowledge and highlights the inherently context-dependent, situated, and enculturating nature of learning" (p.39). This type of apprenticeship has been termed cognitive apprenticeship (Collins, Brown, \& Duguid, 1989), and focuses on two aspects of teaching and learning: (a) revealing the process that expert teachers use to handle complex tasks; and, (b) learning through guided experiences in which cognitive and metcognitive processes are explored and utilized. A cognitive apprenticeship suggests field experiences that focus on cognitive and metacognitive processes in learning, scaffolding by an expert mentor, purposeful task selection, increasing complexity of tasks, and experiences that are contextually based in 
diverse classroom settings (Keehn et al., 2001). The processes of clarifying goals, articulating what the desired performance consists of and what it looks like (demonstration, scaffolding, making thinking visible, reflecting and practice with coaching) are essential for preservice teachers. These processes need to be thought out across courses and clinical learning experiences (Hammerness et al., 2005).

More practicum experiences and student teaching integrated with course work appear to make a difference in teachers' practices, confidence, and long-term commitment to teaching (Andrew, 1990). The nature of the support during clinical work appears to be critical in enabling preservice teachers to make sense of their experience and learn from it. Cognitive research has found that children can learn more when supported within their "zone of proximal development" (Vygotsky, 1978); teachers can learn more when supported by expert practitioners (Hammerness et al., 2005). Powerful learning does not occur from letting a preservice teacher "sink or swim" in a practicum experience (Britzman, 1991; Feiman-Nemser \& Buchmann, 1985). Therefore, it is important for novices to receive the modeling, coaching, and the feedback they need for effective learning through guidance and mentoring (Rodriquez \& Sjostrom, 1995; Sparks, 1986).

The benefits of field experiences to enhance teacher education programs have been documented (Bollin, 1996; Danielson, Kuhlman \& Fluckiger, 1998; DarlingHammond, 1998; Fang \& Ashley, 2004), particularly those that engage preservice teachers with students for sustained lengths of time. Linking field experiences to actual methods courses is important. Preservice teachers whose field experiences are integrated into methods course content can see connections between what they are learning about 
teaching and how this is actually applied with the student in the context of a real classroom (Lemlech \& Kaplan, 1990).

A number of theories have been advanced to describe teachers' development (Berliner, 1994; Feiman-Nemser, 1983; Richardson \& Placier, 2001), and other research has focused on the development of teaching knowledge by examining the differences in thinking between expert and novice teachers (Berliner 1986, 1994; Carter, Cushing, Sabers, Stein, \& Berliner, 1988; Lin, 1999). That research has found that when beginning and experienced teachers are asked to evaluate classroom scenes, novices tend to offer superficial, general observations that do not attend to the intellectual work of the classroom. More expert teachers attend to specific aspects of the classroom that are linked directly to the intellectual work of students and generate more detailed observations and hypotheses about what they see; they qualify their observations and interpretations, and weigh the relative importance of certain kinds of information.

Joyce and Showers (2002) have examined the process of development of specific teaching skills and have described how teachers go through an iterative process of learning, experimenting, and reflecting as they develop new skills for use in the classroom. They have also studied how the developmental process of learning to enact new skills can be supported by skilled coaching. The feedback and the collegial nature of the process appear to stimulate reflection and greater skill development.

Modern learning theory makes clear that expertise is developed within specific domains and learning is situated within specific contexts where it needs to be developed and from which it must be helped to transfer (Hammerness et al., 2005). Emerging evidence suggests that teachers benefit from participating in the culture of teaching by 
working with the materials and tools of teaching practice, from participating in practice and by working with experienced teachers.

Research on expertise (Block, Oakar, \& Hurt, 2002) provides important information on how knowledge should be organized. Experts' knowledge is more than a list of disconnected facts; instead their knowledge is connected and organized around important ideas of their disciplines. College courses are often organized in ways that fail to develop the kinds of connected knowledge structures that support activities such as effective reasoning and problem solving. If teacher educators want novices to develop expert thinking and skills of enactment, then careful thought needs to be given to the components of that skill set, the understandings and skills that are the foundation for others, and what experiences are needed (Darling-Hammond, Hammerness, Grossman \& Shulman, 2005).

Berliner proposed that teachers develop expertise through a set of stages; from novice to advanced beginner, competent, proficient, and ultimately to expert. Teachers appear to develop competence over a period of about 5 to 7 years, and only a small percentage of teachers continue to develop into experts (Berliner, 2001). The metacognitive elements that are involved in the development of expertise can be developed in teacher education, enabling more teachers to reach this level of strong competence and to do so earlier than might otherwise be the case (Hammerness et al., 2005). All of the above have been considered in the design of the supervised clinical practicum in the present study.

A long history of research indicates that teachers, and teacher expertise matter much more than which reading series a school district might choose (Allington, 2002), 
and the reliable evidence on the importance of expertise in reading instruction is routinely ignored, distorted, or misrepresented in policy talk and in the popular press (Shaker \& Heilman, 2002). Studies have reaffirmed that to improve reading instruction we must examine teaching expertise rather than expect a panacea in the form of materials (Allington, Guice, Michelson, Baker \& Li, 1996; Baumann, Hoffman, Moon \& DuffyHester, 1998; Block, Joyner, Joy, \& Gaines 2001; Block \& Mangieri, 1996; Hoffman et al., 1998; Sacks \& Mergendoller, 1997).

Additionally, studies designed to examine the kinds of teacher education that support teacher learning suggest that under the right circumstances with particular kinds of learning experiences, new teachers can develop a more expert practice even as beginning practitioners (Darling-Hammond, 2000; Darling-Hammond \& Macdonald, 2000, 2002; Koppich, 2000; Merseth \& Koppich, 2000; Miller \& Silvernail, 2000; Snyder, 2000; Zeichner, 2000). That research does not suggest that new teachers can immediately develop the kind of expertise that a master teacher develops over years of experience. Such learning about teaching, students, culture, development, and subject matter develops over time. Grossman, Samgorinsky, and Valencia (1999) have distinguished between "appropriating tools" and "mastery", suggesting that, "If mastery means the skill to use a tool effectively, then this more fully realized grasp of a concept most likely would take years of practice to achieve" (p. 18). That research suggests that new teachers can demonstrate more accomplished practice than previously thought when they experience strong, more purposeful preparation (Hammerness et al., 2005).

Cognitive psychologists have found that "deliberate practice," purposefully and critically rehearsing certain kinds of performances is particularly important to the 
development of expertise. Expertise is developed within specific domains and learning is situated within specific contexts where it needs to be developed and from which it must be helped to transfer (Darling-Hammond, Hammerness, Grossman, \& Shulman, 2005). Teacher learning should be developed in ways that derive from and connect to the content and the students being taught.

Bransford, Derry, Berliner, Hammerness, and Beckett (2005) compare the relevance about learning, teaching, and transfer for preservice teachers to the learning of elementary children. Asking preservice teachers to memorize facts about how to teach is as limiting as asking children to memorize scientific facts. Rather, preservice teachers benefit from experiences that immerse them with the materials and tools of teaching practice; working closely with experienced teachers and working with students to practice what they are learning (Darling-Hammond et al., 2005). Learning in the ways preservice teachers are expected to teach may be the most powerful form of teacher education since most teachers tend to teach the way they were taught (Bransford et al., 2005).

Research suggests that teacher preparation is a complex and intricate venture that encompasses much more than following a prescribed list of content that all teachers should know (Maloch et al., 2003). When preservice teachers are provided an opportunity to work with children of varying stages of literacy development, they have the opportunity to begin to understand the wide range of literacy learners that will be in the classrooms they will be teaching. They begin to understand that reading is a developmental process, and that although children may be in a particular grade their literacy development occurs at different rates ( Keehn, et al., 2001) When preservice 
teacher preparation programs strategically provide purposeful course work, apprenticeship opportunities, and a clear vision and focus on reading that cross all of the preservice teachers' experiences, this learning may be sustained throughout the demands of teaching.

\section{Summary}

Early research on the practices of teaching perservice teachers how to teach reading provided sparse and limited information. Studies conducted at a later time were somewhat better able to articulate what is needed in preservice teacher preparation to help preservice teachers learn to teach reading. More recent studies document the overwhelming evidence that purposeful undergraduate preparation contributes to effective teaching of reading, however there are no studies that specifically describe how and under what circumstances elementary education preservice teachers learn how to teach reading.

The knowledge that quality teacher education programs contribute to effective teaching is evident, however, there are variations in the way preservice teachers are prepared to teach reading. Studies have shown extensive field experiences, mentoring, one-on-one tutoring, hypermedia, and a mix of theory and practice contribute to preservice teachers learning about teaching reading. What is missing in those studies is a discussion of the development of expertise to teach reading. It has been documented that reading expertise matters more than materials or a reading series, and the importance of reading expertise is understood, yet the examination of how reading expertise may be developed in preservice teachers has not been addressed. 
Teachers spend a very short period of time learning to teach reading compared to other professions where members have lengthy internships, mentoring, and extensive practice before being allowed to practice their profession. Therefore it is important to examine how and what specific aspects of preservice teachers' knowledge to teach reading contribute to their development of reading expertise. 


\section{CHAPTER III}

\section{METHODOLOGY}

The focus of the present study was to examine the development of reading expertise of elementary education preservice teachers in a clinical practicum under the direct supervision of a reading expert. A quasi-experimental with a comparison group using a mixed method repeated measures pretest-posttest design was utilized. Elementary education preservice teachers observed video cases of three low-achieving readers, responded to a Protocol of Questions at the beginning of their fourth reading course, a clinical practicum, tutored a low-achieving reader for 14 weeks, as part of the practicum, then observed video cases of three different low-achieving readers, and responded to a Protocol of Questions at the end of the clinical practicum. The elementary education preservice teachers program of study for preparation to teach reading were three requisite literacy courses; (a) language and literacy development, (b) teaching primary literacy, and; (c) teaching intermediate literacy. The requisite courses included theory and methodologies to teach reading in addition to field observations and some small group instruction in field, teaching specific lessons on phonics, vocabulary, content area reading or language experience based on course assignments. The fourth reading course, teaching in the context of school, was a clinical practicum. The clinical practicum combined theory and methodologies to teach reading with a practical application of tutoring a low-achieving student in reading under the direct supervision of reading experts, the two instructors who conducted the clinical practicum. 
A comparison group of early childhood education preservice teachers observed the same three video cases of low-achieving readers as the elementary education preservice teachers observed, and responded to the same Protocol of Questions at the beginning of their fourth reading course that did not include a clinical practicum. They observed the same three video cases of three different low-achieving readers as the elementary education preservice teachers observed, and responded to the same Protocol of Questions as the elementary education preservice teachers at the end of their fourth reading course. The early childhood preservice teachers program of study for preparation to teach reading were four literacy courses; (a) language and literacy development, (b) emergent literacy, (c) teaching primary literacy, and; (d) children's literature. Two courses, language and literacy development and teaching primary literacy were the same for the elementary and early childhood education preservice teachers. The other two courses the early childhood education preservice teachers studied were young children's processes of constructing literacy and analyzing classroom practices for early learners, and a course which focused on children's literature. Within the four courses, early childhood preservice teachers participated in teaching experiences in field, based on course assignments. The early childhood education preservice teachers' instructor, an expert in emergent literacy, was an assistant professor who taught the early childhood course, in the Department of Curriculum and Instruction.

This chapter presents (a) the quantitative methodology used to measure elementary education and early childhood preservice teachers' development of reading expertise, (b) the quantitative methodology used to determine if there was a differentiated effect of the clinical practicum depending on the levels of expertise the elementary 
preservice teachers had at the beginning of the practicum; and (c) the qualitative analysis to determine if preservice teachers perceived they acquired the expertise to teach reading.

Derivation of General Research Hypotheses and Specific Research Hypotheses

There is little research that looks at the continuum of how and under what circumstances preservice elementary school teachers develop reading expertise. While in undergraduate teacher preparation programs some time is allocated to the preparation of teaching reading, however, this time is relatively small because of all the other subject areas that must be included in their preparation (Snow, Burns, \& Griffin, 1998). Therefore, it is important to examine the kinds of experiences and methods that may be used to develop reading expertise in elementary education preservice teachers. Elementary education preservice teachers typically complete literacy-related course work with various levels of field experiences in elementary classrooms and prior to graduation participate in an internship during which they gain teaching experience in a classroom setting under the supervision of the classroom teacher. Additionally they are observed and receive formative and summative feedback from university personnel. Internships vary, and the experience may or may not contribute to the development of the preservice teacher's ability to teach the required subject areas taught in elementary schools, and most importantly, the development of the elementary education preservice teacher's ability to teach reading. This study explored whether elementary education preservice teachers were able to acquire a greater level of reading expertise in a supervised clinical practicum prior to student teaching. 
Therefore the following research hypotheses were generated:

\section{General Research Hypotheses}

Hypothesis 1: There is a relationship between participation in a clinical practicum under the direct supervision of a reading expert and elementary education preservice teachers' development of reading expertise.

\section{Specific Research Hypothesis}

H1: Elementary education preservice teachers who participate in a clinical practicum experience tutoring a low-achieving reader under the direct supervision of a reading expert in undergraduate teacher preparation will significantly increase in their development of reading expertise compared to early childhood education preservice teachers who did not participate in a clinical practicum.

\section{General Research Hypothesis}

Hypothesis 2: There will be a differentiated effect of the clinical practicum on the development of reading expertise depending on the entry level of reading expertise elementary education preservice teachers have at the beginning of the practicum.

\section{Specific Research Hypothesis}

H2. Elementary education preservice teachers who, at the onset of the clinical practicum, are in the low and middle third on the pretest will demonstrate significant gains in their level of development of reading expertise.

\section{General Research Hypothesis}

Hypothesis 3. There is a relationship between preservice teachers' participation in a clinical practicum and their perceptions that they have acquired the expertise to teach reading. 


\section{Specific Research Hypothesis}

H3 Elementary education preservice teachers who participate in a clinical practicum tutoring a low-achieving diverse student under the direct supervision of a reading expert in their undergraduate preparation will perceive they have acquired the expertise to teach reading.

Hypothesis 1 is based on the previous work of Michael S. Smith (2005).

His exploratory study examined the feasibility of (a) a reading methods course promoting habits of inquiry in preservice teachers and (b) using video cases as a means of both promoting habits of inquiry and measuring the extent to which a preservice teacher developed the dimensions of inquiry-based teaching. Smith (2005) defined habits of inquiry as: describing and keeping at bay the urge to rush to judgment, analyzing the data by synthesizing the facts of the case with theoretical knowledge about the reading process and child development, and making intelligent instructional and assessment decisions. In Smith's study, he used two primary means to help preservice teachers develop habits of inquiry; first, each preservice teacher tutored a struggling reader once a week for 8 weeks. Second, he used four video cases of four different struggling readers as an instructional tool to help preservice teachers develop habits of inquiry related to the teaching of reading. Smith had preservice teachers $(n=26)$ in a second reading course observe four video cases of four different struggling readers and he facilitated discussions on what they observed, as part of class instruction. He focused preservice teachers' discussions on helping them to develop habits of inquiry, helped them analyze their observations of the video cases and discussed the instructional actions that should be taken to support each video case student's reading development. 
Five of the 26 students enrolled in the course were the participants for his study. Prior to the course, each of the participants observed a video case of a third-grade reader struggling through a reading of the book Pigsty by Mark Teague (1994). A protocol of interview questions was used to prompt participants to determine what they observed and specifically on what they might do if given the opportunity to work with the student. The individual interviews lasted $20-30$ minutes. The protocol of interview questions included two main questions, each with four related sub-questions. Smith used Carol Rodger's model of inquiry (2002) to develop a rubric, using a $0-3$ scale, to rate each participants' responses to the interview questions. After the course, the five participants watched the same video case again and answered the same protocol of interview questions. Smith found the video cases helped move novice teachers towards more sophisticated levels of inquiry, and suggested in his implications they also have the potential for helping to measure preservice teachers' level of expertise. Since the pressure on teacher preparation programs to "scientifically" prove that they do make a difference is growing, research methods are needed such as were used in that study that can begin to measure levels of teacher expertise (Smith, 2005).

\section{Research Context}

Upon completion of three requisite literacy courses, elementary education preservice teachers, who attend an NCATE approved Florida state university, participated in a fourth literacy course, a supervised clinical practicum, prior to student teaching. The elementary education preservice teachers were in the context of an elementary school and met in the school's media center for two hours, two times a week for 16 weeks. During the first hour preservice teachers tutored a low-achieving reader in reading under the 
direct supervision of reading experts; the two instructors who conducted the clinical practicum. During the second hour, after the students were dismissed, the elementary education preservice teachers met with the instructors for class lectures and instruction in administering assessments to students, writing lesson plans, and planning for reading instruction. The criteria for selection for tutoring was second grade students who were low-achieving readers having difficulty in learning how to read, and whose instructional reading level was approximately one to two years below his or her current grade level in school. The students who were selected were most likely to benefit from intensive oneon-one reading tutoring. The students were identified by the school's reading specialist. The selection process was based on choosing students who performed in the lowest $25^{\text {th }}$ percentile on the Dynamic Indicators of Basic Early Literacy Skills (DIBELS), students who were at high to moderate risk for being retained, students who currently were identified and had a PMP (Pupil Monitoring Process), and on classroom teachers' input on each student's needs. Each second grade student was randomly paired with an elementary education preservice teacher on the second week of the clinical practicum.

\section{Participants}

The participants in the study were 84 elementary education preservice teachers enrolled in a clinical practicum situated in the fourth literacy course at an NCTE approved Florida state university and 26 early childhood preservice teachers who were enrolled in a fourth literacy course at an NCTE approved Florida state university and did not participate in a supervised clinical practicum. The preservice teachers were between the ages of 21 and 29; 80\% were Hispanic, 10\% were African American, and 10\% were Caucasian; $94 \%$ of the preservice teachers were women and $6 \%$ were men. 


\section{Instruments and Materials}

For the purpose of this study Smith's (2005) protocol of questions, video cases, and scoring rubric for the protocol of questions were extended to measure the increase in the development of preservice teachers' reading expertise, from novice to expert-like.

\section{Protocol of Questions}

The Protocol of Questions (see Appendix A) used in the study was developed by Michael S. Smith (2005). The Protocol of Questions comes from the exploratory study he conducted to examine the development of preservice teachers' habits of inquiry to teach reading. For the purpose of this study the Protocol of Questions was adapted to measure preservice teachers' development of reading expertise. Figure 1 presents the Protocol of Questions.

\section{Tell me everything you notice about this reader.}

a. What does he/she do when he/she has difficulty decoding words?

b. On line 19 why does she say "if I even meet" instead of "if I ever meet"?

c. On a scale of $0-10$ (zero meaning no meaning, 10, maximum meaning) do you think she is making meaning of what she is reading? Why do you say that?

d. Is this the right leveled text for this student? Why do you say that?

Figure 1. Protocol of questions

Question (b) below main Question I was different for each Protocol of Questions, because that question was dependent upon the reader portrayed in the video case.
II. If you were to work with this reader tomorrow, tell me everything that you would do.

a. What are the reader's strengths?

b. What are the reading needs of this student?

c. What specific reading instruction would you recommend to improve this student's reading?

d. Sum up what your goals for this reader would be. 


\section{Video Cases}

Video cases of six third grade low-achieving students were used in the present study. The video cases portrayed "real-world" reading events that challenge teachers" (e.g., a reader makes several significant miscues but is still able to answer comprehension questions) Smith (2005). Each video case portrayed a low-achieving reader with varying degrees of reading difficulties. The video cases allowed the preservice teachers to scrutinize and reflect upon what was observed on the video.

\section{Video case A}

Video case A portrayed a third grade boy who read a 278 word passage in 6 minutes and 36 seconds. The reader made 22 miscues, and self-corrected two of the miscues. He was a motivated reader, i.e., he appeared to be interested and engaged in the passage, however, he had limited comprehension of the passage and read in a choppy, disfluent manner.

\section{Video case B}

Video case B portrayed a third grade boy who read a 154 word passage in 6 minutes and 40 seconds. The reader made 16 miscues and self-corrected three of the miscues. Although the reader appeared to be engaged in reading he was not fluent, he read word-by-word, with little comprehension of the passage.

\section{Video case C}

Video case $\mathrm{C}$ portrayed a third grade boy who read a 221 word passage in 11 minutes and 9 seconds. The reader made 36 miscues and self-corrected two miscues. The reader was neither motivated nor engaged in reading the passage, his reading was disfluent and he displayed no comprehension of the passage. 


\section{Video case D}

Video case D portrayed a third grade girl who read a 358 word passage in 4 minutes and 54 seconds. The reader made 21 miscues and self-corrected three of the miscues. The student was a motivated and engaged reader who read fluently and was able to comprehend some of the passage.

\section{Video case E}

Video case E portrayed a third grade girl who read a 273 word passage in 5 minutes and 15 seconds. She made 17 miscues, was engaged and motivated and read the passage fluently; however she was not able to comprehend the passage.

\section{Video case $F$}

Video case F portrayed a third grade girl who read a 154 word massage, made eight miscues and self-corrected one miscue. The reader was not fluent or motivated to read the passage and was not engaged in reading. The reader displayed limited comprehension of the passage.

\section{Scoring Rubric}

A scoring rubric for video case responses, (see Appendix B) developed by Smith (2005) was used to rate the quality of responses of the elementary education and early childhood preservice teachers on the Protocol of Questions. Smith (2005) used the Protocol of Questions as interview questions and used the rubric to score the participants' interview responses in his study. The scoring rubric measured the qualities of good teachers of reading.

The scoring rubric in this study was used to rate the elementary education and early childhood preservice teachers' quality of responses on the Protocol of Questions on 
a scale of $0-3$ with $0-1$ indicating "novice" responses to $2-3$ indicating more "expertlike" responses. Five areas of observable reading behavior were rated. The first, miscue analysis, concerns judging a reader's ability to use three cueing systems; semantic (meaning), syntactic (structure), and graphophonic (visual) to decode words. The second, fluency analysis, concerns judging a reader's ability to read at the appropriate rate of speed using appropriate expression and phrasing and attending to punctuation. The third, data analysis, concerns the ability to analyze and interpret a reader's performance based on observation and assessment of miscue analysis, fluency, and comprehension. The fourth, inquiry orientation, concerns the ability to find appropriate information about a reader through reasonable reading assessment technique(s). The fifth, intelligent action, concerns the ability to make reasonable instructional decisions directed to reading strategy instruction, not just fixing mistakes.

\section{Procedures}

\section{Supervised Clinical Practicum}

The clinical practicum began the week of January 8, 2007 with 84 elementary education preservice teachers in attendance and ended on April 19, 2007. Three classes of elementary education preservice teachers participated in the clinical practicum. The classes met in the media center of two different elementary schools. There were two instructors; one met with preservice teachers two days a week in School One and two days a week in School Two; instructor two met with preservice teachers two days a week in School One. Although there were two different instructors for the clinical practicum the materials, textbooks, assignments, syllabus for the course, the methodologies, and the number of times the students were tutored were the same. 
The early childhood education preservice teachers were also enrolled in a fourth literacy course, children's literature (see Appendix K). The course focused on the role of children's literature and its role in early childhood classrooms. Early childhood preservice teachers observed an adult and a child or children during a read aloud and analyzed dialogic inquiry as well as reading patterns that scaffold children's development (cognitive, language, personality, moral and social development). The fourth class that early childhood education preservice teachers were enrolled in did not include a supervised clinical practicum.

\section{One-on-One Tutoring}

The elementary education preservice teachers tutored one-on-one two days a week for two hours in the media center for 14 weeks. The first week of the clinical practicum the elementary education preservice teachers administered reading assessments; the Basic Reading Inventory (Johns, 2005), Pre-Phonemic Awareness Assessment, Phonics Mastery Survey, Attitude Survey, and an Interest Inventory (DeVries, 2004) to the student. They wrote lesson plans based on the guided comprehension model (McLaughlin, 2003), using a lesson plan format developed by the instructors (see Appendix C). Following each tutoring session the elementary education preservice teachers met with the instructors and were instructed in lesson planning, time management, comprehension strategies for low-achieving readers, and the use of teaching ideas. In addition, the preservice teachers learned theoretical knowledge about reading comprehension, writing, spelling, phonics, phonemic awareness, vocabulary and fluency from the course textbooks (DeVries, 2004; Johns, 2005; McLaughlin, 2003). 
The elementary education preservice teachers' lesson plans were written in order to help them develop the ability to teach reading responsively and effectively based on individual assessments. The guided comprehension model (McLaughlin, 2003) of Explain, Demonstrate, Guide, Practice, and Application was used to teach the targeted needs of the students using explicit, systematic instruction. The lesson plan included the comprehension strategy, the appropriate leveled book (instructional reading level of the student) and a list of all other books (title, author) listed under materials. Each lesson plan was reviewed and feedback was given to each elementary education preservice teacher prior to delivery of the lesson to the student.

The preservice teachers created a Literacy Niche for their student (see Appendix D). The Literacy Niche was an organized, attractive, useful collection of text and nontext materials displayed on a science board. The niche was the student and elementary education preservice teacher's area; the function was more important than its appearance, i.e., it contained student artifacts, student book marks, a fluency check chart to monitor the student's fluency progress, and "How To" process charts, to help the student remember reading or writing processes previously taught during a tutoring session.

During the one-on-one tutoring sessions the elementary education preservice teachers were given feedback on their tutoring sessions by the instructor in their respective class. A Tutoring Observation Checklist (see Appendix E), was used by the instructors to give feedback to the preservice teachers' delivery of the reading comprehension lesson, appropriate materials provided for the student, i.e., appropriately leveled texts and quality children's literature, completion of fluency checks, and 
appropriate instruction in phonics, phonemic awareness, and vocabulary development, as based on the reading needs of each student through assessment. The Tutoring Observation Checklist was also used to make notes to the preservice teacher regarding the delivery of his or her lesson to the student, to make recommendations about appropriate instruction or materials, and to answer any questions the preservice teacher had about the student or about specific reading instruction for the student. Each preservice teacher reflected upon his or her lesson at the end of each tutoring session.

\section{Continuum of Reading Development}

The elementary education preservice teachers worked collaboratively to develop a continuum of reading development to compare, contrast and analyze information and assessment results of three students. The purpose for developing a reading continuum was to help elementary education preservice teachers recognize the variability in reading levels across children in the same grade. Within the class, groups of three preservice teachers worked collaboratively to chart each of their student's areas for growth, i. e., comprehension, vocabulary, phonics, phonemic awareness, fluency, on a developmental continuum (see Appendix F). After charting the areas for growth, the three preservice teachers then individually wrote an instructional plan for each of their students, using the areas for growth to make recommendations for interventions in comprehension, vocabulary, phonics, phonemic awareness and fluency to address the individual reading needs of each of their students. Each of the three preservice teachers defined and described specific reading strategies that would benefit his or her student. Last, each preservice teacher explained how and why the strategies would be appropriate and would benefit their student in gaining greater reading proficiency. 


\section{Theme-Based Unit Plan/Two Hour Time Block}

Based on the backward design (Wiggins \& McTighe, 1999) the elementary education preservice teachers constructed a unit on a theme (weather, transportation, or oceans), and were instructed to begin planning by identifying the desired results and creating goals and objects (see Appendix G). The purpose of writing a unit plan was for the preservice teachers to gain experience in developing a wide range of instructional practices, approaches, and methods which addressed all components of reading instruction across the curriculum. The theme-based unit plan enabled them to gain experience, knowledge and the understanding that reading is cross-curricular and extends to social studies and science. In conjunction with the theme-based unit plan they developed a 2-hour instructional time block using the guided comprehension model (McLaughlin, 2003) and information from the theme they selected. The two-hour time block included an opening routine, teacher-directed whole class instruction, small group instruction and literacy centers. The two-hour instructional time block included detailed lesson plans written for the specific theme (weather, transportation, oceans), and descriptions of specific literacy centers based upon the theme of the unit plan (see Appendix H).

\section{Case Study}

Last, using data collected from assessments, lesson plans, fluency checks, and other areas of reading such as vocabulary, phonics, phonemic awareness, the student's writing ability, and the student's work, the preservice teachers created a Case Study (see Appendix I), on each of their students. Using the data collected from the assessments administered to each of their students and the lessons taught, the preservice teachers 
looked across the instruments and lessons to develop a case study of their student. Part one, Student Data, contained student information such as the instructional plan developed from the continuum, and the assessments administered to the student. Part two, Teaching and Learning, contained the preservice teachers' lesson plans, reflections, tutoring observation checklists, and student artifacts. Part three was an overall reflection which asked the preservice teachers two questions; "What did you learn about the reading process and reading instruction through the experience with a clinical practicum?" and "What did you know about literacy instruction at the beginning of this semester and how does this compare to what you know now?" The purpose of developing a Case Study was to help elementary education preservice teachers evaluate their own professional development as a reading teacher. It allowed them to make recommendations to the student, to the school and to the parents for continued reading growth, and for them to reflect on what they gained as a reading teacher from their overall experience and participation in the clinical practicum. Figure 2 presents the schedule for the supervised clinical practicum.

\begin{tabular}{|c|c|}
\hline Class Meeting & $\begin{array}{c}\text { Tutoring Session } \\
\text { One-on-One, two hours per week }\end{array}$ \\
\hline $\begin{array}{l}\text { Week One } \\
\text { Review reading assessments: Basic } \\
\text { Reading Inventory, Phonemic Awareness, } \\
\text { Interest Inventory, Phonics Survey, } \\
\text { Writing Assessment }\end{array}$ & $\begin{array}{l}\text { Prepare appropriate assessment protocols. } \\
\text { Develop a Tool Kit containing all } \\
\text { necessary protocols }\end{array}$ \\
\hline $\begin{array}{l}\text { Week Two } \\
\text { Informal instruments taught in previous } \\
\text { literacy courses. } \\
\text { Basic Reading Inventory, Phonemic } \\
\text { Awareness Assessment, Phonics Mastery } \\
\text { Survey, Interest Inventory, Reading } \\
\text { Attitude Survey, and Writing Assessment }\end{array}$ & $\begin{array}{l}\text { Preservice teachers analyze assessments } \\
\text { and look at results to plan for reading } \\
\text { instruction and determine student's reading } \\
\text { instructional level. }\end{array}$ \\
\hline
\end{tabular}




\begin{tabular}{|c|c|}
\hline $\begin{array}{l}\text { Week Three } \\
\text { Preservice teachers teach student the } \\
\text { comprehension strategy prediction using } \\
\text { title and text. }\end{array}$ & $\begin{array}{l}\text { Preservice teachers develop detailed lesson } \\
\text { plan using a Lesson Plan Format on } \\
\text { prediction using objectives, procedures and } \\
\text { assessments and determine appropriate } \\
\text { leveled books for students based on } \\
\text { student's reading instructional level from } \\
\text { the BRI. }\end{array}$ \\
\hline $\begin{array}{l}\text { Week Four } \\
\text { Preservice teachers teach retelling using } \\
\text { literary elements: character, setting, events, } \\
\text { and resolution, using direct instruction. }\end{array}$ & $\begin{array}{l}\text { Preservice teachers develop and teach a } \\
\text { detailed lesson plan on retelling } \\
\text { comprehension strategy using a Story Map } \\
\text { as a teaching idea, and select books for the } \\
\text { student at the appropriate reading } \\
\text { instructional level. }\end{array}$ \\
\hline $\begin{array}{l}\text { Week Five } \\
\text { Preservice teachers teach retelling using } \\
\text { literary elements: Who, Where, What } \\
\text { Happened, How Did It End, using direct } \\
\text { instruction. }\end{array}$ & $\begin{array}{l}\text { Preservice teachers develop and teach a } \\
\text { detailed lesson plan on retelling } \\
\text { comprehension strategy using a Draw and } \\
\text { Label teaching idea. } \\
\text { Preservice teachers identify student's } \\
\text { instructional need in phonemic awareness } \\
\text { and fluency based on data from Phonemic } \\
\text { Awareness Assessment. }\end{array}$ \\
\hline $\begin{array}{l}\text { Week Six } \\
\text { Preservice teachers teach previewing text } \\
\text { and vocabulary development and } \\
\text { phonemic awareness or phonics strategy. }\end{array}$ & $\begin{array}{l}\text { Preservice teachers develop and teach a } \\
\text { detailed lesson plan on previewing and } \\
\text { vocabulary comprehension strategies using } \\
\text { a Predict-o-Gram teaching idea. A } \\
\text { strategy for phonemic awareness and } \\
\text { fluency is identified and a detailed plan for } \\
\text { student is written. }\end{array}$ \\
\hline $\begin{array}{l}\text { Week Seven } \\
\text { QAR comprehension lesson is taught; } \\
\text { preservice teachers teach students how to } \\
\text { locate information to answer literate and } \\
\text { higher order thinking questions. Phonemic } \\
\text { awareness and fluency strategies are taught } \\
\text { to student. }\end{array}$ & $\begin{array}{l}\text { Preservice teachers develop a detailed } \\
\text { lesson plan on question-answer- } \\
\text { relationships: locating information in text } \\
\text { to answer literate and higher order thinking } \\
\text { questions, using a QAR teaching idea to } \\
\text { support the reading strategy. }\end{array}$ \\
\hline $\begin{array}{l}\text { Week Eight } \\
\text { Vocabulary lesson is implemented using } \\
\text { Concept of Definition Map, students gain } \\
\text { information by extracting concepts from } \\
\text { information text. }\end{array}$ & $\begin{array}{l}\text { Preservice teachers develop a detailed } \\
\text { lesson plan on vocabulary development, } \\
\text { using the Concept of Definition Map } \\
\text { teaching idea; phonemic awareness } \\
\text { strategies and fluency strategies and select } \\
\text { expository text for students based on } \\
\text { reading instructional level of student. }\end{array}$ \\
\hline
\end{tabular}




\begin{tabular}{|c|c|}
\hline $\begin{array}{l}\text { Week Ten } \\
\text { Reciprocal teaching is taught using four } \\
\text { comprehension strategies: prediction, } \\
\text { questioning, clarifying and summarizing. }\end{array}$ & $\begin{array}{l}\text { Preservice teachers develop a detailed } \\
\text { lesson plan on prediction, questioning, } \\
\text { clarifying and summarizing, using } \\
\text { Reciprocal Teaching. }\end{array}$ \\
\hline $\begin{array}{l}\text { Week Eleven } \\
\text { Reciprocal teaching, four comprehension } \\
\text { strategies: prediction, what they text will } \\
\text { be about, questioning, asking literal and } \\
\text { higher order thinking questions, clarifying, } \\
\text { asking what the student doesn't } \\
\text { understand, and summarizing, asking the } \\
\text { student the main idea of what he/she read. }\end{array}$ & $\begin{array}{l}\text { Theme-Based Unit: Using a wide range of } \\
\text { instructional practices, approaches and } \\
\text { methods which address all components of } \\
\text { reading across the curriculum; preservice } \\
\text { teachers develop a } 6 \text { week unit plan } \\
\text { integrating content areas and reading. } \\
\text { Preservice teachers develop a two hour } \\
\text { instructional time block to teach reading. }\end{array}$ \\
\hline $\begin{array}{l}\text { Week Twelve } \\
\text { Preservice teachers administer post } \\
\text { assessments; Basic Reading Inventory, } \\
\text { Phonemic Awareness }\end{array}$ & $\begin{array}{l}\text { Case Study: Using data from assessments } \\
\text { and lessons preservice teachers develop a } \\
\text { case study of tutored student. Case Study } \\
\text { contains preservice teachers' assessments, } \\
\text { lesson plans, student artifacts and } \\
\text { preservice teacher reflection. }\end{array}$ \\
\hline $\begin{array}{l}\text { Week Thirteen } \\
\text { Museum Day: Tutored student explains } \\
\text { what he/she learned and discusses the } \\
\text { various artifacts created during tutoring } \\
\text { i.e., bookmarks of books read, word walls, } \\
\text { vocabulary. }\end{array}$ & $\begin{array}{l}\text { Parents are invited to the media center in } \\
\text { the elementary schools and the preservice } \\
\text { teacher and student meet with the parents } \\
\text { to share what was learned throughout the } \\
\text { semester through the use of their Literacy } \\
\text { Niche and artifacts. }\end{array}$ \\
\hline $\begin{array}{l}\text { Week Fourteen } \\
\text { Preservice teachers present Case Study of } \\
\text { their student. }\end{array}$ & $\begin{array}{l}\text { Handout: "How I will Teach Reading" } \\
\text { Preservice teachers develop a handout in } \\
\text { which they describe how they will teach } \\
\text { reading when they begin their first year of } \\
\text { teaching. }\end{array}$ \\
\hline
\end{tabular}

Figure 2. A clinical practicum in the context of an elementary school.

Preservice teachers used the following questions to reflect on their practices after each tutoring session.

1. What did the performance of the student indicate? (fluency, explicit instruction in phonemic awareness, phonics, vocabulary or comprehension strategy) What does the student need more instruction in and why?

2. Explain the comprehension strategy you taught and how this lesson is targeting a reading need identified by the Basic Reading Inventory, Phonemic 
Awareness Assessment, and fluency and from what research says good readers do.

3. Explain how this information will guide the next lesson. What will you teach next?

At the end of the semester the elementary education preservice teachers reflected on two questions which were included in their final assignment, the case study of the student.

1. What did I learn about the reading process and reading instruction through the clinical practicum experience?

2. What did you know about literacy instruction in the beginning of the semester and how does this compare to what you know now?

The elementary education preservice teachers ended their one-on-one tutoring sessions in the two elementary schools on April 16 and 17, 2007 with a culminating activity; "Museum Day," a day in which parents were invited to meet the preservice teacher/tutor and a student-led conference was conducted by the student/tutee. The preservice teacher and the student shared what was learned in reading using the Literacy Niche that was developed with the student and preservice teacher throughout the clinical practicum.

In addition to one-on-one tutoring, and as part of the clinical practicum the preservice teachers participated in a group projects, and individual projects. These projects were experiences that were included in the practicum to provide the preservice teachers with theory and methodologies of teaching reading that supported their one-onone teaching of reading and through application of what they learned through guided mentorship. They were also provided with experiences to expand their thinking about 
teaching reading outside the limits of one-on-one tutoring, i. e., completing a unit plan for a class, designing a two-hour reading time block for a class, developing a case study of their student, developing a case study of their student, and developing a continuum of reading development. The preservice teachers were assessed on those projects and assignments as part of their final grade for the practicum. The combination of all of the above was included to develop the reading expertise of elementary education preservice teachers in a clinical practicum. The projects and assignments the elementary education preservice teachers completed for the course were not included in the data or data analysis for this study.

\section{Variable List}

Five variables were measured by the Protocol of Questions:

Miscue analysis: Errors from the three cueing systems; semantic (meaning), syntactic (structure) and graphophonic (visual).

Fluency: A readers speed, expression, phrasing, and attention to punctuation.

Data analysis: The ability to analyze/interpret a reader's performance based on observation and assessment of miscue analysis, fluency and comprehension. Inquiry orientation: The ability to find appropriate information about a reader through reasonable reading assessment technique(s).

Intelligent action: The ability to make reasonable instructional decisions geared to reading strategy instruction, not fixing mistakes.

There were three classes of elementary education preservice teachers who participated in a clinical practicum and one class of early childhood preservice teachers who did not participate in a clinical practicum. The practicum was conducted in two 
elementary schools, School One and School Two. There were two instructors, one instructor conducted a practicum in School One and School Two, and the other instructor conducted a practicum in School One.

The dependent variable was the posttests of the Protocol of Questions, the rated response scores of elementary education preservice teachers after participating in a clinical practicum, and rated response scores of early childhood preservice teachers who did not participate in a clinical practicum.

\section{Coding of Pretest and Posttest Protocol of Questions}

There were 62 elementary education preservice teachers' pre and posttest Protocol of Questions included in the analysis. Twenty-two pre or posttest Protocol of Questions were discarded because they were either incomplete or absent from the final count. Each elementary education preservice teacher's pretest and posttest Protocol of Questions were coded in the following manner. First, schools were differentiated by School One = D, and School Two $=$ G. Second, codes were created using the month of the pretest, the year, an identification number assigned to each preservice teacher, and the Video Case (A, B, C) that was observed and matched each pretest Protocol of Questions. The coding for a preservice teacher's pretest was coded DJ701A, DJ701B, DJ701C, School One, and GJ770A, GJ770B, GJ770C, School Two. A similar procedure was used for the posttests; the schools were differentiated by School One = D, School Two = G. Second, codes using the month of the posttest, the year, the same preservice teacher's identification number as the pretest, and the Video Case (D, E, F) that was observed and matched to each posttest Protocol of Questions. The coding for a preservice teacher's posttest was 
DM701D, DM701E, DM701F, School One, and GM770D, GM770E, GM770F, School Two.

Two copies were made of each preservice teacher's pretest Protocol of Questions and each preservice teacher's posttest Protocol of Questions. File folders were then used to store each set of the duplicated copies of elementary education preservice teachers' pretest and posttest Protocol of Questions (A, B, C) (D, E, F). There were two file folders with the same preservice teacher's pretest Protocol of Questions and two file folders with the same preservice teacher's posttest Protocol of Questions. Each file folder was identified by the pretest Protocol of Questions code assigned to the preservice teacher, for example, DJ701ABC. A second set of folders was used to store each set of the duplicated copies of the preservice teachers' posttest Protocol of Questions. Each file folder was identified by the posttest Protocol of Questions code assigned to the preservice teacher; for example DM701DEF. There were a total of 124 file folders containing a preservice teacher's pretest and posttest Protocol of Questions (A,B,C) (D, E, F).

There were 12 early childhood preservice teachers pre and posttest Protocol of Questions included in the analysis. Fourteen of the pretest or posttest Protocol of Questions were discarded because they were either incomplete or absent the day of the pretest or posttest. The early childhood preservice teachers pretest and posttest Protocol of Questions were put in order according to their student identification number. Each early childhood preservice teacher's pre and posttest Protocol of Questions were coded in the following manner. First the class was identified by the university $=$ F. Second, codes were created using $\mathrm{E}=$ pretest, $8=$ the year, an identification number for each preservice teacher; 01,02 ; and the video case (A, B, C) that was observed and matched each pretest 
Protocol of Questions. Coding for an early childhood teacher's pretest was FE801A, FE801B, and FE801C. A similar procedure was used for the posttests. First the class was identified by the university $=F$. Second, codes were created using the posttest, the year, an identification number for each preservice teacher, and the video case (D, E, F) that was observed and matched each posttest Protocol of Questions. Coding for and early childhood teacher's posttest was FO801D, FO801E, and FO801F.

Two copies were made of each early childhood preservice teacher's pre and posttest Protocol of Questions. File folders were used to put each set of the copies of the pretest and posttest Protocol of Questions (A, B, C) (D, E, F). There were a total of 24 file folders containing an early childhood preservice teacher's pre and posttest Protocol of Questions.

\section{Selection of Raters}

One of the reading instructors was the researcher who is knowledgeable about the preservice teachers and their abilities. In order to avoid bias, six reading experts were asked to rate the responses of the preservice teachers on the pretest and posttest Protocol of Questions from video cases $(\mathrm{A}, \mathrm{B}, \mathrm{C})$ and $(\mathrm{D}, \mathrm{E}, \mathrm{F})$. The six reading experts were selected based on their level of education, having advanced degrees in reading; expertise in the field of reading, and the years of experience in the field of teaching reading. Four

of the reading experts had Masters Degrees in Reading Education and their expertise was teaching elementary and middle school students reading, on average for 15 to 20 years. The fifth reading expert received a Masters Degree in Reading Education, and was a doctoral student currently at the dissertation level, and with expertise in teaching reading to elementary students in a classroom setting, one-on-one reading tutoring, and teaching 
undergraduate literacy courses to preservice teachers. The sixth reading expert received a Masters Degree in Reading Education and Doctorate in Curriculum and Instruction with the main focus of study on reading, with expertise teaching elementary children reading and teaching undergraduate and graduate level literacy courses to preservice teachers. Organization of Pretest and Posttest Protocol of Questions for Raters

First, the file folders of the elementary education preservice teachers Protocol of Questions were organized so that each rater would not receive all posttests or all pretests, rather they would receive a random mix of pretest Protocol of Questions and posttest Protocol of Questions. The file folders were then divided up so that raters one and two received folders containing pretest and posttest Protocol of Questions from the first group of 20 elementary education preservice teachers. Raters three and four received folders containing pretest and posttest Protocol of Questions from the next group of 21 elementary education preservice teachers. Raters five and six received folders containing pretest and posttest Protocol of Questions from the last group of 21 elementary education preservice teachers. Each rater's set of file folders were put in a file box with a scoring rubric for each elementary education preservice teacher's Protocol of Questions.

Second, file folders of the early childhood preservice teachers Protocol of Questions were organized so that each rater would receive a random mix of pretest and posttest Protocol of Questions. The file folders were divided between raters one and two, three and four, and five and six, each receiving four pretest or posttest Protocol of Questions. Each set of folders were bound together for each rater with a scoring rubric for each early childhood preservice teachers Protocol of Questions. 


\section{Workshop for Raters}

A three hour workshop was held for the six raters in a video viewing room in the university's library on June 13, 2007 at 4:00 P. M. The raters were informed of the purpose of the study and given background information of the study. Each rater was given a folder containing three reading scripts of each of the third grade students from the Video Cases, three Protocol of Questions, three scoring rubrics, and the same three completed Protocol of Questions of elementary education preservice teachers who were not participants in the study. Each document was explained to the raters and questions were asked and answered.

First, the raters observed video case A, completed a running record (Clay, 1987) on the reader in the video case, and individually completed the Protocol of Questions for that reader. Next they each discussed their responses to each section of the Protocol of Questions to establish a baseline. The raters compared and contrasted their responses to be sure they all observed the same reading behaviors of the student on the video case. Second, they proceeded to score the quality of responses of a preservice teacher's Protocol of Questions, one who was not included in the study, using the scoring rubric both of which were provided in their file folder. It was explained that when rating the preservice teacher's responses to the Protocol of Questions using the scoring rubric, they were looking at the quality of the preservice teacher's responses to what they observed on the video case, and the scale was $0=$ "novice" responses to $3=$ "expert-like" responses.

Next, each rater discussed the numerical score they assigned to the preservice teacher's response in each area; miscue analysis, fluency analysis, data analysis, inquiry orientation, and intelligent action. Last, there was articulation among the six raters about 
the Protocol of Questions and scores they assigned using the scoring rubric, and a consensus for each score assigned to the preservice teacher's Protocol of Questions was reached for each of the five areas on the rubric. The same procedures followed for video case $\mathrm{B}$, and video case $\mathrm{C}$; they observed each video case, completed a running record for each video case observed, responded to the Protocol of Questions for each reader on the video case and then scored a preservice teacher's Protocol of Questions for video case B and $\mathrm{C}$ using the scoring rubric. Each rater discussed the numerical scores they assigned to each of the five areas and a consensus for each of the scores was reached for each of the five areas. After going through the procedures for each video case, the researcher was confident the raters were well-trained; this was based on the knowledge the raters had about reading instruction, the practice the raters received, lengthy discussions of how and why certain responses were rated, and consensus for scores among the six raters.

The elementary education preservice teachers' Protocol of Questions were divided among the six raters. Two raters were given file boxes containing the same 20 preservice teachers' pretest or posttest Protocol of Questions, two raters were given file boxes containing the next set of the same 21 preservice teachers' pretest or posttest Protocol of Questions, and two raters were given file boxes containing the last set of the same 21 preservice pretest or posttest Protocol of Questions. The timeline established for the raters to complete the scoring of the pretest and posttest Protocol of Questions was June 13, 2007 to August 10, 2007.

\section{Data Collection}

The first day of the clinical practicum, in a group setting, preservice teachers were asked to observe three third grade readers portrayed in video cases $(\mathrm{A}, \mathrm{B}, \mathrm{C})$ in the media 
center of each respective elementary school. After observing each video case the preservice teachers conducted a running record (Clay, 1987), and made notes about the reader they observed. The instructors distributed a Protocol of Questions following each video case $(\mathrm{A}, \mathrm{B}, \mathrm{C})$ and asked the preservice teachers to write responses to each question, based upon their observations about the reader in each video case. The preservice teachers were instructed not to discuss the video cases or their answers to the Protocol of Questions with each other. The written responses of the preservice teachers to the Protocol of Questions reflected what they knew based on based three previous reading courses, and unsupervised field experience. Each set of Protocol of Questions following each observation of each video case $(\mathrm{A}, \mathrm{B}, \mathrm{C})$ were collected and stored in a file cabinet for later analysis.

The elementary education preservice teachers participated in a 14 week supervised clinical practicum in which each preservice teacher worked one-on-one with a low achieving reader two times per week, on-site at two different elementary schools. A class lecture and discussions followed each tutoring session. The video cases were neither discussed nor referred to at any time during the clinical practicum.

On April 18 and 19, 2007 the elementary education preservice teachers observed three different third grade readers portrayed in video cases $(D, E, F)$ in the media center of each respective elementary school. After observing each video case the preservice teachers conducted a running record (Clay, 1987), and made notes about the reader they observed. The instructors distributed a Protocol of Questions following the observation of each Video Case (D, E, F) and asked the preservice teachers to write responses to each question, based upon their observations about the reader in each video case. The 
preservice teachers were instructed not to discuss the video cases or their answers to the Protocol of Questions with each other. The written responses of the preservice teachers on the Protocol of Questions reflected what they learned from three previous literacy classes having some unsupervised field experience, and the fourth literacy class; 14 weeks of supervised reading instruction working with a low-achieving reader in a clinical practicum. Each set of Protocol of Questions following each observation of the video cases (D, E, F) were collected and stored in a file cabinet with the first set of responses on the Protocol of Questions of each video case (A, B, C) for later analysis.

At the beginning of the 2008 spring semester, in a group setting, early childhood preservice teachers who were enrolled in a fourth literacy course, were asked to observe the same three third grade readers as the elementary education preservice teachers observed, video cases (A, B, C), in a college classroom. After observing each video case the early childhood preservice teachers conducted a running record (Clay, 1987), and made notes about the reader they observed. The researcher distributed a Protocol of Questions following each video case (A, B, C) and asked the early childhood preservice teachers to write responses to each question, based on their observations about the reader in each video case. They were instructed not to discuss the video cases or their responses to the Protocol of Questions with each other. The written responses of the early childhood preservice teachers to the Protocol of Questions reflect what they knew based on three previous literacy courses having some unsupervised field experiences, and a fourth literacy class which did not include a clinical practicum. Each set of Protocol of Questions was collected and stored in a file cabinet for later analysis. 
At the end of the 2008 spring semester, in a group setting, the same early childhood preservice teachers, who were enrolled in a fourth literacy course, were asked to observe the same three third grade readers as the elementary education preservice teachers observed, video cases (D, E, F), in a college classroom. After observing each video case the early childhood preservice teachers conducted a running record (Clay, 1987), and made notes about the reader they observed. The researcher distributed a Protocol of Questions following each video case (D, E, F) and asked the early childhood preservice teachers to write responses to each questions, based upon their observations about the reader in each video case. They were instructed not to discuss the video cases or their responses to the Protocol of Questions with each other. The written responses of the early childhood preservice teachers to the Protocol of Questions reflected what they knew about reading based on completion of four reading courses with some unsupervised field experiences.

The six raters who scored the elementary education preservice teachers pretest and posttest Protocol of Questions scored the pretest and posttest Protocol of Questions of the early childhood preservice teachers.

\section{Statistical Treatment}

An interclass correlation coefficients analysis was carried out to test the reliability of the scores the six reading experts assigned to the quality of the elementary education preservice teachers responses and the quality of the early childhood preservice teachers responses to the Protocol of Questions.

Since there were three different readers on the pretest video cases $(A, B, C)$ and three different readers on the posttest video cases (D, E, F), a multivariate analysis was 
carried out on the five areas of observable reading behaviors of the readers to test for differences among the three video cases $(\mathrm{A}, \mathrm{B}, \mathrm{C})$ and a second MANOVA tested for differences among the three video cases $(\mathrm{D}, \mathrm{E}, \mathrm{F})$. If there were no differences within the pretest videos $(\mathrm{A}, \mathrm{B}, \mathrm{C})$ and within the posttest videos $(\mathrm{D}, \mathrm{E}, \mathrm{F})$, the responses to the Protocol of Questions were combined in further analyses.

There were three classes of elementary education preservice teachers who participated in a clinical practicum, two instructors and two different elementary schools. Therefore, a 3(class) x 2(time) multivariate analysis of variance (MANOVA) was performed on the five areas of observable reading behaviors; miscue analysis, fluency analysis, data analysis, inquiry orientation, and intelligent action from the pretest Protocol of Questions to posttest Protocol of Question to see if the classes could be combined in further analysis.

\section{Research Hypothesis HI states:}

Elementary education preservice teachers who participate in a clinical practicum experience tutoring a low-achieving reader under the direct supervision of a reading expert will significantly increase in their development of reading expertise compared to early childhood preservice teachers who did not participate in a clinical practicum.

A multivariate analysis of variance (MANOVA) was performed to see if there was a difference from the pre to posttest Protocol of Questions, if there was a difference by group (the elementary education preservice teachers' experimental group and the early childhood preservice teachers' comparison group), and if a group by time interaction exists. For significant effects, univariate ANOVAs were performed to see if there were 
differences on the Protocol of Questions for miscue analysis, fluency analysis, data analysis, inquiry orientation and intelligent action. For significant univariate ANOVAS, Holmes sequential Bonferroni was used to control for the probability of a Type I error in post hoc analysis for mean comparisons.

Research Hypothesis $H 2$ states:

Elementary education preservice teachers who, at the onset of the clinical practicum, are in the low and middle third on the pretest will show significant gains in their level of development of reading expertise.

To test this hypothesis the elementary education preservice teachers were divided into approximate thirds based on their pretest scores in each of the five areas of observable reading behavior; miscue analysis, fluency analysis, data analysis, inquiry orientation and intelligent action. Five one-way ANOVAs were carried out on the areas of reading observable reading behavior to see if mean gains were larger in the lower third than the upper third. For significant effects Holm's sequential Bonferroni procedure was used to compare pairs of means.

SPSS (v.15) was used to conduct all statistical analyses. For the multivariate tests, results were declared significant if $\mathrm{p}<.05$, and for univariate tests, the overall $\mathrm{p}<.05$ was adjusted by Holm's sequential Bonferroni procedure.

Research Hypothesis $H 3$ states:

Elementary education preservice teachers who participate in a clinical practicum experience tutoring a low-achieving diverse student under the direct supervision of a reading expert in their undergraduate teacher preparation will perceive that they have acquired the expertise to teach reading. 


\section{Qualitative Analysis}

As a means to acquire more insight into the elementary education preservice teachers' perceptions of acquiring reading expertise, at the end of the clinical practicum they reflected upon two questions. The first question asked the preservice teachers, "What did I learn about reading instruction and what did I learn about the reading process through the experience with this clinical practicum?" The second question asked preservice teachers, "What did you know about literacy instruction in the beginning of the semester and how does this compare to what you know now?"

The responses to the questions were analyzed qualitatively using procedures and techniques suggested by Merriam (1988) and Miles and Huberman (1994). First, the responses of the elementary preservice teachers who answered the questions were typed. The typed responses were read and reread, and responses were highlighted that related to the preservice teachers' perceptions acquiring reading expertise. Coding procedures as suggested by Miles and Huberman were used. Codes were attached to "chunks" of the varying sizes of the highlighted responses; words, phrases, sentences, or whole paragraphs. The significance of the "chunks" as related to preservice teachers' responses to their perceptions of acquiring reading expertise were coded using labels such as confident, learned how to teach reading, gained knowledge of teaching reading, prepared to be a reading teacher. The codes were used to organize and cluster the parts related to preservice perceptions of acquiring reading expertise. Six topics were initially identified; (a) learned how to teach reading, (b) gained confidence to teach reading, (c) overcame fear of teaching reading, (d) felt more prepared to teach reading, (e) gained expertise to teach reading, and (f) realized that how to teach reading impacted student learning. The 
researcher revisited the initial topics, and further refined to four topics; and relabeled; (a) gained confidence and felt prepared to teach reading, (b) gained knowledge of how teach reading, (c) gained expertise to teach reading, and; (d) realized how reading was taught impacted student learning.

The researcher looked for recurring phrases or common threads from the topics. Pattern coding was used to group the topics into a smaller number of themes (Miles \& Huberman, 1994). The pattern codes turned around three themes; (a) Preservice Teachers' Increased Feelings of Self-Efficacy to Teach Reading, (b) Preservice Teachers' Perceptions of Acquiring Reading Expertise and (c) Preservice Teachers' Insight: How Reading was Taught Impacted Student Achievement. Last, the initial responses of the preservice teachers were revisited to highlight information related to the misconceptions of teaching reading the preservice teachers noted that they had at the beginning of the practicum.

\section{Summary}

It is important to examine the kinds of experiences that may contribute to the development of reading expertise in preservice teachers. A clinical practicum which utilizes one-on-one tutoring to a low-achieving reader under the direct supervision of reading expert in the context of a school, provides preservice teachers with a real-life situation and provides knowledge and experience in the reality of what is needed in order to teach reading. This experience provides elementary education preservice teachers with a strong knowledge base and meaningful experiences that may enable them to develop the expertise needed to make more informed decisions about reading instruction and the reading needs of students, especially low-achieving readers. 
A quasi-experimental with a comparison group using a mixed method repeated measures pretest posttest design was used to determine if there was an increase in elementary education preservice teachers reading expertise, from novice to more expertlike, as compared to the development of early childhood preservice teachers' reading expertise. Elementary education preservice teachers were divided into approximate thirds based on their pretest scores on the Protocol of Questions to see if mean gains after the clinical practicum were greater in the lower and middle third. Further analysis, using the responses to the two reflection questions, was provided to determine if preservice teachers perceive they have acquired the expertise to teach reading. 


\section{CHAPTER IV}

\section{RESULTS}

The main focus of the present study was to examine the development of reading expertise of elementary education preservice teachers. This study examined the effect of a supervised clinical practicum on the development of reading expertise of elementary education preservice teachers under the direct supervision of a reading expert. The study also examined the extent in which reading expertise was developed in elementary education preservice teachers (experimental group) as compared to the development of reading expertise of early childhood preservice teachers who did not participate in a supervised clinical practicum (comparison group). Quantitative and qualitative methods were used for data analysis. Quantitative data analysis was used to measure elementary education preservice teachers' responses to a Protocol of Questions after observing three video cases of struggling readers at the beginning of a clinical practicum and three different video cases of low-achieving readers at the end of the clinical practicum and compare their responses to early childhood preservice teachers' responses to the same Protocol of Questions after observing three video cases of low-achieving readers at the beginning of their fourth literacy course and three different video cases of low-achieving readers at the end of that course. Quantitative data analysis was also utilized to examine the differentiated effect of the clinical practicum on the level of expertise of the elementary education preservice teachers. Finally, qualitative analysis was conducted to determine if elementary education preservice teachers' perceived they had acquired the expertise to teach reading. 


\section{Overall Sample Characteristics}

Eighty-four elementary education preservice teachers responded to the Protocol of Questions at the beginning and at the end of the clinical practicum. Twenty-two elementary education preservice teachers' Protocol of Questions were discarded because they were either incomplete or the preservice teacher did not respond to either the pretest or posttest Protocol of Questions. Twenty-six early childhood preservice teachers responded to the Protocol of Questions at the beginning of the semester of their fourth reading course and at the end of the semester. Fourteen early childhood education preservice teachers' Protocol of Questions were discarded because they were either incomplete or were absent the day of the pretest or posttest Protocol of Questions. Of the 84 preservice teachers in the study, $80 \%$ were Hispanic, $10 \%$ were African-American, $10 \%$ were Caucasian; $94 \%$ of the preservice teachers were women and $6 \%$ were men.

\section{Demographic Descriptive Statistics of Elementary Education Preservice Teachers}

Sixty-two elementary education preservice teachers were enrolled in a clinical practicum, their fourth reading course. They completed the Protocol of Questions at the beginning and at the end of the clinical practicum. There were two instructors; one instructor taught two classes at School One and School Two. The second instructor taught one class at School Two. Table 1 presents the class and number of elementary education preservice teachers taught by each instructor.

Twelve early childhood preservice teachers were enrolled in a fourth literacy course (comparison group). They completed the Protocol of Questions at the beginning and at the end of the semester. There was one early childhood instructor who taught the early childhood literacy class at the university campus. 
Table 1

Number of Elementary Education Preservice Teachers Taught by Instructor and School (Experimental Group)

\begin{tabular}{lccc}
\hline School & Instructor 1 & Instructor 2 & Total \\
\hline School 1 & $12(33.3 \%)$ & $0(0 \%)$ & $12(19.1 \%)$ \\
School 2 & $24(66.7 \%)$ & $26(100 \%)$ & $50(80.9 \%)$ \\
\hline Total & $36(100 \%)$ & $26(100 \%)$ & $62(100 \%)$ \\
\hline
\end{tabular}

Scoring Procedures for Protocol of Questions

\section{Video Cases}

Six video cases depicted six low-achieving third grade students who had varying degrees of reading difficulties. For example, one reader read a 278 word passage, made 22 miscues and self-corrected two miscues. Although he appeared to be interested in the passage, his reading was disfluent and his comprehension was limited. Another reader read a 154 word passage, made 16 miscues and self-corrected three miscues. This reader also appeared to be interested in reading but he was not fluent; he read word-by-word, and had little comprehension of the passage. The video cases allowed the preservice teachers to observe each reader, conduct a running record (Clay, 1987), and make notes in order to reflect upon what they observed about the reader on each video case. Protocol of Questions

The Protocol of Questions used at the beginning and end of the clinical practicum consisted of two main questions and four questions that followed each main question. The preservice teachers responded in writing to the questions about each reading on a 
Protocol of Questions. Question I b was different for each Protocol of Questions (See page 57, Figure 1) depending on the video case being observed.

\section{Observable Reading Behaviors}

A scoring rubric was used to rate the preservice teachers' quality of responses on the Protocol of Questions on a scale of $0-3$ with 0 indicating $0-1$ as "novice" responses and $2-3$ indicating more "expert-like" responses. There were five areas of observable reading behaviors on the scoring rubric; miscue analysis, fluency analysis, data analysis, inquiry orientation, and intelligent action. Miscue analysis are errors in oral reading; errors from the three cueing systems; semantic (meaning), syntactic (structure), and graphophonic (visual). Reading fluency is a reader's speed, expression, phrasing and attention to punctuation. Data analysis concerns one's ability to analyze and interpret a reader's performance based on observation and assessment of miscue analysis, fluency and comprehension. Inquiry orientation is one's ability to find appropriate information about a reader through reasonable reading assessment technique(s). Intelligent action is one's ability to make reasonable instructional decisions about a reader, and those decisions are geared to reading strategy instruction, not fixing mistakes.

\section{Reading Experts}

There were six reading experts, paired, to use the above rubric to score each of the elementary education and early childhood preservice teachers' quality of responses to the pretest and posttest Protocol of Questions using numerical scores. As indicated above, high numerical scores $(2-3)$ indicated "expert-like" responses. "Expert-like" responses indicated the preservice teachers noticed reading errors of the reader on the video cases 
on five observable reading behaviors; miscue analysis, fluency analysis, data analysis, inquiry orientation, and intelligent action. "Expert-like" responses were responses displaying a deeper understanding of the reader, such as noticing the three cueing systems and analyzing them; noticing the readers' speed, expression, attention to punctuation; pointing out a relationship between fluency and comprehension; seeking to interpret error analysis, fluency, and meaning making, hypothesizing the reader's performance; seeking to find out appropriate information through assessment techniques; and the ability to make at least two or three reasonable instructional decisions. Low numerical scores $(0-$ 1) indicated "novice-like" responses. "Novice" responses indicated the preservice teachers did not notice errors of the readers on the video cases from the three cueing systems and did not analyze them; they noticed none, or only one of the following three: speed, expression and attention to punctuation; they did not interpret the facts from either a fluency and meaning-making focus; they did not seek to find appropriate information about the reader through assessment techniques; and they did not discuss reasonable instructional decisions, on the five observable reading behaviors, miscue analysis, fluency analysis, data analysis, inquiry orientation, and intelligent action. Since two reading experts scored each of the elementary education and early childhood preservice teachers' pretest or posttest Protocol of Questions interrater reliability was established. Table 2 presents the calculation of interclass correlation coefficients to test the reliability of the six reading experts. 
Table 2

Interclass Correlation Coefficients for Interrater Reliability of Elementary Education Preservice Teachers and Early Childhood Preservice Teachers $(n=62)$

\begin{tabular}{ccccccccc}
\hline & \multicolumn{3}{c}{ Pretest Video Cases } & & \multicolumn{3}{c}{ Posttest Video Cases } \\
\cline { 2 - 7 } Factor & $\mathrm{A}$ & $\mathrm{B}$ & $\mathrm{C}$ & $\mathrm{D}$ & $\mathrm{E}$ & $\mathrm{F}$ \\
\hline Miscue Analysis & 0.58 & 0.65 & 0.75 & 0.53 & 0.65 & 0.62 \\
Fluency Analysis & 0.59 & 0.74 & 0.69 & 0.60 & 0.64 & 0.72 \\
Data Analysis & 0.63 & 0.69 & 0.70 & 0.60 & 0.74 & 0.64 \\
Inquiry Orientation & 0.64 & 0.62 & 0.56 & 0.48 & 0.70 & 0.71 \\
Intelligent Action & 0.56 & 0.57 & 0.57 & & 0.59 & 0.71 & 0.69 \\
\hline
\end{tabular}

Reliability coefficients ranged from 0.56 to 0.75 for the pretest video cases and from 0.48 to 0.74 for the posttest video cases. These are "moderate" to "substantial" reliability estimates (Landis \& Koch, 1977). Therefore, for the following analyses, the pair of raters' values from the scoring rubric were averaged for each preservice teacher and used as ratings on the five variables; miscue analysis, fluency analysis, data analysis, inquiry orientation and intelligent action, measured by the Protocol of Questions. Analyses of Video Cases and Increase in Level of Reading Expertise

The study used video cases (A, B, C) of three readers prior to the clinical practicum and video cases $(\mathrm{D}, \mathrm{E}, \mathrm{F})$ of three different readers at the end of the clinical practicum. Since the goal of the study was to measure the development of reading expertise of elementary education preservice teachers who participated in a clinical practicum their responses on the pretest and posttest video cases were analyzed to 
determine whether there was an increase in reading expertise compared to early childhood preservice teachers who did not participate in a clinical practicum.

\section{Testing the Pretest Video Cases}

First, an analysis was carried out on the five areas of observable reading behaviors of the readers from three video cases $(\mathrm{A}, \mathrm{B}, \mathrm{C})$ at the beginning of the clinical practicum and at the beginning of the fourth course of the early childhood preservice teachers, and the readers from three video cases $(\mathrm{D}, \mathrm{E}, \mathrm{F})$ at the end of the clinical practicum, and at the end of the fourth course of the early childhood preservice teachers, to see if responses differed within sets.

Multivariate analysis of variance (MANOVA) indicated there were significant differences for the pretest Protocol of Questions for video cases $(\mathrm{A}, \mathrm{B}, \mathrm{C}), \mathrm{F}(10,284)=$ 3.35, $\mathrm{p}<.001$. Univariate ANOVAs with Holm's sequential Bonferroni adjustments indicated significant differences among videos $(\mathrm{A}, \mathrm{B}, \mathrm{C})$ for miscue analysis; $\mathrm{F}(2,146)=$ $10.09, \mathrm{p}<.001$; fluency analysis; $\mathrm{F}(2,146)=5.99, \mathrm{p}=.007$; data analysis; $\mathrm{F}(2,146)=$ $10.06, \mathrm{p}<.001$; inquiry orientation; $\mathrm{F}(2,146)=4.06, \mathrm{p}=<.025$ but not for intelligent action; $\mathrm{F}(2,146)=0.56, \mathrm{p}=.550$. For miscue analysis, fluency analysis, and data analysis the preservice teachers scored video case A significantly higher (more "expert-like") than the other two video cases $(B, C)$. In reviewing the reader on video case $A$, it became clear to the researcher that his problematic reading was very obvious, he read in a choppy, disfluent manner, he made twenty-two miscues and only self-corrected two of the miscues. Therefore, the preservice teachers were able to display a greater level of reading expertise on this reader since his reading problems were more easily discerned than the readers on the video cases B and C. 
Analyses testing the Hypothesis H1 were conducted using a combined pretest Protocol of Questions score using video cases (A, B, C) and a combined pretest using only video case B and video case C. Statistical results were similar for both pretest video cases sets so only the analyses which used video cases (A, B, C) combined are presented. Testing the Posttest Video Cases

Multivariate analysis of variance (MANOVA) indicated there were no significant differences for the posttest Protocol of Questions for video cases (D, E, F), F (10,284) = $1.48, \mathrm{p}=.145$. Thus, posttest ratings were averaged across the three video cases for each preservice teacher, resulting in five rating scores per preservice teacher for their responses on the pretest Protocol of Questions and five rating scores for the posttest Protocol of Questions.

School/Instructor for Elementary Education Preservice Teachers Experimental Group

Since there were three different classes of elementary education preservice teachers, two instructors and two different elementary schools, a multivariate analysis of variance (MANOVA) was performed on the five areas of observable reading behaviors; miscue analysis, fluency analysis, data analysis, inquiry orientation and intelligent action from the pretest Protocol of Questions to posttest Protocol of Questions. There was a significant main effect of class, $F(10,110)=4.70, p<.001$, but not a significant interaction of class by time, $\mathrm{F}(10,110)=0.88, \mathrm{p}=0.577$. Examining the five ratings on the pretest Protocol of Questions and the posttest Protocol of Questions demonstrates the pretest ratings on the Protocol of Questions for School Two, Instructor Two were lower than School One, Instructor One and School Two at pretest. Table 3 presents these findings. 
Table 3

Means and Standard Deviation of Protocol of Questions on Pretest and Posttest by

School and Instructor (Experimental Group)

\begin{tabular}{|c|c|c|c|c|c|c|}
\hline & \multicolumn{2}{|c|}{$\begin{array}{c}\text { School } 1 / \text { Instructor } 1 \\
n=12 \\
\end{array}$} & \multicolumn{2}{|c|}{$\begin{array}{c}\text { School 2/Instructor } 1 \\
n=24\end{array}$} & \multicolumn{2}{|c|}{$\begin{array}{c}\text { School } 2 / \text { Instructor } 2 \\
n=26\end{array}$} \\
\hline & $M$ & $S D$ & $M$ & $S D$ & $M$ & $S D$ \\
\hline & \multicolumn{6}{|c|}{ Miscue Analysis } \\
\hline Pretest & 1.47 & 0.93 & 1.09 & 0.77 & 0.76 & 0.63 \\
\hline \multirow[t]{2}{*}{ Posttest } & 1.76 & 0.61 & 1.54 & 0.76 & 1.01 & 0.71 \\
\hline & \multicolumn{6}{|c|}{ Fluency Analysis } \\
\hline Pretest & 1.18 & 1.01 & 0.80 & 0.74 & 0.57 & 0.58 \\
\hline \multirow[t]{2}{*}{ Posttest } & 1.83 & 0.68 & 1.50 & 0.81 & 1.06 & 0.72 \\
\hline & \multicolumn{6}{|c|}{ Data Analysis } \\
\hline Pretest & 1.47 & 0.71 & 1.22 & 0.67 & 0.77 & 0.60 \\
\hline \multirow[t]{2}{*}{ Posttest } & 2.02 & 0.51 & 1.73 & 0.81 & 1.10 & 0.68 \\
\hline & \multicolumn{6}{|c|}{ Inquiry Orientation } \\
\hline Pretest & 1.04 & 0.40 & 0.97 & 0.65 & 0.46 & 0.44 \\
\hline \multirow[t]{2}{*}{ Posttest } & 1.60 & 0.45 & 1.46 & 0.65 & 0.70 & 0.52 \\
\hline & \multicolumn{6}{|c|}{ Intelligent Action } \\
\hline Pretest & 1.07 & 0.53 & 0.86 & 0.66 & 0.48 & 0.45 \\
\hline Posttest & 2.08 & 0.50 & 1.65 & 0.69 & 0.97 & 0.48 \\
\hline
\end{tabular}

Because there was no significant interaction between class and time and the class sizes differed, the analyses of Hypothesis $H I$ were conducted excluding the class variable. 


\section{Results of Testing the Research Hypotheses}

Hypothesis $H 1$ stated that:

Elementary education preservice teachers who participate in a clinical practicum experience tutoring a low-achieving reader under the direct supervision of a reading expert will significantly increase in their development of reading expertise compared to early childhood preservice teachers who did not participate in a clinical practicum.

To test this hypothesis a multivariate analysis of variance (MANOVA) was conducted on each of the elementary education and early childhood preservice teachers' responses to the pretest and posttest Protocol of Questions by group. There was a significant main effect by group $\mathrm{F}(5,68)=5.71, \mathrm{p}<.001$, and a significant time effect from the pre to posttest Protocol of Questions for the five areas of observable reading behaviors, $\mathrm{F}(5,68)=2.52, \mathrm{p}<.038$. There was also a significant interaction of group by time from pre and posttest Protocol of Questions in all five areas, $\mathrm{F}(5,68)=3.82, \mathrm{p}=.004$. Since the multivariate interaction was significant, each of the five variables, miscue analysis, fluency analysis, data analysis, inquiry orientation and intelligent action were tested for interaction of group by time with a univariate ANOVA. Table 4 presents these findings. 
Table 4

Pretest and Posttest Means for Protocol of Questions for Experimental Group ( $n=62)$

and Comparison Group $(n=12)$

\begin{tabular}{|c|c|c|c|c|c|c|}
\hline \multirow[b]{2}{*}{ Group } & \multicolumn{2}{|c|}{ Pretest } & \multicolumn{2}{|c|}{ Posttest } & \multirow[b]{2}{*}{$F^{*}$} & \multirow[b]{2}{*}{$p$} \\
\hline & $M$ & $S D$ & $M$ & $S D$ & & \\
\hline & \multicolumn{4}{|c|}{ Miscue Analysis } & 0.98 & .326 \\
\hline Experimental & 1.02 & 0.78 & 1.36 & 0.76 & & .004 \\
\hline \multirow[t]{2}{*}{ Comparison } & 1.07 & 0.43 & 1.13 & 0.36 & & .831 \\
\hline & \multicolumn{4}{|c|}{ Fluency Analysis } & 3.28 & .074 \\
\hline Experimental & 0.78 & 0.76 & 1.38 & 0.79 & & $<.001$ \\
\hline \multirow[t]{2}{*}{ Comparison } & 0.65 & 0.45 & 0.69 & 0.39 & & .883 \\
\hline & \multicolumn{4}{|c|}{ Data Analysis } & 4.67 & .034 \\
\hline Experimental & 1.08 & 0.70 & 1.52 & 0.79 & & $<.001$ \\
\hline \multirow[t]{2}{*}{ Comparison } & 1.08 & 0.27 & 0.96 & 0.29 & & .064 \\
\hline & \multicolumn{4}{|c|}{ Inquiry Orientation } & 8.04 & .006 \\
\hline Experimental & 0.76 & 0.58 & 1.16 & 0.69 & & $<.001$ \\
\hline \multirow[t]{2}{*}{ Comparison } & 0.60 & 0.42 & 0.44 & 0.39 & & .391 \\
\hline & \multicolumn{4}{|c|}{ Intelligent Action } & 14.58 & $<.001$ \\
\hline Experimental & 0.74 & 0.59 & 1.44 & 0.71 & & $<.001$ \\
\hline Comparison & 0.75 & 0.54 & 0.64 & 0.50 & & .570 \\
\hline
\end{tabular}

Note. Ratings are scored $0-3$ with Novice equaling 0 and Expert-Like equaling 3. *Interaction $F$ and $p$ value given for pre to post difference The interaction between group and time is indicative of the gains reported in the table. 


\section{Discussion of the Results of Testing Research Hypothesis One}

The results for each of the five areas of observable reading behaviors below will be discussed individually.

\section{Miscue Analysis}

There was no significant interaction of group by time, $p=0.326$, however, there was an observed increase in mean ratings of 1.02 to 1.36 from the pre to posttest Protocol of Questions for the elementary education preservice teachers for miscue analysis.

For pretest to posttest Protocol of Questions for miscue analysis, early childhood teachers' mean rating of 1.07 and 1.13 respectively, indicated a minor increase in miscue analysis.

Fluency Analysis

There was no significant interaction of group by pretest and posttest, $\mathrm{p}=0.074$, however, there was an observed increase in mean ratings of 0.78 to 1.38 from the pre to posttest Protocol of Questions for the elementary education preservice teachers for fluency analysis.

For pretest to posttest Protocol of Questions for fluency analysis, early childhood preservice teachers' mean rating of 0.65 and 0.69 respectively, indicated a minor increase in fluency analysis.

\section{Data Analysis}

There was a significant interaction of group by pretest and posttest $p=0.034$ with a significant increase in mean ratings of the experimental group of elementary education preservice teachers from the pre to posttest Protocol of Questions for data analysis $\mathrm{p}=$ 
0.034 , but not for the comparison group of preservice teachers, $p=.604$. From pretest to posttest for data analysis, the elementary education preservice teachers' mean rating of 1.08 to 1.52 increased significantly for data analysis.

For pretest to posttest Protocol of Questions for data analysis, early childhood preservice teachers' mean rating of 1.08 and 0.96 respectively, indicated a decrease in data analysis.

\section{Inquiry Orientation}

There was a significant interaction of group by pretest and posttest, $\mathrm{p}=.006$, with a significant increase in mean ratings of the experimental group of elementary education preservice teachers from pre to posttest Protocol of Questions on inquiry orientation $\mathrm{p}<.001$, but not for the comparison group of preservice teachers, $\mathrm{p}<.391$. From pretest to posttest Protocol of Questions for inquiry orientation, the elementary education preservice teachers' mean rating of 0.76 to 1.52 increased significantly for inquiry orientation.

For pretest to posttest Protocol of Questions for inquiry orientation, early childhood preservice teachers' mean rating of 0.60 and 0.44 respectively, indicating a decrease for inquiry orientation.

\section{Intelligent Action}

There was a significant interaction of group by pretest and posttest, $\mathrm{p}<.001$, and there was a significant increase in mean ratings from the pretest to posttest Protocol of Questions for intelligent action, $\mathrm{p}<.001$, but not for the comparison group, $\mathrm{p}<.570$. From pretest to posttest Protocol of Questions for intelligent action the mean rating of 
0.74 to 1.44 indicated the elementary education preservice teachers, increased significantly in intelligent action scores.

For the comparison group of early childhood preservice teachers, the pre to posttest Protocol of Questions for intelligent mean of 0.75 to 0.64 respectively, indicated a decrease in intelligent action.

Hypothesis $H 1$ was supported by three of the five variable ratings for the comparison group; data analysis, inquiry orientation and intelligent action, indicating the clinical practicum had an effect on helping elementary education preservice teachers develop greater expertise about teaching reading. Within the experimental group of elementary education preservice teachers, the development of reading expertise in all five areas, miscue analysis, fluency analysis, data analysis, and inquiry orientation increased significantly pre-post, after having participated in a clinical practicum.

H2 stated:

Elementary education preservice teachers who, at the onset of the clinical practicum, are in the low and middle third on the pretest will demonstrate significant gains in their level of development of reading expertise.

To test this hypothesis a one-way ANOVA with pregrouping was carried out on the five areas of observable reading behaviors; miscue analysis, fluency analysis, data analysis, inquiry orientation and intelligent action. For each variable, pretest scores were divided into three groups, with approximately one-third of the preservice teachers in each group. A one-way ANOVA was then carried out on the gain scores to see if the lower and middle groups made significantly higher gains from pretest to posttest than the upper third group. Table 5 presents these findings. 
Table 5

Elementary Education Preservice Teachers' Gain in Reading Expertise by Pretest Group

\begin{tabular}{|c|c|c|c|c|c|c|}
\hline \multirow{2}{*}{\multicolumn{2}{|c|}{ Groupings by Thirds }} & \multirow[b]{2}{*}{$n$} & \multicolumn{2}{|c|}{ Gains } & \multirow[b]{2}{*}{$F$} & \multirow[b]{2}{*}{$p$} \\
\hline & & & $M$ & $S D$ & & \\
\hline & & & \multicolumn{2}{|c|}{ Miscue Analysis } & 15.79 & $<.001$ \\
\hline Low & $(0.00-0.50)$ & 21 & $0.76^{\mathrm{b}}$ & 0.69 & & \\
\hline Middle & $(0.51-1.17)$ & 22 & $0.66^{\mathrm{b}}$ & 0.87 & & \\
\hline \multirow[t]{2}{*}{ High } & $(1.18-3.00)$ & 19 & $-0.51^{a}$ & 0.79 & & \\
\hline & & & \multicolumn{2}{|c|}{ Fluency Analysis } & 14.37 & $<.001$ \\
\hline Low & $(0.00-0.17)$ & 20 & $1.22^{\mathrm{b}}$ & 0.83 & & \\
\hline Middle & $(0.18-0.83)$ & 20 & $0.83^{\mathrm{b}}$ & 0.81 & & \\
\hline \multirow[t]{2}{*}{ High } & $(0.84-3.00)$ & 22 & $-0.17^{\mathrm{a}}$ & 0.95 & & \\
\hline & & & \multicolumn{2}{|c|}{ Data Analysis } & 6.86 & .002 \\
\hline Low & $(0.00-0.67)$ & 20 & $0.88^{\mathrm{b}}$ & 0.71 & & \\
\hline Middle & $(0.68-1.17)$ & 23 & $0.50^{\mathrm{b}}$ & 0.83 & & \\
\hline \multirow[t]{2}{*}{ High } & $(1.18-3.00)$ & 19 & $-0.09^{a}$ & 0.91 & & \\
\hline & & & \multicolumn{2}{|c|}{ Inquiry Orientation } & 7.72 & $<.001$ \\
\hline Low & $(0.00-0.50)$ & 25 & $0.53^{\mathrm{b}}$ & 0.56 & & \\
\hline Middle & $(0.51-1.00)$ & 21 & $0.60^{\mathrm{b}}$ & 0.60 & & \\
\hline \multirow[t]{2}{*}{ High } & $(1.01-3.00)$ & 16 & $-0.09^{\mathrm{a}}$ & 0.59 & & \\
\hline & & & \multicolumn{2}{|c|}{ Intelligent Action } & 4.62 & .014 \\
\hline Low & $(0.00-0.33)$ & 15 & $0.79^{b}$ & 0.47 & & \\
\hline Middle & $(0.34-0.83)$ & 21 & $0.99^{\mathrm{ab}}$ & 0.71 & & \\
\hline High & $(0.84-3.00)$ & 26 & $-0.42^{\mathrm{a}}$ & 0.70 & & \\
\hline
\end{tabular}

Note. Within each observable reading behavior, means with different superscripts are significantly different using Holm's Sequential Bonferroni procedures, $\mathrm{p}<.05$; e.g., in Miscue Analysis the high pretest group's mean (a) is significantly different than the mean gain scores for the Low (b) and Middle (b) groups. However, the Low (b) and Middle (b) Groups mean gains are not significantly different. 
Discussion of the Results of Testing Research Hypothesis Two

Miscue Analysis

There was a significant difference in the elementary education preservice teachers' gains in expertise in miscue analysis by pretest group, $\mathrm{p}<.001$. The lower third and middle third groups ( $\mathrm{M}=0.76$ and 0.66 respectively) scored significantly higher on the posttest than the upper third group $(\mathrm{M}=-0.51)$.

Fluency Analysis

There was a significant difference in the elementary education preservice teachers' gains in expertise in fluency analysis, by pretest group, $\mathrm{p}<.001$. The lower third and middle third groups ( $M=1.22$ and 0.83 respectively) scored significantly higher on the posttest than the upper third group $(\mathrm{M}=-0.17)$.

Data Analysis

There was a significant difference in the elementary education preservice teachers' gains in expertise in data analysis by pretest group, $p=.002$. The lower third and middle third groups $(\mathrm{M}=0.88$ and 0.50 respectively) scored significantly higher on the posttest than the upper third group $(\mathrm{M}=-0.09)$.

Inquiry Orientation

There was a significant difference in the elementary education preservice teachers' gains in expertise in inquiry orientation by pretest group, $\mathrm{p}<.001$. The lower third and middle third groups ( $\mathrm{M}=0.53$ and 0.60 respectively) scored significantly higher on the posttest than the upper third group $(\mathrm{M}=-0.09)$ 


\section{Intelligent Action}

There was a significant difference in the elementary education preservice teachers' gains in expertise in intelligent action by pretest group, $p=0.014$. The lower third and middle third groups ( $\mathrm{M}=0.79$ and 0.99 respectively) scored significantly higher on the posttest than the upper third group $(\mathrm{M}=-0.42)$.

$H 2$ was supported by the increase in mean gains in the low and middle third groups in the five areas of observable reading behaviors, miscue analysis, fluency analysis, data analysis, inquiry orientation and intelligent action.

\section{Summary of Results of Quantitative Analyses}

This study introduced the use of video cases to measure the development of reading expertise in elementary education preservice teachers who participated in a clinical practicum under the direct supervision of a reading expert. There were six reading experts who scored the quality of responses to the pretest Protocol of Questions or posttest Protocol of Questions using the scoring rubric developed by Smith (2005).

An analysis was carried out on the five areas of reading behaviors from video cases $(A, B, C)$ and video cases $(D, E, F)$. There was a significant difference in the pretest video cases $(\mathrm{A}, \mathrm{B}, \mathrm{C})$, with the preservice teachers scoring video case $\mathrm{A}$ significantly higher than video cases $(B, C)$. There were no significant differences for posttest video cases (D, E, F).

Since there were three different classes of preservice teachers, analyses were carried out to see if there were class differences across pretests and posttests. There was a significant main effect of class, but not a significant interaction of class by time. The 
pretest ratings on the Protocol of Questions for school two, instructor two were lower than school one, instructor one and school two at pretest.

Results of testing research Hypothesis $H I$ indicated that elementary education preservice teachers' reading expertise increased significantly in data analysis, inquiry orientation and intelligent action as compared to early childhood education preservice teachers. There were minor increases in miscue analysis and fluency analysis of the early childhood education preservice teachers. Within the experimental group of elementary education preservice teachers there were significant gains in their expertise in all five areas; miscue analysis, fluency analysis, data analysis, inquiry orientation and intelligent action.

Results of testing research Hypothesis $H 2$ indicated that elementary education preservice teachers who, at the onset of the clinical practicum, were in the low and middle third based on their responses on the pretest Protocol of Questions demonstrated significant gains in their level of development of reading expertise in miscue analysis, fluency analysis, data analysis, inquiry orientation, and intelligent action.

\section{Qualitative Analysis}

H3 stated:

Elementary education preservice teachers who participated in a clinical practicum experience tutoring a low-achieving student under the direct supervision of a reading expert in their undergraduate teacher preparation will perceive they have acquired the expertise to teach reading.

To test this hypothesis preservice teachers' responses to two questions were analyzed using procedures and techniques suggested by Merriam (1988) and Miles and 
Huberman (1994). The questions were, "What did I learn about reading instruction and what did I learn about the reading process through the experience with this clinical practicum?" "What did you know about literacy instruction in the beginning of the semester and how does this compare to what you know now?

There were 46 preservice teachers included in this analysis. Each preservice teacher was identified with a number beginning with 701 and ending in 747 . First, the researcher highlighted the responses of each preservice teacher who answered the questions about learning how to teach reading. Second, the highlighted responses were typed along with the preservice teachers' identifying number. Third, the typed responses were reread, and this time the responses highlighted were related to preservice teachers' perceptions of acquiring the expertise to teach reading. Fourth, the highlighted responses related to preservice teachers' perceptions of acquiring expertise to teach reading were typed. Last, the responses were read again, and this time each response was coded with words such as "confident", "capable", "prepared", "learned how to teach reading", “experience", "gained expertise", "student growth", or "comfortable". The codes were used to organize and cluster the parts related to preservice perceptions of acquiring reading expertise. Through inductive reasoning recurring phrases or common threads were identified and three themes emerged; (a) self-efficacy to teach reading, (b) preservice teachers perceptions of acquiring reading expertise, and (c) preservice teachers realization that their knowledge impacted student achievement. In order to determine the entry level thinking of the preservice teachers had at the beginning of the clinical practicum, the original set of typed responses were revisited and reread. Responses 
related to any preconceived notions or misconceptions of teaching reading the preservice teachers may have had, were highlighted.

\section{Discussion of Research Hypothesis Three}

Three themes will be discussed: (a) Preservice Teachers' Increased Feelings of Self-efficacy to Teach Reading; (b) Preservice Teachers' Perceptions of Acquiring Reading Expertise; and (c) Preservice Teachers' Insight: How Reading was Taught Impacted Student Achievement.

\section{Self-Efficacy to Teach Reading}

Prior to the clinical practicum preservice teachers had preconceived notions and misconceptions about teaching reading. Dan Lorties' (1975) apprenticeship of observation is supported through responses of these preservice teachers; they observed the "idea" of teaching but not the experience. One preservice teacher thought "reading was taught in ways in which they were taught to read," or the "the teacher performed a set of predetermined exercises after reading." Another preservice teacher thought you would teach a reading strategy and "hope" students would understand. "I always thought the teacher goes around the classroom having students read out loud and then the teacher would correct the student if they make an error in something they have read." "I came into this clinical practicum knowing only how I was taught to read through the experiences I encountered during my education.” One preservice teacher, at the beginning of the practicum, began tutoring her student in the same way she was taught to read. "At the beginning of the practicum I believe I taught reading the way I was taught." Another preservice teacher's notion of teaching reading was limited to the kinds of information found in textbooks. "I knew only what I read in textbooks and heard from 
my professors." "I had a thin layer of literacy instruction knowledge." A preservice teacher simply stated, "I found myself wondering how I would get through this course when I had absolutely no knowledge of how to teach reading."

As indicated above, the apprenticeship of observation (Lortie, 1975) offers a limited vantage point for preservice teachers to acquire knowledge of teaching. Prior to the clinical practicum elementary education preservice teachers spend time in field placements observing practicing teachers. Preservice teachers' observations of experienced teachers in classrooms may have the tendency to appear to novices that teaching reading is easy instead of informing preservice teachers about the complexity of teaching reading. A preservice teacher referred to previous classroom observations in field and stated "the reading instruction observed in a real classroom was very routine; the students performed a set of pre-determined simplistic exercises after each reading assignment." Some preservice teachers believed teaching reading was easy, or they already knew how to teach reading. "I walked into the classroom (clinical practicum) thinking I knew how to teach reading." "I thought teaching reading would be easy;" one preservice teacher raised the question, "I thought to myself how hard could it be to teach reading to a child?"

Through participation in the clinical practicum preservice teachers were able to not only dispel the misconceptions they had about teaching reading but they were able to express beliefs of self-efficacy to teach reading. "This course was the only one that taught me something I needed to know in order to teach reading." "I have truly learned how to teach reading properly." "There is no doubt in my mind that effective instruction using teaching ideas and writing strategies is the proper way to teach students how to 
read." "What I know now that the clinical practicum is over is different from what I knew at the beginning. I know now that I can teach a student or a whole class of students with confidence and ability." One preservice teacher expressed that she did not have all the knowledge she needed to know about reading but through the clinical practicum she had a starting point in which to teach reading.

The knowledge I have now about the reading process is concrete and clear but I am still nervous and I do not know everything about reading. When I started I was clueless and now I feel as though I have an idea. Now I feel like I can succeed. I have more knowledge and confidence now versus when I started.

According to Bandura (1989) efficacy beliefs influence behavior, and self-

efficacy is the belief that one can accomplish a task successfully. Bandura, (1977) stated that a person's self-efficacy increases as a result of motivation, knowledge and opportunities to act. The preservice teachers who experienced a clinical practicum gained knowledge about teaching reading and had the opportunity to apply the knowledge by learning how to teach a low-achieving elementary student to read.

This course has been an eye-opening experience in that it has made me realize that I am able to teach reading. This clinical practicum has provided me with the instruction. No other class has provided me with this feeling. It has made me feel better prepared and more qualified to face a classroom. I feel I am able to meet students' reading needs.

Throughout the clinical practicum the preservice teachers were taught how to write lesson plans using specific reading strategies. Many preservice teachers attributed their self-efficacy to learning various reading strategies. "I feel confident enough to go into a class to teach reading. I have learned a lot of effective strategies that I did not know about and most importantly I have learned how to teach them and that's what made me confident." "I feel that I now have the tools I need to be able to teach a student how 
to read. I am confident I can teach a classroom of students." "I feel more confident towards teaching reading now than I did before due to the fact that I learned phonemic awareness, phonics, and comprehension strategies." Another offered:

This gave me insight to reading instruction. Before, I had some knowledge of teaching reading but no where near what I know now. I am a lot more confident than I was before. Before I didn't know any strategies to use in reading but now I know so many strategies I can use towards teaching reading and I know if something doesn't work I have others to choose from.

Preservice Teachers' Perceptions of Acquiring Reading Expertise

Reading expertise is defined as the ability to progress from learning the basic elements of teaching reading, to accumulating knowledge of how to teach reading, to making decisions about what they are going to do, and reflecting on what is working based on their experience. According to Hammerness et al. (2005) the metacognitive elements that are involved in the development of expertise can be developed in teacher education. Hammerness et al. (2005) also contend that expertise is developed when learning is situated within specific contexts. Within that context of learning, expertise is developed and that learning must also be helped to transfer. Contextualized learning, based on the principle of transfer of training (Harris \& Sipay, 1990) implies that for maximum transfer of skills learned, the context of a setting should be similar to a school setting.

Directly working with children during this semester has contributed to my knowledge base of literacy instruction in many ways. I was able to get handson experience. I was able to work with a student two times a week for an entire semester. I implemented lessons with the student and taught her many comprehension strategies that I learned in class. Learning the different comprehension strategies was not about taking notes, but actually implementing the comprehension strategies and this was a great experience. I moved from theory to practice. I learned the theory in class and was able to practice the theory tutoring the student. 
Preservice teachers' learning how to teach reading was situated in the context of an elementary school where they learned how to teach reading in a clinical practicum under the supervision of a reading expert. Because of this support, many preservice teachers perceived they had acquired the expertise needed to teach reading. "I feel that I will walk out of the experience richer in knowledge in literacy and prepared to face the work of teaching. My knowledge and preparedness is due to this experience." "Without the clinical practicum I would not know how to teach reading. This experience provided the application I needed to practice all the skills I have learned." "I actually learned how to teach reading to a child."

The clinical course has given me the essential tools I will need to become a successful instructor. It has given me the necessary tools to correctly and accurately conduct reading assessments to discover a child's strengths and areas for growth in reading.

One-on-one tutoring has had powerful affect on helping students with reading difficulties, and this situation is considered the most effective method of instruction (Juel, 1996; Wasik \& Slavin, 1993). Additionally, Hedrick, McGee, and Mittag (2000) concluded that preservice teachers who tutored at-risk students in reading learned from their experiences. The preservice teachers perceived their experience tutoring a lowachieving student one-on-one in reading contributed to their acquisition of reading expertise. "The tutoring experience has helped me gain expertise in reading, beginning with administering the reading assessments on the student. Understanding the importance of assessments helped me realize how I should begin helping my student.” "The tutoring experience has provided me with the necessary information, the expertise, and the strategies I used to support my student's learning." 
Many preservice teachers articulated how much they learned about teaching reading from working with their student. "Working directly with a student contributed to my knowledge of reading instruction. Working with a student helped me to become confident enough to teach reading." "I actually learned how to teach reading to a child hands-on. I learned how to teach the different parts of reading such as phonemic awareness, fluency, phonics, vocabulary and writing." "I learned so much because I was working directly with a child. I applied what I learned in class when I worked with the student." "After taking this class I know how to actually teach reading. This has given me a great perspective on the differences in each child and that I must meet those individual needs." One student compared learning to teach reading to that of novice to expert. "This course has submerged me into the process of teaching reading and has taken me from novice to expert."

Collins, Brown and Newman (1989) discussed a type of apprenticeship termed cognitive apprenticeship. This type of apprenticeship focuses on two aspects of teaching and learning; (a) revealing the process that expert teachers use to handle complex tasks; and (b) learning through guided experiences in which cognitive and metcognitive processes are explored and utilized. Throughout the clinical practicum the preservice teachers were guided through the process of teaching a low-achieving student to read.

Working directly with a student contributed to my knowledge base of literacy instruction because it was a hands-on experience. I was able to implement my previous knowledge, moving from theory to actually practicing and working with a student in a one-on-one setting. This allowed me to address the student's needs and strengths in order to be able to help the student become a better reader. 
A cognitive apprenticeship suggests field experiences that focus on cognitive and metacognitive processes in learning, scaffolding by an expert mentor, purposeful task selection, increasing complexity of tasks, and experiences that are contextually based on diverse classroom settings (Keehn et al., 2001). The preservice teachers' participation in a clinical practicum mirrors the description of a cognitive apprenticeship, and in particular, scaffolding by an expert mentor contributed to the development of reading expertise. A cognitive apprenticeship is aptly described by one student.

Getting ready to teach the students, the professor began explaining to us what we would be doing and also how we would be implementing reading strategies. She also described to us how we would be conducting assessments that would facilitate our creating of appropriate lesson plans. She continued to explain to us how to create lesson plans that would help us to be ready to teach the students. These explanations continued throughout the course of the semester and I really believe that the explaining she did with the hands-on approach of working with students helped me to become confident in successfully teaching a child to use these reading strategies.

Preservice Teachers' Insight: Their Knowledge of Teaching Reading Impacted Student

Achievement.

What teachers know has substantial influence on what students learn (DarlingHammond \& McLaughlin, 1999) and there is a consistently positive relationship between teacher preparation and student outcomes (National Reading Panel, 2000; DarlingHammond, 1999). The preservice teachers, through the clinical practicum experience, gained an understanding of how to teach reading. Some of the preservice teachers realized that what they learned about teaching reading had a direct impact on the reading achievement of the student they tutored. "The experience of tutoring a student for so many weeks and seeing their progress has helped me to realize the impact I can 
have as an educator." "I was able to "practice" teaching reading concepts. I taught the student several reading strategies, which I feel confident improved his reading."

Since many of the preservice teachers had limited experiences tutoring a student in reading prior to the practicum, through this tutoring experience they were able to witness first-hand the progress their student made in reading.

I never had an experience where I was able to see the amount of progress and improvement in a student's ability to read and write that was directly related to the use of my own lesson plans, activities and teaching. I was able to see the direct result of my one-on-one teaching and how it affected her.

In addition, preservice teachers understood not only the student's achievement, but their learning about teaching reading had also been impacted.

My growth and progress as a teacher has influenced my student's growth and progress in reading. We both made tremendous progress, her in her reading skills and me in my teaching skills. I believe my progress is a direct result of my instruction, my willingness to learn and improve as a teacher, and the opportunity to work closely with a struggling reader.

Based upon the responses of the preservice teachers, they perceived they acquired the expertise to teach reading. Tutoring a student one-on-one was a way for preservice teachers to apply what they learned about teaching reading from requisite reading courses and in their continuation to learn from class lectures and mentoring in the clinical practicum. The preservice teachers were definitive in perceiving that teaching reading was not something that could be learned by reading about; the experience on how to teach reading was essential.

Results of $H 3$ suggest that after participation in a supervised clinical practicum elementary education preservice teachers perceived they had acquired the reading expertise needed to teach reading. 


\section{Summary}

Elementary education preservice teachers developed greater expertise in all five areas of observable reading behaviors, miscue analysis, fluency analysis, data analysis, inquiry orientation and intelligent action. The most significant increase was inquiry orientation and intelligent action. Inquiry orientation is the ability to make more informed decisions about reading instruction instead of hasty decisions based on superficial knowledge of reading. Intelligent action requires a higher level of reading expertise of teaching reading to make knowledgeable decisions on what to do for a student instructionally. Typically, elementary education preservice teachers would not be expected to gain a more expert-like level of expertise without having had the experience of learning how to teach reading. There were minor increases for the comparison group of early childhood preservice teachers on miscue analysis, fluency analysis, and data analysis; and minor decreases from pretest to posttest on inquiry orientation and intelligent action. Results indicated the early childhood preservice teachers did not acquire the same level reading expertise at the conclusion of their fourth literacy course as the elementary education preservice teachers.

Elementary education preservice teachers who, at the onset of the clinical practicum, were in the low and middle third groups based on their responses to the pretest Protocol of Questions, made significant gains in their reading expertise in miscue analysis, fluency analysis, data analysis, inquiry orientation and intelligent action. The elementary education preservice teachers who entered the clinical practicum with a higher level of knowledge of miscue analysis, fluency analysis, data analysis, inquiry 
orientation, and intelligent action did not demonstrate gains in their development of reading expertise.

Last, results of the qualitative analysis indicate elementary education preservice teachers' responses what they learned about reading and the reading process and what they learned about teaching reading after having participated in a clinical practicum, suggest they perceived they acquired the reading expertise to teach reading. 


\section{CHAPTER V}

\section{CONCLUSIONS}

The purpose of the study was to examine the effect of a supervised clinical practicum on the development of reading expertise of elementary education preservice teachers. The study addressed two needs in the reading preparation of elementary education preservice teachers; (a) better ways in which elementary education preservice teachers are prepared to teach reading and (b) to better understand the benefits of a supervised clinical practicum in which reading expertise may be developed in elementary education preservice teachers. This chapter will: (a) restate the problem, (b) summarize the procedures, (c) summarize the findings, (d) identify the study's limitations, (e) conclusions and $(\mathrm{g})$ implications for preservice teacher education in reading preparation. Restatement of the Problem

Since the No Child Left Behind Act of 2001 (2002), mandate demands "highly qualified" teachers to teach all children to read, there is a need to look at ways in which elementary education preservice teachers are prepared to teach reading. The present study; (a) addressed ways in which elementary education preservice teachers are prepared to teach reading and (b) examined the effect of a clinical practicum on elementary education preservice teachers' development of reading expertise.

\section{Design and Procedures}

The present study used quantitative methodology to measure elementary education and early childhood preservice teachers' development of reading expertise, and examined the differentiated effect of a clinical practicum on the level of expertise of elementary education preservice teachers, and qualitative methodology to determine if 
elementary education preservice teachers perceived they acquired the expertise to teach reading. Sixty-two elementary education preservice teachers were enrolled in a fourth reading course, a clinical practicum. The elementary education preservice teachers were instructed on assessment techniques, comprehension strategies, and phonemic awareness and fluency strategies throughout the practicum. Each elementary education preservice teacher tutored a low-achieving second grade student in reading for 14 weeks. Throughout the tutoring sessions the preservice teachers were supervised and mentored by two reading experts; feedback was given to the elementary education preservice teachers regarding the quality of their lesson plans, appropriateness of materials, and delivery of reading lessons to the students.

At the beginning of the clinical practicum the 62 elementary education preservice teachers responded to a pretest Protocol of Questions after observing video cases of three low-achieving third grade students. At the completion of the clinical practicum the 62 elementary education preservice teachers responded to a posttest Protocol of Questions after observing video cases of three different low-achieving third grade students. Twelve early childhood preservice teachers were participants in the study and served as a comparison group. The early childhood education preservice teachers were enrolled in a fourth literacy course that did not have a clinical practicum. The early childhood education preservice teachers responded to a pretest Protocol of Questions after observing the same three video cases of low-achieving third grade students as the elementary education preservice teachers observed, at the beginning of the semester. At the end of the semester the early childhood education preservice teachers observed the same three video cases of three different low-achieving students as the elementary 
education preservice teachers observed, and responded to a posttest Protocol of Questions.

These data were analyzed by six reading experts who rated the quality of responses of the elementary education and early childhood preservice teachers on the Protocol of Questions after having observed video cases of six low-achieving readers. The six reading experts used a scoring rubric (Smith, 2005) to rate the responses of the elementary and early childhood preservice teachers on a scale of $0-3$; with scores of $0-$ 1 novice-like responses and $2-3$ more expert-like responses. Five areas of observable reading behavior were rated; miscue analysis, when a reader uses three cueing systems; semantic (meaning), syntactic (structure), and graphophonic (visual) to decode words; fluency analysis, when a reader uses the appropriate rate of speed, reads using appropriate expression and phrasing and attends to punctuation; data analysis, one's ability to analyze and interpret a reader's performance based on observation and assessment of miscue analysis, fluency, and comprehension; inquiry orientation, one's ability to find appropriate information about a reader through reasonable reading assessment technique(s); and intelligent action, the ability to make reasonable instructional decisions directed to reading strategy instruction, not just fixing mistakes.

Elementary education preservice teachers responded to two questions at the end of the clinical practicum: What did I learn about reading instruction and what did I learn about the reading process? What did I know about literacy instruction at the beginning of the clinical practicum and how does this compare to what I know now? 


\section{Summary of Major Findings}

\section{Quantitative Findings}

Hypothesis $H 1$ stated that:

Elementary education preservice teachers who participate in a clinical practicum experience tutoring a low-achieving reader under the direct supervision of a reading expert will significantly increase in their development of reading expertise compared to early childhood preservice teachers who did not participate in a clinical practicum. Specifically, how well are both groups able to assess:

- Miscue analysis: Errors from the three cueing systems; semantic (meaning), syntactic (structure) and graphophonic (visual).

- Fluency: A reader's speed, expression, phrasing, and attention to punctuation.

- Data analysis: Data in order to analyze/interpret a reader's performance based on observation and assessment of miscue analysis, fluency and comprehension.

- Inquiry orientation: Appropriate information about a reader through reasonable reading assessment technique(s).

- Intelligent action: And make reasonable instructional decisions geared to reading strategy instruction, not fixing mistakes.

A multivariate analysis of variance (MANOVA) was conducted on each of the elementary education preservice teachers and early childhood preservice teachers' responses to the pretest and posttest Protocol of Questions by group. There was a significant main effect by group $\mathrm{F}(5,68)=2.52$, $\mathrm{p}<.038$. There was also a significant interaction by group on the pretest and posttest Protocol of Questions in all five areas, $F(5,68)=3.82 f, p<.004$. Since the interaction was significant, each of the five variables, 
miscue analysis, fluency analysis, data analysis, inquiry orientation and intelligent action were tested with a univariate ANOVA.

Hypothesis $H 1$ was supported by three of the five variable ratings, data analysis, inquiry orientation and intelligent action, for the experimental group indicating the clinical practicum had an effect on developing elementary education preservice teachers' reading expertise, as compared to the comparison group of early childhood education preservice teachers who did not make significant gains in reading expertise.

Additionally, within the experimental group, the elementary education preservice teachers' scores increased significantly in all five areas, miscue analysis, fluency analysis, data analysis, inquiry orientation and intelligent action.

After participating in a supervised clinical practicum the elementary education preservice teachers increased their expertise in miscue analysis, fluency analysis, data analysis, inquiry orientation and intelligent action.

For miscue analysis there was no significant interaction of group by time, $\mathrm{p}=0.326$, although there was an observed increase in mean ratings from the pretest to posttest Protocol of Questions for the elementary education preservice teachers for miscue analysis from 1.02 to 1.36 . In order to demonstrate a more expert-like level of expertise in analyzing readers' miscues, the elementary education preservice teachers and early childhood preservice teachers needed to identify the readers' errors from two or three cueing systems, and analyze errors from a meaning-making point of view.

For fluency analysis there was no significant interaction of group by time, $\mathrm{p}=0.074$, although there was an observed increase in mean ratings from the pretest to posttest Protocol of Questions for elementary education preservice teachers for fluency 
analysis from 0.78 to 1.38 . In order to demonstrate a more expert-like level of expertise of fluency analysis, the elementary education preservice teachers and early childhood preservice teachers needed to notice the reader's speed, expression, and attention to punctuation in addition to pointing out a relationship between fluency and comprehension.

For data analysis there was a significant interaction of group by time $\mathrm{p}=0.034$ with a significant increase in mean ratings of 1.08 to 1.52 from the pretest to posttest Protocol or Questions for elementary education preservice teachers for data analysis, but not for the early childhood education preservice teachers, whose mean ratings 1.08 to 0.96 decreased. In order to demonstrate a more expert-like level of expertise in analyzing data about a reader, the elementary education preservice teachers and early childhood preservice teachers needed to interpret facts they observed about the reader (i.e., error analysis, fluency, and meaning making) and connect the facts about the reader with their previous experiences or knowledge base in order to base reading instruction on an informed interpretation of the reader's performance. This indicated the elementary education preservice teachers were able to make more informed decisions about reading instruction based on their knowledge of error analysis, fluency, and comprehension.

For inquiry orientation there was a significant interaction of group by pretest and posttest, $\mathrm{p}=.006$, with a significant increase in mean ratings of 0.76 to1.16 of the elementary education preservice teachers pretest to posttest Protocol of Questions for inquiry orientation, but not for the early childhood education preservice teachers, whose mean ratings, 0.60 to 0.44 decreased. In order to demonstrate a more expert-like level of expertise the elementary education preservice teachers and early childhood preservice 
teachers viewed the facts about each reader from a tentative point of view (not make hasty instructional decisions) through reasonable assessment techniques to make more informed instructional decisions. This indicated the elementary education preservice teachers made more informed and decisive decisions about reading instruction instead of making hasty decisions, which are usually based upon a superficial knowledge of teaching reading. Inquiry orientation includes having knowledge of appropriate reading assessments that would allow a teacher to make more informed decisions about reading instruction.

For intelligent action there was a significant interaction of group by pretest and posttest, $\mathrm{p}=<.001$, with a significant increase in mean ratings of 0.74 to1.44 of the elementary education preservice teachers pretest to posttest Protocol of Questions for intelligent action, but not for the early education preservice teachers, whose mean ratings decreased, 0.75 to 0.64 . In order to demonstrate a more expert-like level of expertise of intelligent action the preservice teachers needed made reasonable instructional decisions about the reader (based on the facts presented in the videos) and decisions about reading instruction for the reader were focused on strategy development.

This indicated the elementary education preservice teachers gained a higher level of reading expertise and understanding of teaching reading to make relevant and knowledgeable decisions on what to do for a student instructionally in order to improve students' reading ability. Intelligent, knowledgeable and informed decisions about relevant reading instruction for low-achieving readers are particularly difficult to make at the undergraduate level. Preservice teachers usually lack experience in teaching reading, 
classroom experience, and they especially lack the understanding of how to teach reading and the knowledge that is required to teach reading.

After tutoring a low-achieving reader in a clinical practicum the preservice teachers learned how to assess a student's reading needs and were mentored through the process of learning how to teach reading by reading experts. Through this process of learning how to teach reading they were able to make knowledgeable and insightful decisions about reading instruction that improved the reading of a low-achieving reader and it also helped them understand the complex process of how to teach reading. Therefore, this suggests that elementary education preservice teachers were able to develop a higher level of reading expertise to teach reading after participating in a supervised clinical practicum.

There were minor increases from the pretest to posttest Protocol of Questions for the comparison group of early childhood elementary preservice teachers' reading expertise on miscue analysis and fluency analysis. The increase in expertise may be that elementary education and early childhood preservice teachers' preparation to teach reading is similar in this respect. Four reading courses are required for both groups of preservice teachers and within those four courses there is an overlap of two courses; language and literacy development and teaching primary literacy. Miscue analysis and fluency analysis are not only discussed in each of those courses but the preservice teachers are required to complete assignments in field, administering assessments in oral reading (miscue analysis, fluency analysis) and developing and teaching reading strategy lessons to small groups students. Additionally they learn how to conduct a running record (Clay, 1987); a miscue analysis of a student's oral reading and how to analyze a 
student's decoding ability. The combination of textbook knowledge, the experience of assessing oral language, and the development of lesson plans to teach selected reading strategies may have contributed to the increase in early childhood education preservice teachers' expertise in miscue analysis and fluency analysis.

There were minor decreases from pretest to posttest for the comparison group on data analysis, inquiry orientation and intelligent action. As noted in a previous discussion, data analysis, inquiry orientation and intelligent action require a higher level of reading expertise and understanding of teaching reading that goes beyond textbook knowledge of teaching reading and the superficial idea of how to teach reading. With regards to course similarities and the increase in expertise in miscue and fluency analysis, conversely, course differences required for early childhood elementary preservice teachers are factors that may have contributed to the decrease in expertise on data analysis, inquiry orientation and intelligent action. One course focuses on children's literature and its role in early childhood classrooms. The early childhood preservice teachers observe an adult and a child or children during a read aloud and analyze when dialogic inquiry takes place as well as reading patterns that scaffold children's development. The other course focuses on a young child's process of constructing meaning through literacy. The early childhood preservice teachers assess a child using running records, dialogic journals, miscue analysis and observations. Both courses require the early childhood preservice teachers to work a case study on a student. Though the early childhood education preservice teachers have textbook knowledge to teach reading and acquire knowledge through field experiences observing and developing a case study of a student, their experiences do not include a supervised clinical practicum where higher levels of reading 
expertise may be developed. Therefore, there was little indication the early childhood education preservice teachers developed expertise in the areas of data analysis, inquiry orientation and intelligent action after having completed four reading courses in their program.

Hypothesis $H 2$ stated:

Elementary education preservice teachers who, at the onset of the clinical practicum are in the low and middle third on the pretest will demonstrate significant gains in their level of development of reading expertise.

A one-way ANOVA with pregrouping was carried out on the five areas of observable reading behaviors; miscue analysis, fluency analysis, data analysis, inquiry orientation and intelligent action. For each variable, pretest scores divided the elementary education preservice teachers into three groups, with approximately one-third of the elementary education preservice teachers in each group. A one-way ANOVA was then carried out on the gain scores to see if the lower and middle groups made significantly higher gains than the upper third group. The elementary education preservice teachers who, at the onset of the clinical practicum were in the low and middle third on the pretest demonstrated an increase in mean gains in their level of development of reading expertise.

For miscue analysis the lower third and middle third groups $(\mathrm{M}=0.76$ and 0.66 respectively) scored significantly higher on the posttest than the upper third group ( $\mathrm{M}=-$ 0.51). The lower and middle third groups, after completing the clinical practicum made significant gains in expertise in noticing errors from the three cueing systems: semantic, syntactic and graphophonemic and were able to analyze them from a meaning-making 
point of view. The elementary education preservice teachers who entered the clinical practicum with a higher level of knowledge of miscue analysis did not make significant gains in expertise of miscue analysis

For fluency analysis the lower third and middle third groups $(\mathrm{M}=1.22$ and 0.83 respectively) scored significantly higher on the posttest than the upper third group (M=0.17). The lower and middle third groups, after completing the clinical practicum made significant gains in expertise in noticing the speed, expression and attention to punctuation in addition to pointing out the relationship between fluency and comprehension and were able to recommend appropriate instruction for fluency. The elementary education preservice teachers who entered the clinical practicum with a higher level of knowledge of fluency analysis did not make significant gains in expertise.

For data analysis the lower third and middle third groups $(\mathrm{M}=0.88$ and 0.50 respectively) scored significantly higher on the posttest than the upper third group (M=0.09). The lower third and middle third groups, after completing the clinical practicum made significant gains in expertise; they were able to analyze and interpret facts such as error analysis, fluency and meaning-making to make a more informed explanation about reading instruction. The elementary preservice teachers who entered the clinical practicum with a higher level of knowledge of data analysis did not make significant gains in expertise.

The lower third and middle third groups ( $\mathrm{M}=0.53$ and 0.60 respectively) scored significantly higher on the posttest than the upper third group $(\mathrm{M}=-0.09)$. The lower third and middle third groups after participating in a clinical practicum made significant gains in expertise in making more knowledgeable and informed decisions about instruction 
rather than making hasty decisions based on superficial knowledge. The elementary education preservice teachers who entered the clinical practicum with a higher level of knowledge of inquiry orientation did not make significant gains in expertise.

The lower third and middle third groups $(M=0.79$ and 0.99 respectively) scored significantly higher on the posttest than the upper third group $(\mathrm{M}=-0.42)$. The lower third and middle third groups after participating in a clinical practicum made significant gains in expertise in making two or three reasonable instructional decisions that are geared to strategy development, not fixing mistakes. The elementary education preservice teachers who entered the clinical practicum with a higher level of knowledge of intelligent action did not make significant gains in expertise.

According to the statistical analysis, the low and middle third groups made significant gains in their level of reading expertise from pre to posttest. The interpretation of the gain scores may be confounded due to the regression effect. Results of the statistical analysis, (a one-way ANOVA) were aligned with what is known about statistical regression, i.e., the tendency of preservice teachers who score lowest on a pretest to score higher on a posttest and preservice teachers who score highest on a pretest to score lower on a posttest. The preservice teachers whose entry level of reading expertise was high at the onset of the clinical practicum did not display gain scores. This may be attributed to the possibility that they may have had prior experiences teaching reading to students outside of the university setting. 
Hypothesis $H 3$ stated:

Elementary education preservice teachers who participated in a clinical practicum experience tutoring a low-achieving a low-achieving diverse student under the direct supervision of a reading expert in their undergraduate teacher preparation will perceive they have acquired the expertise to teach reading.

Three themes were identified from the qualitative analysis: (a) Self-Efficacy to Teach Reading; (b) Preservice Teachers' Perceptions of Acquiring Reading Expertise; and (c) Preservice Teachers Gained Insight: Their Knowledge of Teaching Reading Impacted Student Achievement. Each theme provided information to support what was found in the review of the literature (Bandura, 1977; Kennedy, 1998; Lortie, 1975; Munby, Russell, \& Martin, 2001; Shaw \& Dvorak, 2007) regarding the reading preparation of elementary education classroom teachers. Additionally, according to Kennedy, (1998) preservice teacher preparation is the ideal place to change preservice teachers' misconceptions; their initial frames of reference about teaching reading, since it is between their experiences as students in classrooms and their future experiences as teachers. This is supported by the elementary education preservice teachers' participation in a supervised clinical practicum. The clinical practicum allowed them to understand teaching reading in ways different from what they learned from their own experiences, thus it enabled them to see the teaching of reading from a more focused and informed point of view.

The elementary education preservice teachers were able to experience first-hand that teaching reading was not as easy as they thought it was. Through their own process of learning to teach a low-achieving student to read, they realized that the process of 
teaching reading was complex, and required practice and experience in order to teach reading knowledgably. Most important, what they learned about teaching reading from previous reading classes and the on-going learning in clinical practicum was applied and practiced by tutoring a low-achieving student in reading. The elementary education preservice teachers believed they acquired the attributes of teaching reading that were needed to become a better, more informed teacher of reading.

Finally, the elementary education preservice teachers gained an understanding that teaching reading was not something that could be learned by reading about it in a textbook or what they previously thought about how reading was taught. The connection to what they learned about teaching reading from textbooks and prior reading courses to the application and experience of how to teach reading was essential.

\section{Limitations}

The participants in the study were 84 elementary education preservice teachers and 26 early childhood preservice teachers. Twenty-two elementary education preservice teachers' pretest or posttests were discarded because they were incomplete. Fourteen early childhood preservice teachers' pretest or posttest were discarded because they were incomplete or absent the day of the pretest or posttest. This diminished the total number of participants in the study; 62 elementary education preservice teachers and 12 early childhood preservice teachers for quantitative analysis. The number of elementary education preservice teachers whose reflections were included in the qualitative analysis was 46.

The elementary education preservice teachers whose entry level of reading expertise was high at the onset of the clinical practicum did not display gain scores. This 
might be attributed to prior experiences teaching reading outside the university setting. Many preservice teachers may substitute teach or are employed as paraprofessionals where they would have access to reading programs and gain experience teaching reading using those reading programs. This may account for their higher level of reading expertise. However, data regarding prior experiences teaching reading was not collected or documented and is a limitation of the study.

This study extended the work of Smith (2005) and in his study he interviewed each of five participants and asked probing questions to acquire more insight into their responses. Since there were considerably more participants in the current study, and they observed six videos, the elementary education and early childhood preservice teachers were to write their answers on the Protocol of Questions. Since the responses were written there was no opportunity to ask probing questions which may have enabled the researcher to gain more insightful information; responses were limited to what was written.

\section{Conclusions}

The purpose of this study sought to (a) measure the development of elementary education preservice teachers' reading expertise through the use of video cases after participating in a supervised clinical practicum, and results of the elementary education preservice teachers were compared to those of the early childhood preservice teachers who did not participate in a clinical practicum; (b) determine if there was a differentiated effect of a supervised clinical practicum based on the level of expertise elementary education preservice teachers had at the beginning the practicum; and, (c) examine 
elementary education preservice teachers' perceptions after participating in a clinical practicum to determine if they perceived they acquired the expertise to teach reading. Hypothesis $H 1$ stated that:

Elementary education preservice teachers who participate in a clinical practicum experience tutoring a low-achieving reader under the direct supervision of a reading expert will significantly increase in their development of reading expertise compared to early childhood preservice teachers who did not participate in a clinical practicum.

Independent of the early childhood preservice teachers, elementary education preservice teachers, after participating in a clinical practicum made significant gains in all five areas; miscue analysis, fluency analysis, data analysis, inquiry orientation, and intelligent action. In relation to the early childhood preservice teachers, the elementary education preservice teachers made significant gains in three areas; data analysis, inquiry orientation, and intelligent action. This indicates the clinical practicum was a major factor in developing reading expertise in elementary education preservice teachers. The supervised clinical practicum reflects a type of apprenticeship termed cognitive apprenticeship (Collins, Brown \& Newman, 1989) and is aligned with two aspects of teaching and learning: (a) looking at the process that expert teachers use to handle complex tasks; and, (b) learning through guided experiences in which cognitive and metacognitive processes are explored and utilized.

A cognitive apprenticeship suggests field experiences that focus on cognitive and metacognitive processes in learning, scaffolding by an expert mentor, purposeful task selection, increasing complexity of tasks, and experiences that are contextually based in 
diverse classroom settings (Keehn et al., 2001). This framework was paralleled in the clinical practicum; the elementary education preservice teachers gained knowledge about teaching reading, were mentored and given feedback from reading experts, tasks selected for the students were based on assessment, throughout the tutoring the preservice teachers added phonics, phonemic awareness and fluency strategies were added to their repertoire, and this was accomplished in the context of an elementary school.

Expertise to teach reading develops over time and may be developed within specific domains. It was suggested in the review of the literature that the development of expertise can be developed in teacher education (Hammerness et al., 2005) however, until the current study; the development of reading expertise has not been measured to see whether or not preservice teachers are developing the expertise that is needed to teach reading in their teacher preparation program.

Typically, elementary education preservice teachers would not be expected to gain the level of expertise they achieved in this study's teacher preparation program without having had the experience of learning how to teach reading. The results of this study support that reading expertise can be developed in preservice teachers prior to student teaching and was achieved through a supervised clinical practicum which included one-on-one tutoring of a low-achieving student in the context of an elementary school.

Hypothesis $H 2$ stated:

Elementary education preservice teachers who, at the onset of the clinical practicum are in the low and middle third on the pretest will demonstrate significant gains in their level of development of reading expertise. 
Findings revealed that the elementary education preservice teachers who, at the onset of the clinical practicum were in the low and middle third groups, based on the pretest Protocol of Questions, demonstrated an increase in mean gains in their level of reading expertise after participating in the clinical practicum. This is important since some preservice teachers entered the practicum with a lower level of expertise; if they did not have the benefit of a supervised clinical practicum they may not have gained the reading expertise to learn how to teach reading. The participation in a clinical practicum is aligned with the way people learn when supported within their "zone of proximal development" (Vygotsky, 1978) the elementary education preservice teachers learned how to teach reading through the support of reading experts; within their "zone of proximal development" (Vygotsky, 1978).

Learning to teach reading is a developmental process. The process in learning how to teach reading usually begins in preservice teacher preparation. Since there is little time allocated to develop this process, it is important to look at the ways in which preservice teachers are prepared to teach reading effectively, and in particular, to those preservice teachers who are in the low and middle groups to ensure they develop the expertise to teach reading. It is equally as important to determine if this developmental process of learning to teach reading actually takes place. Supervised experiences such as a clinical practicum may be one way in which preservice teachers have the opportunity to begin the process of learning how to teach reading. Providing supervised experiences that are situated in settings that reflect the challenges of diverse populations and lowachieving readers allow preservice teachers to understand the wide range of students that will be in the classrooms they will be teaching. 
The elementary education preservice teachers whose entry level of expertise was in the low and middle third may not have made gains in expertise without the benefit of the clinical practicum. Their frames of reference, a superficial knowledge of teaching reading, and the misconceptions they may have had about teaching reading quite possibly would have remained unchanged. Participation in a supervised clinical practicum, learning the process of teaching reading, having the support of a reading expert, the elementary education preservice teachers who were in the low and middle groups made significant gains in their level of reading expertise, and without this support they may not have begun to learn how to teach reading effectively.

Hypothesis $H 3$ stated:

Elementary education preservice teachers who participated in a clinical practicum experience tutoring a low-achieving a low-achieving diverse student under the direct supervision of a reading expert in their undergraduate teacher preparation will perceive they have acquired the expertise to teach reading.

At the beginning of the clinical practicum many preservice teachers expressed their beliefs about teaching reading were more aligned to what they as students knew about teaching reading and some thought they actually knew how to teach reading as a result of their observations in field classes, or experiences they may have had outside their college experience. As the clinical practicum progressed it became clear to most preservice teachers that they did not know as much about teaching reading as they thought.

As part of the practicum they learned how to teach reading to a low-achieving student through the use of assessment techniques and appropriate reading instruction. In 
particular, at the onset of the practicum and through the use of the assessments they learned that all students are not at the same reading level as their grade placement. They continued to learn about the theory and methodologies of teaching reading during the class lectures. Throughout this process the elementary education preservice teachers were able to consult with the reading experts on concerns they had about their student, and the appropriateness of reading strategies and materials. The preservice teachers were frequently observed by the reading experts during their tutoring sessions and they received feedback on the delivery of their lessons, the rapport they had with the student, and the appropriate use of materials and preparedness for tutoring. The feedback they received was applied to each consecutive tutoring session. The preservice teachers began to see first-hand the result of their applied knowledge of teaching reading to the student's learning.

At the end of the practicum most of the elementary preservice teachers perceived they acquired the expertise needed to teach reading and realized that reading was not taught in ways they initially thought. They expressed feelings of confidence in their ability to teach reading and felt they were better prepared to teach reading. Participation in the clinical practicum not only contributed to their knowledge of how to teach reading but also contributed to their perceptions that they acquired the expertise to teach reading effectively.

\section{Implications}

The purpose of the study was to examine the development of reading expertise to teach reading through a supervised clinical practicum. The preservice teachers who entered the clinical practicum with a high level of reading expertise may not need as 
much support to learn how to teach reading. However, without the support of an undergraduate teacher preparation program which includes a supervised clinical practicum, the low and middle groups of preservice teachers would enter the teaching profession less prepared to teach reading well, and, without a firm foundation to build on may never improve. As discussed in the review of the literature, preservice teachers who have no other frame of reference to teach reading would be inclined to teach reading in ways in which they were taught (Lortie, 1975), or, when they begin teaching would rely solely on reading curriculum materials mandated by a school system instead of having their own knowledge and ideas about teaching reading. It is imperative to include a supervised clinical practicum in undergraduate teacher preparation for those low and middle groups of preservice teachers to obtain the highest level of reading expertise possible in order to be effective teachers of reading. Developing reading expertise at this critical point means they are going to be able to have a positive impact on the reading achievement of the children they encounter throughout their teaching career.

Participation in a clinical practicum had an effect on elementary education preservice teachers' development of reading expertise. The early childhood education preservice teachers had similar experiences in their undergraduate preparation program to learn how to teach reading. However, there were differences in their preparation and those differences may be related to the absence of a supervised clinical practicum since there was little evidence of early childhood preservice teachers' increase in reading expertise. An important implication from this study may be the inclusion of a clinical practicum for early childhood preservice teachers. 
Undergraduate reading courses provide elementary education and early childhood preservice teachers with theory and field experiences, however, the field experiences are frequently not supervised by reading experts on-site. Therefore, a clinical practicum which includes a one-on-one tutoring component supervised by a reading expert on-site seems to be significant in developing the reading expertise needed to teach reading.

The elementary education preservice teachers realized at the end of the clinical practicum that their knowledge of learning how to teach reading impacted the reading achievement of the students they tutored. This is an important implication for the preparation of "high quality" teachers that is needed to teach all children to read. Based on the current study, the probability is very high that all preservice teachers who will be classroom teachers of reading would benefit from a supervised clinical practicum such as the one in this study, thus helping to fulfill the No Child Left Behind Act of 2001 (2002) requirement of "high quality" teachers in order to reach the goal of all children reading proficiently by 2013-2014.

In the past, preservice teacher education programs have been criticized as being overly theoretical, with little connection to practice; courses were fragmented and there was a lack of a clear conception of teaching. Frequently programs offer unrelated courses without the concept of teaching and learning, and this does not affect practice among new teachers (Zeichner \& Gore, 1990). More recent research suggest that field experiences linked with actual course methods are beneficial to preservice learning about teaching reading (Bollin, 1996; Danielson, Kuhlman \& Fluckiger, 1998; DarlingHammond, 1998; Fang \& Ashley, 2004), however, the field experiences and courses discussed in that research varied in content and methods. The clinical practicum that the 
elementary education preservice teachers participated in had many elements of a carefully constructed program, i. e., theory, methodology, experience, and mentoring, to help them develop reading expertise to teach reading. Therefore, the results of the current study and the nature of this supervised clinical practicum may be of interest to other colleges and universities who wish to provide preservice teachers with the kinds of clinical learning experiences that contribute to the development of reading expertise.

In summary, in this study, elementary education preservice teachers' development of reading expertise was measured and compared to early childhood preservice teachers' development of reading expertise. The result of the integration of quantitative and qualitative methodologies provided insights into elementary education preservice teachers' processes of developing expertise to teach reading. The application of this kind of supervised clinical practicum seems to be promising as a way to develop preservice teachers' understanding, knowledge and expertise to teach reading, and to ultimately have a positive impact on the reading achievement of the students they will be teaching. 


\section{LIST OF REFERENCES}

Allington, R. (2002). What I've learned about effective teaching instruction from a decade of studying exemplary elementary classroom teachers. Phi Delta Kappan, $83(10), 740-747$.

Allington, R., Guice, S. Michaelson, N., Baker, K., \& Li, S. (1996). Literature-Based Curriculum in High-Poverty Schools. In M. Graves, P. V D. Broek, \& B. Taylor (Eds.), The first R: Every child's right to read (pp.73-96). New York: Teachers College Press.

Allington, R. \& McGill-Franzen, A. (2000). Looking back, looking forward: A conversation about teaching reading in the $21^{\text {st }}$ century. Reading Research Quarterly, 35(1), 136-153.

Anders, P., Hoffman, J., \& Duffy, G. (2000). Teaching teachers to teach reading: Paradigm shifts, persistent problems, and challenges. In M. Kamil, P. Mosenthal, P. D. Pearson \& R. Barr (Eds.), Handbook of reading research: Vol 3 (pp. 721744). Mahwah, NJ: Lawrence Erlbaum.

Andrew, M. D. (1990). Differences between graduates of 4-year and 5-year teacher preparation programs. Journal of Teacher Education, 41(2), 45-51.

Au, K. H. (1980). Participation structures in a reading lesson with Hawaiian children: Analysis of a culturally appropriate instructional event. Anthropology and Education Quarterly, 1(2), 91 - 115.

Austin, M. C., \& Morrison, C. (1962). The torch lighters: Tomorrow's teachers of Reading. Cambridge, MA: Harvard University Press.

Ball, D. L., \& Cohen, D. K. (1999). Developing practice, developing practitioners: Toward a practice-based theory of professional education. In L. DarlingHammond and G. Sykes (Eds.), Teaching as the learning profession: Handbook of policy and practice. (pp. 3 - 32). San Francisco, CA: Jossey-Bass.

Bandura, A. (1977). Self-efficacy: Toward a unifying theory of behavioral change. Psychological Review, 84, $191-215$.

Bandura, A. (1989). Social cognitive theory. In R. Vasta (Ed.), Annals of child development. Vol. 6. Six theories of child development (pp. 1 -60). Greenwich, CT: JAI Press. 
Banks, J., Cochran-Smith, M., Moll, L., Richert, A., Zeichner, K., LePage, P., DarlingHammond, L., Duffy, H, \& McDonald. (2005). In L. Darling-Hammond \& J. Bransford (Eds.), Preparing teachers for a changing world: What teachers should learn and be able to do. (pp. 390 - 441). San Francisco, CA: JosseyBass.

Banton Smith, N. (2002). American reading instruction. Newark, DE: International Reading Association.

Barone, D., \& Morrell, E. (2007). Multiple perspectives on preparing teachers to teach reading. Reading Research Quarterly, 42(1), 167-180.

Baumann, J. F., Hoffman, J. V., Moon, J., \& Duffy-Hester, A. (1998). Where are teachers' voices in the phonics/whole language debate: Results from a survey of U. S. elementary teachers. The Reading Teacher, $50,636-651$.

Baumann, J. F., Hoffman, J. V., Duffy-Hester, A. M. \& Ro, J. M. (2000). The first R yesterday and today: U. S. elementary reading instruction practices reported by teachers and administrators. Reading Research Quarterly, 35(3), 338-377

Baumann, J. F., Moon, J.R., Duffy-Hester, A. M., \& Hoffman, J. V. (2000). Then and now: Perspectives on the status of elementary reading instruction by prominent reading educators. Reading Research and Instruction, 39(3), 236 - 264.

Baumgartner, F., Koerner, M., \& Rust, F. (2002). Exploring roles in student teacher placements. Teacher Education Quarterly, 29, 35-58.

Berliner, D. C. (1986). In pursuit of the expert pedagogue. Educational Researcher, 15(7), 5-13.

Berliner, D. C. (1994). Expertise: The wonder of exemplary performances. In J. Mangieri \& C. C. Block (Eds.), Creating powerful thinking in teachers and students: Diverse perspectives (pp. 161 - 186). Fort Worth, TX: Harcourt Brace College Publishers.

Berliner, D. C. (2001). Learning about and learning from expert teachers. International Journal of Educational Research, 35(5), 463-483

Block, C. C., Joyner, J., Joy, J., \& Gaines, P. (2001). Process-based comprehension: Four educators' perspectives. In C. C. Block, \& M. Presley (Eds.), Researchbased comprehension practices (pp. 119-134). New York: Guilford.

Block, C. C., \& Mangieri, J. N. (1996). Reason to read: Thinking strategies for life through literature. Boston, MA: Pearson. 
Block, C. C., Oakar, M., \& Hurt, N. (2002). The expertise of literacy teacher: A continuum from preschool to grade 5. Reading Research Quarterly, 37(2), 178 206.

Bollin, G. (1996).Using multicultural tutoring to prepare preservice teachers for diverse classrooms. The Educational Forum, 61, 68 - 76.

Borko, H., \& Shavelson, R. J. (1990). Teachers' decision making. In B. Jones and L. Idols (Eds.), Dimensions of thinking and cognitive instruction. Hillsdale, NJ: Erlbaum.

Bransford, J., Darling-Hammond, L, \& LePage, P. (2005). Introduction. In L. DarlingHammond \& J. Bransford (Eds.) Preparing teachers for a changing world (pp. 139). San Francisco, CA: Jossey-Bass.

Bransford, J., Derry, Berliner, Hammerness, \& Beckett. (2005). Theories of learning and their roles in teaching. In L. Darling-Hammond \& J. Bransford (Eds.) Preparing teachers for a changing world (pp. 40 - 87). San Francisco, CA: Jossey-Bass.

Britzman, D. (1991). Practice makes practice. Albany: State University of New York Press.

Brown, J. S., Collins, A., \& Duguid, P. (1989). Situated cognition and culture of learning. Educational Researchers, 18, $32-42$.

Carter, K., Cushing, K., Sabers, D., Stein, P. \& Berliner, D. (1998). Expert-novice differences perceiving and processing visual classroom information. Journal Of Teacher Education, 39(3), 25-31.

Clay, M. M. (1985). The early detection of reading difficulties, $3^{\text {rd }}$ Ed. Portsmouth, NH: Heinemann.

Clay, M. M. (1992). Reading recovery: A guidebook for teachers in training. Portsmouth NH: Heinemann.

Cobb, J. (2000). The effects of an early intervention program with preservice teachers as tutors on the reading achievement of primary grade at risk children. Reading Horizons, 41(3), 155 - 173.

Cochran-Smith, M. (2000). The future of teacher education: Framing the questions that matter. Teaching Education, 11(1), 13-24. 
Cochran-Smith, M, \& Lytle, S. (1999). Relationships of knowledge and practice: teacher learning in communities. In A. Iran-Nejad \& P. D. Pearson (Eds.), Review of research in education, 24, (pp. 249 - 305). Washington, DC: American Educational Research Association.

Collins, A. Brown, J. S., \& Newman, S. E. (1989). Cognitive apprenticeship: Teaching the craft of reading, writing, and mathematics. In L B. Resnick (Ed.), Knowing, learning, and instruction: Essays in honor of Robert Glaser (pp. 453 -494). Mahwah, NJ: Erlbaum.

Danielson, K. E., Kuhlman, W., \& Fluckiger, J. (1998). Benefits of literacy field experiences: Three views. Reading Horizons, 39(1), 33 - 47.

Darling-Hammond, L. (1990). "Teacher professionalism: What and how." In A. Lieberman (ed.), Schools as collaborative cultures: Creating the future now. Washington DC: Falmer Press.

Darling-Hammond, L. (1997). What matters most: Teaching for America's future. New York: National Commission on Teaching and America's Future

Darling-Hammond, L. (1998). Teacher learning that supports student learning. Educational Leadership, 55(5), 1-8.

Darling-Hammond, L. (1999). Teacher quality and student achievement: A review of state policy evidence. Seattle, WA: Center for the Study of Teaching and Policy.

Darling-Hammond, L. (2000). Studies of excellence in teacher education: Preparation in the undergraduate years. Washington, DC: American Association of Colleges For Teacher Education.

Darling-Hammond, L. \& Cobb, V. (1996). The changing context of teacher education. In L. Darling-Hammond \& G. Sykes (Eds.), Teaching as the learning profession: Handbook of policy and practice. (pp. 14 - 59). San Francisco, CA: JosseyBass.

Darling-Hammond L., Hammerness, K., Grossman, P., Rust, F., \& Shulman, L. (2005). The design of teacher education programs. In L. Darling-Hammond \& J. Bransford (Eds.), Preparing teachers for a changing world: What teachers should learn and be able to do. (pp. 390 - 441). San Francisco, CA: JosseyBass. 
Darling-Hammond L., \& MacDonald, M. (2000). Where there is learning there is Hope: The preparation of teachers at the Bank Street College of Education. In L. Darling-Hammond (Ed.), Studies of excellence in teacher education: Preparation at the graduate level (pp. 1 -95). Washington, DC: American Association of Colleges for Teacher Education.

Darling-Hammond, L., \& McLaughlin. (1999). Investing in teaching as a learning profession. In L. Darling-Hammond \& G. Sykes (Eds.), Teaching as the learning profession: Handbook of policy and practice. (pp. $376-411)$. San Francisco, CA: Jossey-Bass.

Darling-Hammond L., Pacheco, A., Michelli, N., LePage, P., Hammerness, K., \& Youngs, P.(2005). Implementing curriculum renewal in teacher education: Managing organizational and policy change. In L. Darling-Hammond \& J. Bransford (Eds.), Preparing teachers for a changing world: What teachers should learn and be able to do. (pp. 440 - 479). San Francisco, CA: JosseyBass.

Deford, D. E. (1985). Validating the construct of theoretical orientation in reading instruction. Reading Research Quarterly, 20(3), 351-357

Denton, J. J.(1982). Early field experience influence on performance in subsequent coursework. Journal of Teacher Education, 33(2), 19-23.

DeVries, B. A. (2004). Literacy assessment and intervention for the elementary classroom. Scottsdale, AZ: Holcomb Hathaway Publishers.

Dewey, J. (1933). How we think. New York: Collier.

Donovan, M. S., Bransford, J. D., \& Pellegrino, J. W. (1999). How people learn: Bridging research and practice. Washington, DC: National Academies Press.

Duffy, A. M.. \& Atkinson, T. S. (2001). Learning to teach struggling (and nonstruggling) elementary school readers: An analysis of preservice teachers' knowledge. Reading Research and Instruction, 41(1), 83 - 102.

Ehri, L. C. \& Williams, J. (1996). Learning to read and learning to teach reading. In F. Murray (Ed.), The teacher educator's handbook. (pp. 231 -243). San Francisco, CA: Jossey-Bass

Fang, Z., \& Ashley, C. (2004). Preservice teachers' interpretations of a field-based reading block. Journal of Teacher Education, 55(1), 39 - 55. 
Feiman-Nemser, S. (1983). Learning to teach. In L. S. Shulman and G. Sykes (Eds.), Handbook of teaching a policy (pp. 150-171). New York: Longman.

Feiman-Nemser, S. (1990). Teacher preparation: Structural and conceptual analysis. In W. R. Houston, M. Haberman, and J. P. Sikula (Eds), Handbook of research on teacher education (pp. 212-233). New York: Macmillan.

Floden, R. E., McDiarmid, G. W., \& Werners, N. (1989). What are they trying to do? Perspectives on teacher educators' purposes. East Lansing, MI: National Center for Research on Teacher Education, Michigan State University.

Goodlad, J. I., Soder, R., \& Sirotnik, K. A. (1990). Places where teachers are taught. San Francisco,CA: Jossey-Bass.

Grossman, P. L., Smagorinsky, P., \& Valencia, S. (1999). Appropriating tools for teaching English: A theoretical framework for research on learning to teach. American Journal of Education, 108(1), 1-29.

Hammerness, K., Darling-Hammond, L., Bransford, J., Berliner, D., Cochran-Smith, M., McDonald, M., \& Zeichner. (2005). In L. Darling-Hammond \& J. Bransford (Eds.), Preparing teachers for a changing world: What teachers should learn and be able to do. (pp. 390 - 441). San Francisco,CA: Jossey-Bass.

Harmon, J., Hedrick, W., Martinez, M., Perez, B., Keehn, S., Fine, J. C., Eldridge, D., Flint, A. S., Littleton, D. M., Bryant-Shanklin, M., Loven, R., Assaf, L., \& Sailors, M. (2001). Features of excellence of reading teacher preparation programs. In J. V. Hoffman, D. L. Schallert, C. M. Fairbanks, J. Worthy, \& B. Maloch (Eds.), Fiftieth yearbook of the National Reading Conference (pp. 262274). Chicago: National Reading Conference.

Harris, A., and Sipay, E. (1990). How to increase reading ability. White Plains, NY: Longman.

Harris, T. L. and Hodges, R. E. (1995). The literacy dictionary: The vocabulary of reading and writing. Newark, DE: International Reading Association

Hatano, G., \& Inagaki, K. (1986). Two courses of expertise. In H. Stevenson, H. Azuma, and K. Hakuta (Eds.) Child development and education in Japan (pp. 262-272). New York: Freeman.

Heath, S. B. (1983). Ways with words: Language, life, and work in communities and classrooms. Cambridge, UK: Cambridge University Press.

Hedrick, W. B. (1999). Preservice teachers tutoring $3^{\text {rd }}, 4^{\text {th }}$, and $5^{\text {th }}$ graders one-on-one within the school setting. Reading Research and Instruction, 38(3), $211-219$. 
Hedrick, W. B., McGee, P. A., \& Mittag, K. (2000). Preservice teacher learning through one-on-one tutoring: Reporting perceptions through email. Teaching and Teacher Education, 16(1), 47-63.

Henry, M. (1983). The effect of increased exploratory field experiences upon the perceptions and performance of student teachers. Action in Teacher Education, $5(1-2), 66-70$.

Hoffman, J. V. (2004). Achieving the goal of a quality teacher of reading for every classroom: Divest, test, or invest? Reading Research Quarterly, 39, 119 - 128.

Hoffman, J. V., McCarthey, S. J. \& Elliot, B. (1998). The literature-based basals in first-grade classrooms: Savior, satan, or same-old, same-old? Reading Research Quarterly. 33(2), 168-197.

Hoffman, J. V., Roller, C. M., Maloch, B., Sailors, M., \& Beretvas, N., and the National Commission on Excellence in Elementary Teacher Preparation for Reading Instruction. (2003). Prepared to make a difference: Final report of the National Commission on Excellence in elementary Teacher Preparation for Reading Instruction. Newark, DE: The International Reading Association.

Hoffman, J. V., Roller, C., Maloch, B., Sailors, M., Duffy, G., \& Beretvas, S. N. (2005) Teachers' preparation to teach reading and their experiences and practices in the first three years of teaching. The Elementary School Journal, 105(3) 267-287.

Hoffman, J. V., Roller, C., \& National Commission on Excellence in elementary Teacher Preparation for Reading Instruction. (2001). The IRA Excellence in Reading Teacher Preparation Commission's Report: Current practices in reading teacher Education at the undergraduate level in the United States. In C. Roller (Ed.), Learning to teach reading: Setting the research agenda (pp. $32-79$ ). Newark, DE: International Reading Association.

Howey, K. R., \& Zimpher, N. L. (1989). Profiles of preservice teacher education: Inquiry into the nature of programs. Albany: State University of New York Press.

Hughes, J. E., Packard, B. W., \& Pearson, P. D. (1997). Reading classroom explorer: Visiting classrooms via hypermedia. In C. K. Kinzer, K. A. Hinchman, \& D. J. Leu (Eds.), Inquiries in literacy theory and practice, 46, pp. $494-506$.

Chicago: IL: National Reading Conference.

Hughes, J. E., Packard, B.W., \& Pearson, P. D. (2000). Pre-service teachers' experiences using hypermedia and video to learn about literacy instruction. Retrieved from http://www.ciera.org/library/archive/2000-06/art-online-0006.html 
International Reading Association (2001). Features of early field experiences at sites of excellence in reading teacher education programs. Newark, DE: Author.

International Reading Association (2003). Prepared to Make a Difference: The Report of the National Commission on Excellence in elementary Teacher Preparation for Reading Instruction. Newark, DE: Author.

Johns, J. L. (2005). Basic reading inventory: Pre-primer through grade twelve \& early literacy assessment. $\left(9^{\text {th }}\right.$ ed). Dubuque, IA: Kendall Hunt.

Johnson, D., \& Tschannen-Moran, M. (2003). Teachers' sense of efficacy for literacy instruction scale: The development of a new instrument. Paper presented at the National Reading Conference, Scottsdale, AZ.

Joyce, B., \& Showers, B. (2002). Student achievement through staff development ( $3^{\text {rd }}$ ed). Alexandria, VA: Association for Supervision and Curriculum Development.

Juel, C. (1996). What makes literacy tutoring effective? Reading Research Quarterly, $31,268-289$

Keehn, S., Harmon, J., Hedrick, W., Martinez, M., \& Perez, B. (2001). A study of the impact of a reading-specialization program on first-year teachers. In J. V. Hoffman, D. L. Schallert, C. M. Fairbanks, J. Worthy, and B. Maloch (Eds.), Fiftieth Yearbook of the National Reading Conference (pp. 323-332) Chicago: National Reading Conference

Kennedy, M. (1999). The role of preservice teacher education. In L. Darling-Hammond and G. Sykes (Eds.). Teaching as a learning profession: Handbook of policy and practice (pp. 54 - 85). San Francisco, CA: Jossey Bass

Koppich, J. (2000). Trinity University: Preparing teachers for tomorrow's schools. In L. Darling-Hammond (Ed.), Studies of excellence in teacher education: Preparation in a five-year program (pp. 1-48). Washington, DC: American Association of Colleges for Teacher Education.

Lampert, M., \& Ball, D. L. (1998). Teaching, multimedia, and mathematics: Investigations of real practice. New York: Teachers College Press.

Landis, J. F. \& Koch, G. G. (1977). The measurement of observer agreement for categorical data. Biometrics, 33, (pp. 159-174).

Lee, C. D. (1993). Signifying as a scaffold for literacy interpretation: The pedagogical implications of an African American discourse genre. Urbana, IL: National Council of Teachers of English. 
Lefever-Davis, S. (2002). The preparation of tomorrow's reading teachers. The Reading Teacher, 56(2), 196-197.

Leinhardt, G., \& Greeno, J. (1986). The cognitive skill of teaching. Journal of Educational Psychology, 78(2), 75-95.

Lemlech, J., \& Kaplan, S. (1990). Learning to talk about teaching: Collegiality in Clinical teacher education. Action in Teacher Education, 12, 13 - 19.

Linek, W. M., Sampson, M. B., Raine, I. L., Klakamp, K. \& Smith, B. (2006). Development of literacy beliefs and practices: Preservice teachers with reading specializations in a field-based program. Reading Horizons, 46(3), 183-210.

Lortie, D. (1975). Schoolteacher: A sociological study. Chicago: University of Chicago Press.

Maloch, B., Fine, J., \& Flint, A. S. (2003). "I feel like I'm ready": Exploring the influence of quality teacher preparation on beginning teachers. The Reading Teacher, 56(4), 348-350.

Maloch, B., Flint, A., Eldridge, D., Harmon, J., Loven, R., Fine, J., Bryant-Shanklin, M., \& Martinez, M. (2003). Understandings, beliefs, and reported decision making of first-year teachers from different teacher preparation programs. Elementary School Journal, 103, 431-458.

McGill-Franzen, A. (2001). Policy and instruction: What is the relationship? In M. Kamil, P. Mosenthal, P. D. Pearson \& R. Barr (Eds.), Handbook of reading research: Vol 3 (pp. 721-744). Mahwah, NJ: Lawrence Erlbaum.

McLaughlin, M. (2003). Guided comprehension in the primary grades. Newark, DE: International Reading Association.

Merriam, S. B. (1988). Case study research in education: A qualitative approach. San Francisco, CA: Jossey-Bass.

Merseth, K. K., \& Koppich, J. (2000). Teacher education at the University of Virginia: A study of English and mathematics preparation. In L. Darling-Hammond (Ed.), Studies of excellence in teacher education: Preparation in a five-year program (pp. 49-81). Washington, DC: American Association of Colleges for Teacher Education Publications.

Miles, M. B., \& Huberman, A. M. (1994). An expanded sourcebook: Qualitative data analysis $\left(2^{\text {nd }}\right.$ ed.). Thousand Oaks, CA: Sage Publications. 
Miller, L., \& Silvernail, D. L. (2000). Learning to become a teacher: The Wheelock Way. In L. Darling-Hammond (Ed.), Studies of excellence in teacher education Preparation in the undergraduate years (pp. 67 -107). Washington, DC: American Association of Colleges for Teacher Education Publications.

Morrison, C., \& Austin, M. C. (1977). The torch lighters revisited. Newark DE: International Reading Association.

Munby, H., Russell, T., \& Martin, A.K. (2001). Teachers' knowledge and how it develops. In V. Richardson (Ed.), Handbook of research on teaching ( $4^{\text {th }}$ ed., pp. $\left.877-905\right)$. Washington, DC: American Educational Research Association.

National Association of State Directors of Teacher Education. (1996).The 1996-1997 NASDTEC Manual on Certification and Preparation of Educational Personnel In the United States and Canada. T. E. Andrews, L. Andrews, \& C. Pape, (Eds.). Dubuque, IA: Kendall Hunt

National Commission of Excellence in Education (1983). A nation at risk: The imperative for educational reform. Washington, DC: U. S. Government Printing Office

National Center for Education Statistics (2008a). Participation in Education. Indicator5 Racial/ethnic distribution of public school students. Washington, DC: U. S. Department of Education.

National Center for Education Statistics (2008b). Participation in Education. Indicator7 Language minority school-age children. Washington, DC: U. S. Department of Education.

National Reading Panel. (2000). Report of the National Reading Panel: Teaching children to read: An evidence-based assessment of the scientific research literature on reading and its implications for reading instruction. Washington, DC: National Institute of Child Health and Human Development. Retrieved from www.nichd.nih.gov/publications/nrp

National Research Council (2000). How people learn: Brain, mind, experience, and school (Expanded ed.). Washington, DC: National Academies Press.

No Child Left Behind Act of 2001, Pub. L. No. 107-110 § 115, Stat. 1425 (2002).

Pinnell, G., Lyons, E., Deford, D., Bryk, A., \& Selzer, M. (1994). Comparing instructional models for the literacy education of high-risk first graders. Reading Research Quarterly, 29, 9-39. 
Richardson, V., \& Placier, P. (2001). Teacher change. In V. Richardson (Ed.), Handbook of research on teaching ( $4^{\text {th }}$ ed., pp. 905-947). Washington, DC: American Educational Research Association.

Risko, V. J., Roskos, K., \& Vukelich. (2002). Prospective teachers' reflection: Strategies qualities and perceptions in learning to teach reading. Reading Research and Instruction, 41(2), 149 - 175.

Rodgers, C. (2002). Defining reflection: Another look at John Dewey and reflective thinking. Teachers College Record, 104(4), 843-865.

Rodriquez, Y., \& Sjostrom, B. (1995). Culturally responsive teacher preparation evident in classroom approaches to cultural diversity: A novice and an experienced teacher. Journal of Teacher Education, 46, 304-311.

Sacks, C. H. \& Mergendoller, J. R. (1997). The relationship between teachers' theoretical orientation toward reading and student outcomes in kindergarten children with different initial reading abilities. American Educational Research Journal, 34, 721-739.

Sailors, M., Keehn, S., Martinez M., Harmon, J., Hedrick, W., Fine, J., \& Eldridge D. (2004). Features of early field experiences at sites of excellence in reading teacher education programs. $53^{\text {rd }}$ Yearbook of the National Reading Conference (pp. 342-355). Scottsdale AZ: National Reading Conference

Shaker, P., \& Heilman, E. (2002). Advocacy versus authority: silencing the education professoriate. AACTE Policy Perspectives, 3(1), $1-6$.

Shanahan, T. (1998). On the effectiveness and limitations of tutoring in reading. In P. D. Pearson \& A. Iran-Nejad (Eds.), Review of Research in Education, 23, 217-234. Washington, DC: American Educational Research Association.

Shaw, D. M. \& Dvorak, M. J. (2007). Promise and possibility: Hope for teacher education: Preservice literacy instruction can have an impact. Reading Research and Instruction, 46 (3), 223-254.

Shulman, L. S. (1986). Those who understand: Knowledge growth in teaching. Educational Researcher, 15(2), 4 -14.

Simon, H. A. (1980). Problem solving and education. In D. T. Tuma and R. Reif (Eds.), Problem solving and education: Issues in teaching and research (pp. 81-96). Hillsdale, NJ: Erlbaum.

Smith, M. S. (2005). Helping preservice teachers develop habits of inquiry: Can it be done? Reading Research and Instruction, 45(1), 39-68. 
Snow, C., Burns, M., \& Griffin. P. (1998). Preventing reading difficulties in young children. Washington, DC: National Academy Press.

Snow, C., Griffin, P., \& Burns, M.(Eds.). (2005). Knowledge to support the teaching of reading: Preparing teachers for a changing world. San Francisco, CA: JosseyBass

Snyder, J. (2000). Knowing children-understanding teaching: The developmental teacher education program at the University of California, Berkeley. In L. Darling-Hammond (Ed.), Studies of excellence in teacher education: Preparation at the graduate level (pp. 97-172). Washington, DC: American Association of Colleges for Teacher Education.

Sparks, G. M. (1986). The effectiveness of alternative training activities in changing teaching practices. American Educational Research Journal, 23(2), 217-225.

Su, Z. (1997). Teaching as a profession and as a career: Minority candidate's perspectives. Teaching and Teacher Education, 13, 325-340.

Tochon, F., \& Munby, H. (1993). Novice and expert teachers time epistemology: A wave function from didactics to pedagogy. Teaching and Teacher Education, 9, 205-218.

Tomkins, G. (2003). Literacy for the $21^{\text {st }}$ century: Teaching reading and writing in prekindergarten through grade 4. Upper Saddle River: NJ, Merrill Prentice Hall.

Vacca, J. A. L., Vacca, R. T., \& Gove, M. K. (1995). Reading and learning to read $\left(3^{\text {rd }}\right.$ ed.) New York: Harper Collins

Valencia, S. W. \& Buly, M. R. (2004). Behind test scores: What struggling readers really need. The Reading Teacher, 57 (6), $520-531$.

Villegas, A. M., and Lucas, T. (2002a). Educating culturally responsive teachers: A coherent approach. Albany: State University of New York Press.

Vygotsky, L. S. (1978). Mind in society: The development of higher psychological processes. Cambridge, MA: Harvard University Press.

Wasik, B. A. \& Slavin, R. E. (1993). Preventing early reading failure with one-on-one Tutoring: A review of five programs. Reading Research Quarterly, 28, 178-200.

Wiggins, G., \& McTighe, J. (1998). Understanding by design. Alexandria, Va: Association for Supervision and Curriculum Development. 
Zeichner, K. M. (2000). Ability-based teacher education: Elementary teacher education at Alverno college. In L. Darling-Hammond (Ed.), Studies of excellence in Teacher education: preparation in the undergraduate years (pp. 1 -66). Washington DC: American Association of Colleges for Teacher Education.

Zeichner, K. M., and Gore, J. (1990). Teacher socialization. In W. R. Houston, M. Haberman, J. P. Sikula, and Association of Teacher Educators (Eds.), Handbook of research on teacher education (pp. 329 - 348). New York: Macmillan. 


\section{APPENDIX A}

Instruments

\section{Protocol of Questions for Video Case of Reader \# 1}

I. Tell me everything you notice about this reader.

a. What does he do when he has difficulty decoding words?

b. On line 20 why does he say "collections" instead of "castles?"

c. On a scale of $0-10$ (zero meaning no meaning, 10, maximum meaning), do you think he is making meaning of what he is reading? Why do you say that?

d. Is this the right leveled text for this student? Why do you say that?

II. If you were to work with this reader tomorrow, tell me everything that you would do.
a. What are the reader's strengths?
b. What are the reading needs of this student?
c. What specific reading instruction would you recommend to improve this student's reading?
d. Sum up what your goals for this reader would be.

Adapted from Dr. Michael S. Smith, Protocol of Questions (2005) 


\section{Protocol of Questions for Video Case of Reader \# 2}

I. Tell me everything you notice about this reader.

a. What does she do when she has difficulty decoding words?

b. On line five why does he say "the crow grinned" instead of "the crow glided"?

c. On a scale of $0-10$ (zero meaning no meaning, 10, maximum meaning), do you think she is making meaning of what she is reading? Why do you say that?

d. Is this the right leveled text for this student? Why do you say that?

II. If you were to work with this reader tomorrow, tell me everything that you would do.

a. What are the reader's strengths?

b. What are the reading needs of this student?

c. What specific reading instruction would you recommend to improve this student's reading?

d. Sum up what your goals for this reader would be.

Adapted from Dr. Michael S. Smith, Protocol of Questions (2005) 


\section{Protocol of Questions for Video Case of Reader \# 3}

I. Tell me everything you notice about this reader.

a. What does he do when he has difficulty decoding words?

b. On line 17, why does he say, "dog sit," instead of "dog sat"?

c. On a scale of $0-10$ (zero meaning no meaning, 10, maximum meaning), do you think he is making meaning of what he is reading? Why do you say that?

d. Is this the right leveled text for this student? Why do you say that?

II. If you were to work with this reader tomorrow, tell me everything that you would do.

a. What are the reader's strengths?

b. What are the reading needs of this student?

c. What specific reading instruction would you recommend to improve this student's reading?

d. Sum up what your goals for this reader would be.

Adapted for from Dr. Michael S. Smith, Protocol of Questions (2005) 


\section{Protocol of Questions for Video Case of Reader \# 4}

I. Tell me everything you notice about this reader.

a. What does she do when he has difficulty decoding words?

b. On line 8 why does the reader say "careful" instead of "cheerful"?

c. On a scale of $0-10$ (zero meaning no meaning, 10, maximum meaning), do you think she is making meaning of what he is reading? Why do you say that?

d. Is this the right leveled text for this student? Why do you say that?

II. If you were to work with this reader tomorrow, tell me everything that you would do.

a. What are the reader's strengths?

b. What are the reading needs of this student?

c. What specific reading instruction would you recommend to improve this student's reading?

d. Sum up what your goals for this reader would be.

Adapted from Dr. Michael S. Smith, Protocol of Questions (2005) 


\section{Protocol of Questions for Video Case of Reader \# 5}

I. Tell me everything you notice about this reader.

a. What does he do when she has difficulty decoding words?

b. On line 19 why does he say "if I even meet" instead of "if I ever meet"?

c. On a scale of $0-10$ (zero meaning no meaning, 10, maximum meaning), do you think he is making meaning of what she is reading? Why do you say that?

d. Is this the right leveled text for this student? Why do you say that?

II. If you were to work with this reader tomorrow, tell me everything that you would do.

a. What are the reader's strengths?

b. What are the reading needs of this student?

c. What specific reading instruction would you recommend to improve this student's reading?

d. Sum up what your goals for this reader would be.

Adapted from Dr. Michael S. Smith, Protocol of Questions (2005) 


\section{Protocol of Questions for Video Case of Reader \# 6}

I. Tell me everything you notice about this reader.

a. What does she do when she has difficulty decoding words?

b. On line three why does she say "grow up" instead of "grown up"?

c. On a scale of $0-10$ (zero meaning no meaning, 10, maximum meaning), do you think she is making meaning of what he is reading? Why do you say that?

d. Is this the right leveled text for this student? Why do you say that?

II. If you were to work with this reader tomorrow, tell me everything that you would do.

a. What are the reader's strengths?

b. What are the reading needs of this student?

c. What specific reading instruction would you recommend to improve this student's reading?

d. Sum up what your goals for this reader would be.

Adapted for from Dr. Michael S. Smith, Protocol of Questions (2005) 


\section{APPENDIX B}

Scoring Guide for Video Case Responses

I. Data Collection and Miscue Analysis Code Number of Respondent

3 Notices errors from the following three cueing systems: semantic, syntactic and graphophonemic and analyzes miscues from a meaning-making point of view.

2 Notices errors from two of the following three cueing systems: semantic, syntactic and graphophonemic and analyzes errors from a meaning-making point of view.

1 Notices errors from two of the following three cueing systems: semantic, syntactic and graphophonemic and does not analyze errors from a meaning-making point of view.

0 Does not notice errors from two of the following three cueing s systems: semantic, syntactic and graphophonemic and does not analyze errors from a meaning-making point of view.

II. Data Collection and Fluency Analysis

3 Notices the reader's speed, expression, and attention to punctuation and points out a causal relationship between fluency and comprehension and wants to do something instructionally to help the reader's fluency.

2 Notices at least two of the following three: speed, expression, and attention to punctuation and points out a causal relationship between fluency and comprehension.

1 Notices at least two of the following three: speed, expression, and attention to punctuation and wants to do something instructionally to help the reader's fluency.

0 Notices none or only one of the following three: speed, expression and attention and fails to point out a causal relationship between fluency and comprehension or fails to mention that some instruction with fluency seems appropriate.

III. Level of Data Analysis

3 Seeks to analyze/interpret different layers of facts (i.e., error analysis, fluency, and meaning making) into an integrated explanation that hypothesizes the reader's performance and bases future instruction and/or assessments on this hypothesis.

2 Seeks to analyze/interpret different layers of facts (i.e., error analysis, fluency, and meaning making) into an integrated explanation that hypothesizes the reader's performance but fails to base future instruction and/or assessments on this unifying theory.

1 Seeks to analyze/interpret the facts together from either a fluency and meaning making focus only or from an error-analysis and meaning making focus only.

0 Makes no attempt to analyze/interpret the facts or the analysis/interpretation is partial or faulty.

\section{Inquiry Orientation}

3 Has a questioning wondering attitude (views facts from a tentative point of view) about the reader in both sections of the questionnaire and seeks to find out appropriate information (which he/she wonders about) through reasonable assessment techniques.

2 Has a questioning wondering attitude (views facts from a tentative point of view) about the reader in the first or second section of the questionnaire and seeks to find out appropriate information (that he/she wonders about) through reasonable assessment technique(s).

1 Has a questioning wondering attitude (views facts from a tentative point of view) about the reader in the first or second section of the questionnaire or seeks to find out appropriate information $t$ through reasonable assessment techniques(s)

0 Does not have a questioning, wondering attitude (views facts from a tentative point of view) about the reader in the first or the second section of the questionnaire and does not seek to find appropriate information through reasonable assessment technique(s).

\section{Intelligent Action}

3 All instruction decisions, and there are at least three, are reasonable (based on the facts presented in the video) and instructional decisions are geared to strategy development, not fixing mistakes.

2 Two reasonable instructional decisions are discussed (based on the facts presented in the video) and are geared to strategy development, not fixing mistakes.

1 One reasonable instructional decision is discussed (based on the facts presented in the video) and is geared to strategy development, not fixing mistakes.

0 Discusses no reasonable instructional decision (based on the facts presented in the video or instruction is geared to fixing mistakes, not strategy development.

Dr. Michael Smith, Scoring Guide for Video Cases, (2005) 


\section{APPENDIX C}

\section{Lesson Plan Format}

LESSON PLAN FORMAT

Name

I. SUBJECT/TOPIC/GRADE

II. CONTENT OUTLINE(s) 1. Book/Text 2. Literacy (Reading or Writing)]

III. PROFESSIONAL TEACHING PERFORMANCE

\begin{tabular}{|c|c|c|c|c|c|}
\hline Lesson Parts & $\begin{array}{l}\text { Objectives/Outcomes } \\
\text { (Cognitive Objective, } \\
\text { Reading Objective, } \\
\text { Affective Objective) }\end{array}$ & $\begin{array}{l}\text { FEAP } \\
\text { SSS } \\
\text { TESOL }\end{array}$ & $\begin{array}{l}\text { Lesson } \\
\text { Steps/Procedures } \\
\text { Explain, } \\
\text { Demonstrate, } \\
\text { Guide, Practice, } \\
\text { Application, } \\
\text { Student Reflects }\end{array}$ & Materials & Assessments \\
\hline \multicolumn{6}{|l|}{$\begin{array}{l}\text { Set / Advanced } \\
\text { Organizer }\end{array}$} \\
\hline \multicolumn{6}{|l|}{ Body } \\
\hline \multicolumn{6}{|l|}{ Closure/Transfer } \\
\hline \multicolumn{6}{|l|}{$\begin{array}{l}\text { Modification for } \\
\text { ESE/ESL/Special } \\
\text { Needs }\end{array}$} \\
\hline $\begin{array}{l}\text { Self-Concept } \\
\text { (Capable/Valued/ } \\
\text { Needed \& } \\
\text { Necessary) }\end{array}$ & & & & & \\
\hline
\end{tabular}




\section{APPENDIX D}

\section{Literacy NICHE}

- What is it?

- "A purposefully organized, attractive, useful collection of text and non-text materials displayed on a board"

- The niche is your (student and teacher) nook/area. Its' function is more important than its appearance.

\section{What Should Your Literacy Niche Contain?}

- Display a variety of texts

○ Student Work

○ Writing

○ "How To" (Retell, Predict, etc)

○ "How To" (Write a friendly letter, acrostic poem, etc)

○ Student Bookmarks

○ Vocabulary Words

- Positive reinforcement \& self-esteem items (Bookmark)

- Niche grows and "evolves" as the student moves through tutoring sessions

- Fluency Check Chart

- Lesson plans (materials and student work when appropriate)

\section{Bookmarks}

- Bookmarks are created and provided by you (daily — at each tutoring session)

- Bookmarks should include the name of book, pages read and/or minutes read

- SSR time may be provide during your meetings (3 - 5 minutes at the end of tutoring)

- Completed bookmarks must be posted on niche board 


\section{APPENDIX E}

Tutoring Observation Checklist

\begin{tabular}{|c|c|c|}
\hline $\begin{array}{l}\text { Ready to teach: On } \\
\text { time and appropriate } \\
\text { dress }\end{array}$ & $\begin{array}{l}\text { On Time Yes } \\
\text { Appropriate Dress Yes }\end{array}$ & $\begin{array}{l}\text { No___ } \\
\text { No __ } \\
\text { Comments: }\end{array}$ \\
\hline Name Badge & $\begin{array}{ll}\text { Teacher } & \text { Yes } \\
\text { Student } & \text { Yes }\end{array}$ & $\begin{array}{ll}\text { Teacher } & \text { No__ } \\
\text { Student } & \text { No }\end{array}$ \\
\hline $\begin{array}{l}\text { Lesson plan on } \\
\text { display }\end{array}$ & $\begin{array}{l}\text { Class lesson plan format } \\
\text { Yes___ N/A _ }\end{array}$ & $\begin{array}{l}\text { Lesson Plan: No } \\
\text { Comments: }\end{array}$ \\
\hline $\begin{array}{l}\text { Appropriate } \\
\text { behavior; } \\
\text { Management; }\end{array}$ & $\begin{array}{l}\text { Attitude; actions; ethical, } \\
\text { caring; positive affect } \\
\text { Yes_ }\end{array}$ & $\begin{array}{l}\text { No__ } \\
\text { Comments: }\end{array}$ \\
\hline $\begin{array}{l}\text { Curriculum or } \\
\text { Assessment } \\
\text { Materials }\end{array}$ & $\begin{array}{l}\text { Appropriate interests, levels } \\
\text { of books; quality children's } \\
\text { literature, paper and pencils; } \\
\text { manipulatives; assessment } \\
\text { forms } \\
\text { Yes }\end{array}$ & $\begin{array}{l}\text { No } \\
\text { Comments: }\end{array}$ \\
\hline $\begin{array}{l}\text { Instructional } \\
\text { Environment }\end{array}$ & $\begin{array}{l}\text { Organized; purposeful; } \\
\text { enjoyable; uses niche during } \\
\text { instruction } \\
\text { Yes }\end{array}$ & $\begin{array}{l}\text { No } \\
\text { Comments: }\end{array}$ \\
\hline
\end{tabular}




\begin{tabular}{|c|c|c|}
\hline $\begin{array}{l}\text { Types of Reading } \\
\text { and Writing } \\
\text { Instructional } \\
\text { Approaches }\end{array}$ & $\begin{array}{l}\text { Direct, explicit skill } \\
\text { /strategy instruction; } \\
\text { authentic literature, } \\
\text { construction of meaning, } \\
\text { problem-solving, open- } \\
\text { ended questions } \\
\text { Yes }\end{array}$ & $\begin{array}{l}\mathrm{No}- \\
\text { Comments: }\end{array}$ \\
\hline Teaching Skills & $\begin{array}{l}\text { Teachable moments, } \\
\text { scaffolding; discussion; } \\
\text { "with-it-ness"; content } \\
\text { connections } \\
\text { Yes___ } \\
\text { Unable to Observe }\end{array}$ & $\begin{array}{l}\mathrm{No}- \\
\text { Comments: }\end{array}$ \\
\hline $\begin{array}{l}\text { Evidence of quality } \\
\text { instructional or } \\
\text { assessment } \\
\text { experiences: } \\
\text { Comprehension; } \\
\text { Vocabulary; } \\
\text { Fluency; Phonics; } \\
\text { Phonemic } \\
\text { Awareness; Writing; } \\
\text { Reading Aloud to } \\
\text { Student; SSR }\end{array}$ & Yes __ & $\begin{array}{l}\text { No _- } \\
\text { Comments: }\end{array}$ \\
\hline Links to assessment & Yes_ & No_ \\
\hline $\begin{array}{l}\text { Accommodates } \\
\text { differences or } \\
\text { Modifications }\end{array}$ & Yes__ N/A__ & No_ \\
\hline Comments/Questions & \multicolumn{2}{|c|}{ FIU Tutor/Professor Comments/Questions } \\
\hline
\end{tabular}


APPENDIX F

CONTINUUM OF READING DEVELOPMENT

\begin{tabular}{|l|l|l|l|}
\hline \multicolumn{2}{|l|}{ WORD KNOWLEDGE } \\
\hline $\begin{array}{l}\text { Letter } \\
\text { Names/Sounds }\end{array}$ & & \\
\hline
\end{tabular}


APPENDIX G

THEME-BASED UNIT PLAN

\begin{tabular}{|c|}
\hline GOALS/OBJECTIVES AND CONNECTIONS TO STATE \\
STANDARDS.....Students will be able to........ \\
\hline
\end{tabular}

\begin{tabular}{|c|c|c|c|}
\hline \begin{tabular}{l}
\multicolumn{1}{c}{ Assessment } \\
The following measures \\
can be used for a variety of \\
purposes, including \\
diagnostic, formative, and \\
summative assessment.
\end{tabular} & $\begin{array}{l}\text { Technology } \\
\text { Resources } \\
\text { 1. } \\
2 . \\
\text { 3. } \\
4 . \\
5 .\end{array}$ & $\begin{array}{l}\text { Comprehension } \\
\text { Strategies } \\
\text { 1. } \\
2 . \\
3 . \\
4 . \\
5 .\end{array}$ & $\begin{array}{l}\text { Teaching } \\
\text { Ideas } \\
1 . \\
2 . \\
3 . \\
4 . \\
5 .\end{array}$ \\
\hline \multicolumn{2}{|c|}{$\begin{array}{l}\text { Comprehension Centers } \\
\text { Students will apply the comprehension } \\
\text { strategies and related teaching ideas in the } \\
\text { following comprehension centers: }\end{array}$} & \multicolumn{2}{|c|}{$\begin{array}{l}\text { Comprehension Routines } \\
\text { Students will apply the } \\
\text { comprehension strategies and } \\
\text { related teaching ideas in the } \\
\text { following comprehension } \\
\text { centers. } \\
1 . \\
2 . \\
3 . \\
4 .\end{array}$} \\
\hline Title & Author & Theme & Level \\
\hline \multicolumn{4}{|l|}{1.} \\
\hline \multicolumn{4}{|l|}{2.} \\
\hline \multicolumn{4}{|l|}{3.} \\
\hline 4. & & & \\
\hline
\end{tabular}


APPENDIX $\mathrm{H}$

TWO HOUR INSTRUCTIONAL BLOCK

\begin{tabular}{|c|c|c|}
\hline \multicolumn{3}{|c|}{ Opening Routine 10 minutes of Whole Group Instruction } \\
\hline \multicolumn{3}{|c|}{ Teacher-Directed Whole Group Instruction - 35 minutes } \\
\hline \multicolumn{3}{|c|}{$\begin{array}{l}\text { Grade-level text: Title, Author of Text } \\
\text { Explain } \\
\text { Demonstrate } \\
\text { Guide } \\
\text { Practice } \\
\text { Application } \\
\text { Student Reflects } \\
\text { Effective Writing } \\
\text { Writing Strategy } \\
\text { Working with Words } \\
\text { Vocabulary or Phonics Lesson }\end{array}$} \\
\hline \multicolumn{3}{|c|}{ Students Rotate for Differentiated Instruction -25 minute rotation } \\
\hline Group 1 & Group 2 & Group 3 \\
\hline $\begin{array}{l}\text { Guided Reading Group } \\
\text { Title, Author of Text } \\
\text { Review } \\
\text { Guide } \\
\text { Practice } \\
\text { Reread, retell, and reflect }\end{array}$ & $\begin{array}{l}\text { Literacy Center } \\
\text { Name the Center } \\
\text { Explain } \\
\text { Materials }\end{array}$ & $\begin{array}{l}\text { Literacy Center } \\
\text { Name the Center } \\
\text { Explain } \\
\text { Materials }\end{array}$ \\
\hline $\begin{array}{l}\text { Literacy Center } \\
\text { Name the Center } \\
\text { Explain } \\
\text { Materials }\end{array}$ & $\begin{array}{l}\text { Guided Reading Group } \\
\text { Title, Author of Text } \\
\text { Review } \\
\text { Guide } \\
\text { Practice } \\
\text { Reread, retell, and reflect }\end{array}$ & $\begin{array}{l}\text { Literacy Center } \\
\text { Name the Center } \\
\text { Explain } \\
\text { Materials }\end{array}$ \\
\hline $\begin{array}{l}\text { Literacy Center } \\
\text { Name the Center } \\
\text { Explain } \\
\text { Materials }\end{array}$ & $\begin{array}{l}\text { Literacy Center } \\
\text { Name the Center } \\
\text { Explain } \\
\text { Materials }\end{array}$ & $\begin{array}{l}\text { Guided Reading } \\
\text { Group } \\
\text { Title, Author of } \\
\text { Text } \\
\text { Review } \\
\text { Guide } \\
\text { Practice } \\
\text { Reread, retell, and } \\
\text { reflect }\end{array}$ \\
\hline
\end{tabular}




\section{APPENDIX I}

\section{Tutoring Case Study}

1. Use the data collected from your interview, interest inventory, Basic Reading Inventory, fluency checks, and lessons to look across the instruments and instruction to develop a case study.

2. Stay close to the data, but explain what links are seen.

3. What recommendations would you make to the student, to the school, to the parents for continued growth?

4. How have your gained as a reading teacher from this experience?

Case Study- In a flexible notebook with dividers for each section and your name on the front and side binding:

Page One Preservice Teacher's Name and Address, Phone Number(s)

Email address Contact Person

Section I: Student Data Section

- Narrative of the student

- Instructional Plan showing links, corrected (Continuum)

- BRI Protocol Report , $1^{\text {st }}$, Corrected and $2^{\text {nd }}$ BRI Protocol Report and Protocols

- Fluency Checks

- Phonemic Awareness Protocol Repot

- Interest Inventory Protocol Report

- Recommendations

\section{Section II: $\quad$ Teaching and Learning}

- Lesson Plan/Reflection/ Checklist/ Student work - Each Lesson is followed by the Reflection, Checklist, and student work.

Section II: Overall Reflection

1. What did you learn about the reading process and reading instruction through the experience with a clinical practicum?

2. What did you know about literacy instruction at the beginning of this semester and how does this compare to what you know now? 


\section{APPENDIX K}

Early Childhood Preservice Teachers' Fourth Reading Course

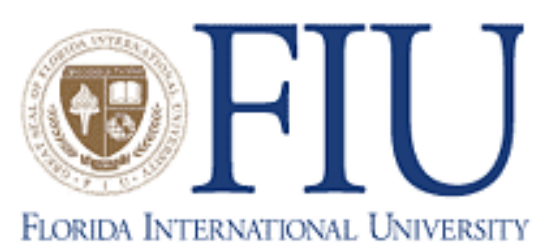

Children's Literature

\section{Spring 2007}

\section{COURSE DESCRIPTION}

Focuses on the exploration of children's literature and its role in Early Childhood classrooms. Current theories and methods about integrating literature into all curriculum areas will be discussed and demonstrated.

\section{PREREQUISITES / COREQUISITES}

No prerequisites / Corequisites 10 FIELD HOURS

\section{COURSE OBJECTIVES}

Upon completion of this course, students will have the following understandings, skills and dispositions:

- Identify characteristics and elements of a variety of literary genres.

- Identify the terminology and appropriate use of literary devices.

- Provide a medium for the exchange of creative uses of children's literature.

- Describe results and implications of research in children's literature and children.

- Demonstrate the many ways in which literature can and does support the goals of early childhood education.

- Identify appropriate techniques for encouraging children to respond to literature in a variety of ways.

- Integrate Literature-Based resources with Language Arts, Math, Social Studies, Science and Art, Physical Education and so on.

- Develop an ability to integrate knowledge and dispositions of instructional practices, curricular materials to promote positive attitude 
toward literary experiences.

- Plan for professional development as a career-long effort and responsibility.

The courses in Early Childhood do have outcomes that are directly related to:

The State of Florida twelve performance standards to which all teachers in the State are held accountable (Assessment, Communication, Continuous Improvement, Critical Thinking, Diversity, Ethics, Human Development and Learning, Knowledge of Subject Matter, Learning Environment, Planning, Role of the Teacher and Technology).

The International Reading Association (IRA) in A Reference for the Preparation of Educators in the United States: Standards for Reading Professionals (revised, 2003). There are five standards that focus on outcomes rather than inputs: Foundational Knowledge and Dispositions; Instructional Strategies and Curriculum Materials; Assessment, Diagnosis and Evaluation; Creating a Literate Environment; and Professional Development.

The Early Learning Standards: Creating the conditions for success. A joint position of the National Association for the Education of Young Children (NAEYC) and the National Association of Early Childhood Specialists (NAECS) in State Departments of Education (SDE) 2002. A developmentally effective system of early learning standards must include four essential features: 1) Emphasize Significant, Developmentally Appropriate and Outcomes, 2) Are developed and reviewed through informed, inclusive processes, 3) Gain their effectiveness through implementation and assessment practices that support all children's development in Ethical, Appropriate Ways, 4) Require a foundation of support for Early Childhood Programs, Professionals and Families 


\section{Class Schedule}

\begin{tabular}{|c|c|c|}
\hline $\begin{array}{l}\text { WEEK / } \\
\text { DATE }\end{array}$ & TOPICS & READINGS AND ASSIGNMENTS \\
\hline $\begin{array}{l}\text { WEEK } 1 \\
\text { JAN } 10\end{array}$ & Course Introduction & \\
\hline $\begin{array}{l}\text { WEEK } 2 \\
\text { JAN } 17\end{array}$ & $\begin{array}{l}\text { Defining Literature for } \\
\text { children } \\
\text { Evaluating literature for } \\
\text { children } \\
\text { Mentoring Workshop }\end{array}$ & Glazer, Chapters $1 \& 2$ \\
\hline $\begin{array}{l}\text { WEEK } 3 \\
\text { JAN } 24\end{array}$ & $\begin{array}{l}\text { Sharing Literature (read } \\
\text { aloud, storytelling, media) } \\
\text { (Genre, style \& sound) }\end{array}$ & $\begin{array}{l}\text { Glazer, Chapter } 3 \\
\text { Book file } 1 \text { Due: Wordless }\end{array}$ \\
\hline $\begin{array}{l}\text { WEEK } 4 \\
\text { JAN } 31\end{array}$ & $\begin{array}{l}\text { Literature and children's } \\
\text { language development. } \\
\text { picture books }\end{array}$ & $\begin{array}{l}\text { Glazer, Chapter } 5 \\
\text { Book file } 2 \text { Due: } \\
\text { Picture books (Alphabet, counting or } \\
\text { concept) }\end{array}$ \\
\hline $\begin{array}{l}\text { WEEK } 5 \\
\text { FEB } 7\end{array}$ & $\begin{array}{l}\text { Field Experience / } \\
\text { Documentation }\end{array}$ & $\begin{array}{l}\text { Topic 1: The making of a reader } \\
\text { Topic } 2 \text { \& 3: Beyond the attentive eye / } \\
\text { Asking good questions }\end{array}$ \\
\hline $\begin{array}{l}\text { WEEK } 6 \\
\text { FEB } 14\end{array}$ & $\begin{array}{l}\text { Field Experience/ } \\
\text { Documentation analysis } \\
\text { Lab work }\end{array}$ & Lab work (No class meeting) \\
\hline $\begin{array}{l}\text { WEEK } 7 \\
\text { FEB } 21\end{array}$ & $\begin{array}{l}\text { Literature and children's } \\
\text { intellectual development. } \\
\text { Folk Literature and } \\
\text { Fantasy/Science fiction } \\
\text { (Genre, style \& sound) }\end{array}$ & $\begin{array}{l}\text { Mid-term exam } \\
\text { Glazer, Chapter } 6 \\
\text { Book file } 3 \text { Due: } \\
\text { Folk Literature or Poetry }\end{array}$ \\
\hline $\begin{array}{l}\text { WEEK } 8 \\
\text { FEB } 28\end{array}$ & $\begin{array}{l}\text { Literature and children's } \\
\text { personality development } \\
\text { Realistic fiction and } \\
\text { informational } \\
\text { (Genre, style \& sound) }\end{array}$ & $\begin{array}{l}\text { Glazer, Chapter } 7 \\
\text { Author's Project Due } \\
\text { Everybody should post author's } \\
\text { project on WebCt } \\
\text { Author's Project Presentation } \\
\text { Book file 4 Due: Informational }\end{array}$ \\
\hline $\begin{array}{l}\text { WEEK } 9 \\
\text { MAR } 7\end{array}$ & $\begin{array}{l}\text { Literature and children's } \\
\text { social and moral } \\
\text { development } \\
\text { Multicultural fiction } \\
\text { (Genre, style \& sound) }\end{array}$ & $\begin{array}{l}\text { Glazer, Chapter } 8 \\
\text { Author's Project Presentations } \\
\text { (continued) } \\
\text { Book file } 5 \text { Due: } \\
\text { Multicultural fiction }\end{array}$ \\
\hline $\begin{array}{l}\text { WEEK } 10 \\
\text { MAR } 14\end{array}$ & $\begin{array}{l}\text { Literature and children's } \\
\text { aesthetic and creative } \\
\text { development } \\
\text { (Genre, style \& sound) }\end{array}$ & $\begin{array}{l}\text { Glazer, Chapter } 9 \\
\text { Topic 5: Bergoff transmediation } \\
\text { Author's Project Due Presentations } \\
\text { (continued) }\end{array}$ \\
\hline
\end{tabular}




\begin{tabular}{|l|l|l|}
\hline $\begin{array}{l}\text { WEEK 10 } \\
\text { MAR 21 }\end{array}$ & SPRING BREAK & NO CLASS \\
\hline $\begin{array}{l}\text { WEEK 11 } \\
\text { MAR 28 }\end{array}$ & Research Project & (Independent work) \\
\hline $\begin{array}{l}\text { WEEK 12 } \\
\text { APR 4 }\end{array}$ & $\begin{array}{l}\text { Evaluating literature for } \\
\text { children }\end{array}$ & $\begin{array}{l}\text { Due: Research Project } \\
\text { Presentations }\end{array}$ \\
\hline $\begin{array}{l}\text { WEEK 13 } \\
\text { APR 11 }\end{array}$ & Literature across the & $\begin{array}{l}\text { Glazer, Chapters 4 \& 10 } \\
\text { Copic 4: }{ }^{*} \text { Thatcher, D.H. (2001). } \\
\text { Reading in the math class: }\end{array}$ \\
\hline $\begin{array}{l}\text { WEEK 14 } \\
\text { APR 18 }\end{array}$ & Jump Start & Jump Start Kit Due \\
\hline
\end{tabular}

\section{Content Outline}

\section{Literature for children/ genre}

- Wordless books

- $\quad$ Picture books: Alphabet, counting and concept

- $\quad$ Folk Literature

- Fantasy

- Poetry

- Realistic Fiction

- Informational)

\section{Book formats / book content}

- $\quad$ Board books \& Chunky Board Books

- $\quad$ Cloth books \& bath books

- $\quad$ Lift \& Flap books

- $\quad$ Musical books and electronic books

- Books with developmental toys attached

- $\quad$ Books \& Character toy sets

- Paperback books

- Hard cover books

- $\quad$ Favorite Authors and Illustrators of Picture Books.

- Book awards (Newberry, Caldecott) Hans Christian Anderson, Laura Ingalls Wilder, Mildred Batchelder, Canadian Children's Book of the year, Amelia Frances Howard-Gibbon, Carnegie, Kate Greenaway 


\section{Style and sound}

- $\quad$ Connotation, imagery, figurative language, hyperbole, understatement, allusion, symbol, puns and wordplay.

- $\quad$ Onomatopoeia, alliteration, assonance, consonance, rhythm

Children's response to literature (developmentally appropriate practice)

- How children become readers

- Dimensions of storyreading

- The power of reading aloud

- Evaluating Books-Words and Story.

- Predictive books

- Looking at the Art. Artists' Tools and Materials. Styles of Artists.

- Response Through Multi-Literacies: drama, art, movement, music, oral \& written language

\section{Literature across the curriculum}

- Literature-based curriculum (Math, Science, Social Studies, Language Arts, Art, Music)

\section{Option 1}

Book File:

$15 \%$

Author/lllustrator Research Project $15 \%$

Jump Start kit

$20 \%$

Creative Projects

$15 \%$

Research Project

$25 \%$

Mid Term exam

$10 \%$

\section{Assignments \& Outcomes}

\section{Book File: $15 \%$ of grade}

Outcomes

- Students will explore a variety of children's literature including multicultural books

- Students will become critical consumers of children's books

- Students will identify different book formats, book content and key authors to develop criteria for selecting quality, age appropriate books that support literacy development.

- Students will identify genre, style and sound in children's books

- Students will suggest different uses of the books within 
a developmentally appropriate perspective.

- Students will gain knowledge and dispositions to select appropriate material

\section{Assignment description}

A book file is an effective way to maintain record of what you have read. There are hundreds of thousands children's books in print and over 5,000 new children's books being published every year. There are books that talk, sing, books with toys attached. In today's diverse publishing world, how do we select good books? The best way to become familiar with children's literature is to read a variety of books in various genres, style and sound. Different genres will be featured during the class sessions.

Students should post each entry on WebCt and bring a hard copy and book of each genre in the assigned day. Each book file should include the following information(No more than two pages):

1. Definition of the genre

2. Identify one book for each genre and copy a picture of the cover

3. Identify the author, title, publisher, date of publication, number of pages and age level for which the book would be appropriate

4. Write a short summary of the book followed by a discussion of the style and sound used in the book

5. Explain the style and sound that the author used (Except for wordless and picture books).

6. Suggest one activity for the book

7. Write a short summary

8. Write your reaction to the book. Explain the reason for choosing this book

9. At least four books should be Caldecott (Illustrator) or any other award winner (see list websites in reference list).

10. In your file entries, identify the books that are award winners in the upper right hand corner under the genre of each book-file book. Discuss why you think that this particular book is an award winner.

Make sure to select quality literature. Disney books or similar collections are not considered quality children's literature and are not appropriate for this task. 
Grading Criteria: Students will earn 2 points for each book file that contains all the criteria described in the assignment. The picture book is worth 1 point.

Absence/late: In the event of an absence, the student must post the assignment on the web the day that was due and make arrangements to havethe assignment delivered to class on time in order to get full credit. Late work will get $50 \%$ of the grade if submitted the following session (web post is not valid for grade). Book files submitted more than one week late will not be accepted.

\section{Author's / Illustrator research project (15\%) Due on WebCt June 5 / Individual presentations will take place in three days (see calendar)}

\section{Outcomes}

- Students will conduct a research on key authors or illustrators that have made significant contributions to early childhood literature.

- Students will collect and discuss their style, use of language and illustrations.

\section{Assignment Description}

- Select a children's key author such as Eric Carle, Bill Martin Jr., Sue Williams, Margaret Brown, Robert Munsch, Joy Cowley, Alma Flor Ada, Laura Joffe Numeroff, Miriam Schlein, Donald Crews, Judith Viorst, David Kirk, Audrey Wood, Don Wood, Maurice Sendak, Denise Fleming among others (with instructor's prior approval).

- Write a short biography and analyze what inspired this author or illustrator to write or illustrate children's books. Include the author's photograph

- Describe the style, use of language and/or illustrations.

- Bring at least 5 books written or illustrated by the selected author/illustrator.

- Post your research project on WebCt.

Jump Start kit $20 \%$

Group (3-4 members) or individual project 


\section{Outcomes}

- Students will develop criteria to select books and media appropriate for children in order to recommend it to parents and teachers

- Students will justify the selection of books based on children's developmental characteristics, book formats, content

- Students will justify the selection of books that support children's language, intellectual, personality, social-moral, aesthetic and creative development

\section{Assignment Description}

1. Select $10-15$ children's books around one topic

2. Include books with different genre and multicultural

3. Take a closer look at the stages of development of a child from birth to grade 3 and what to expect at each stage (see book suggestions)

4. Evaluate literature for children by literary and artistic standards

5. Justify your selection based on children's age level, genre, book format, style and sound and so on that promotes children's

language, intellectual, personality, social-moral, aesthetic and creative development. Support your claim with course readings

6. Some help in judging books can be found in reviews of new books that appear in journals such as The Horn Book, The Journal of Children's Literature, The Reading Teacher or in any of the websites listed in this document

7. Choose a book and design a felt board story

8. Design puppets for a story

9. Choose a story and audiotape a story with music and sound effects

10. Design a book extension that helps children compare two stories

11. Design a book reaction that helps children identify Plot and sequence of events

12. Design a book extension that helps children identify the main ideas from the story

Be ready to present all these artifacts in class. In addition, students should submit a written report of the selected books justifying how they promote language, cognitive, personality, social-moral, aesthetic and creative development. Include a picture of the cover. This written report should also be uploaded to WebCt. 


\section{Research Project 25\%}

This assignment is the artifact that you need to upload in your eFolio. Only "Proficient" work will be authorized to upload on eFolio. Students who don't comply with high quality work will get an "IN" for the course.

Make arrangements with UTS (Ext. 2820) to learn how to use Adobe Premier. You can dedicate one class to work on the lab. Students should submit a research proposal and discuss it with the professor in the assigned day. Please read the assigned readings for your conference.

\section{Creative Projects $15 \%$}

The creative projects consist on 5 class activities.

Students are about to work in teams to design classroom activities or projects. Students who work on the projects will earn 3 points for each project (students who arrive late or leave the class early will not earn points for the activity)

Students who miss class will be able to make up by selecting and bringing a Caldecott or another award winning book and report to the class what was the criteria that granted the author or illustrator the award.

\section{$\underline{\text { Outcomes }}$}

- Students will exercise their imagination to create inviting environment that engage children in literature.

- Students will incorporate the multiple intelligences in designing activities for response to books across the curriculum.

- Students will explore multiple ways to integrate literature in the curriculum

\section{Assignment description}

This is a cooperative group activity of 3-4 participants. Students will design hands on activities to engage children in reading high quality children's books. Students are welcome to bring, post and share resources at all times. 
VITA

\section{HELEN J. ROBBINS}

1968

B. A., Early Childhood Jersey City State College

Jersey City, New Jersey

1999

M. S., Reading Education

Florida International University

Miami, Florida

1968-2003

Classroom Teacher

Miami-Dade County Public Schools

Miami, Florida

2001-2003

Adjunct Professor

Florida International University

Miami, Florida

2002-2003

Graduate Assistant

Florida International University

Miami, Florida

2003-2007

Visiting Instructor

Florida International University

Miami, Florida

2007-2008

Instructor

Florida International University

Miami, Florida

\section{PUBLICATIONS AND PRESENTATIONS}

Robbins, H., \& Fine, J. C. (2007, December). Building preservice teachers expertise to teach reading in a clinical practicum. Paper presented at the annual meeting of the American Reading Forum, Sanibel Island, FL.

Fine J. C., Miller, L., Robbins, H., \& Yribarren, L. (2006, May). How are diverse institutions of higher learning infusing culturally responsive methods into teacher preparation programs? Paper presented at the annual meeting of the International Reading Association, Organization of Teacher Educators, Chicago, IL. May 4, 2006. 
Fine J. C., Robbins, H., Yribarren L., \& Tsalikis, M. (2005, December). Fluency for all: Research on Teachers' impact on students' literacy. Paper presented at the annual meeting of the American Reading Forum, Sanibel Island, FL.

Fine, J. C., Miller, L., Robbins, H., \& Yribarren L. (2005, May). The effects of cognitive apprenticeship on preservice teachers' understanding and use of diversity to support human development and student achievement. Paper presented at the annual meeting of the International Reading Association, Organization of Teacher Educators, San Antonio, TX.

Fine, J. C., Miller, L., Robbins, H., \& Yribarren L. (2005) Content and methods of Teaching literacy: The effect of one-on-one tutoring in preservice clinical education in two low-performing, diverse school settings on the effectiveness of preservice teacher's reading instruction. Florida International University, College of Education Research Conference, Miami, FL.

Fine, J. C., Miller, Lynne D., Robbins, H., \& Yribarren L. (2004, May). The effectiveness of cognitive apprenticeships on pre-service teachers' practices in scaffolding student reading and on student achievement. Paper presented at the annual meeting of the International Reading Association, Organization of Teacher Educators, Reno, NV.

Fine, J. C., Robbins, H., \& Gregg, G. (2003). "Things have to be cut into little pieces": Preservice teachers' field experience tutoring in urban settings. Florida Association of Teacher Educators, Vol. 1 (3). http://www.fate1org/library/ejournal/archives.htm

Fine, J. C., Yribarren L., \& Robbins, H. (2002). “Text - In” the classroom: teachers self-evaluate, reflect, and raise the quality of instruction. Florida Association of Teacher Educators, Vol. 1 (2). http://www.fatelorg/library/ejournal/archives.htm

Fine, J. C., Robbins, H., Yribarren L., \& Tsalikis. (2002) From training to impact: A master's student's application of methods to increase student learning. American Reading Forum, Vol XXII.

http://www.americanreadingforum.com/02yearbook/volume02toc.htm

Fine, J., Robbins, H., Tsalikis, M., \& Yribarren, L. (in review). Fluency for all: Research on teachers' impact on student's fluency. American Reading Forum Yearbook. http://www.americanreadingforum.org

Fine J. C., Robbins, H., \& Yribarren, L. (2002, October). “TEXT-IN” the classroom teachers evaluate reflect and transform instruction. Paper presented at the annual meeting of the Florida Association of Teacher Educators, Dania, FL. 